\title{
AN INVESTIGATION INTO THE PRINCIPLES FOR CREATING AND EVALUATING EFFECTIVE BUSINESS CASES FOR COMPLEX IT INVESTMENTS
}

By

Yao Zhou, B. A

\author{
A thesis \\ Presented to Ryerson University \\ Ted Rogers School of Management \\ In partial fulfillment of the requirements \\ for the degree of \\ Masters of Management Science
}

Toronto, Ontario, Canada, September 2013

CYao Zhou 2013 


\section{AUTHOR'S DECLARATION}

I hereby declare that I am the sole author of this thesis. This is a true copy of the thesis, including any required final revisions, as accepted by my examiners.

I authorize Ryerson University to lend this thesis to other institutions or individuals for the purpose of scholarly research.

I further authorize Ryerson University to reproduce this thesis by photocopying or by other means, in total or in part, at the request of other institutions or individuals for the purpose of scholarly research.

I understand that my thesis may be made electronically available to the public. 


\title{
AN INVESTIGATION INTO THE PRINCIPLES FOR CREATING AND EVALUATING EFFECTIVE BUSINESS CASES FOR COMPLEX IT INVESTMENTS
}

\author{
Yao Zhou \\ Master of Management Science \\ Management of Technology and Innovation \\ Ryerson University, 2013
}

\begin{abstract}
This study combines interviews and online Q-sorting to investigate the principles for effectively creating and evaluating business cases for complex IT investments, such as enterprise information systems. Interviews with nine expert practitioners are analyzed to examine current practices and challenges with the process of creating and evaluating business cases for complex IT investments. An online Q-sorting study using 19 expert practitioners is also analyzed to examine the relative importance of 32 principles for the effective creation and evaluation of business cases for complex IT investments. The findings indicate there are at least two different types of opinions on the most important principles for creating and evaluating the business cases. Furthermore, several principles that have not received much prior study were judged to be highly important such as the need to consider change management, strategic alignment, and the process of "socialization" of a business case for complex IT investments.
\end{abstract}




\section{Extended Abstract}

An important aspect of the information technology (IT) investment decision-making process is creating and evaluating a business case to identify and predict costs, benefits and risks in IT projects, which is generally helpful for investment planning. A business case document is an important project management decision-making tool for planning and evaluating potential investments in technology and process improvement projects. However, the effectiveness of traditional business case approaches for complex IT investments, such as enterprise systems implementations is often questioned. Creating and evaluating an effective business case for complex IT investments is difficult due to the uncertainty around the expected benefits, costs, risks, and timing for these complicated organizational projects that typically involve significant technological and organizational change throughout the lifecycle of the IT system. Since the literature is vague about the principles of how to create a theoretically and empirically supported business case for complex IT investments more effectively, the purpose of this study is to investigate the principles of creating and evaluating business cases and challenges for complex IT investments including enterprise systems implementations and complex ITenabled process change.

This research uses mixed methods comprising of a qualitative analysis of interviews and a more quantitative Q-method analysis of the opinions of expert participants.

Experiences of senior executives, IT project managers, business managers, and scholars are explored to gain better insight into challenges in creating and evaluating business cases for complex IT investments. Further, this research is conducted to uncover prospective solutions to these challenges. Data for this research were generated from two sources: (1) in-depth semi-structured interviews with expert practitioners to uncover the principles and practices associated with creating and evaluating effective business cases for complex IT investments and (2) online Q-sorting to examine the different types of opinions expert participants had on the relative importance of the principles and practices. The findings suggest a more nuanced treatment of traditional business case elements such as benefits, costs, risks are believed to be important. In addition, several practices that have not been previously emphasized in business case preparation were believed to be important, such as the need for socialization of business cases, the need for addressing intangible costs and benefits, and the need for using change management techniques. The concept of socialization of a business case refers to a relatively new concept which emerged from the interviews which is the process of communicating, explaining, and gathering feedback and/or consensus on the elements within a business case.

The contributions of this research are twofold. In terms of theoretical contribution, the research identifies several theoretical principles related to the creation and evaluation of business cases specifically for complex IT investments. This identification of theoretical principles lays the foundation for further research in an area that has seen 
little focus, but is of tremendous interest to IT decision-makers. In terms of practical contribution, this study provides practitioners with principles that could be applied into the process of creating and evaluating business cases to enhance its effectiveness. Furthermore, the results of the Q-method analysis help practitioners to understand various perspectives on the relative importance of different principles for creating and evaluating business cases for complex IT investments.

Keywords: business case, IT investment, decision making, IT project management, ERP implementation 


\section{Acknowledgments}

I would like to express my deepest and most sincerely appreciation to Dr. Tim McLaren, my supervisor, advisor, and mentor. He constantly gave me support and encouragement, provided guidance, valuable suggestions, and spent precious time working with me that made this research possible. Special thanks are due to Dr. Davis Charles and Dr. Ron Babin for actively participating on my thesis committee that greatly enhanced the quality, content and presentation of the thesis. In addition, I particularly thank you to Dr. Murtaza Haider for chairing the thesis committee.

Further, the support of Information Technology Management Faculty in Ted Rogers School of Management at Ryerson University for this research is gratefully acknowledged. I would like to thank Dr. Ayse Bener and Dr. Ozgur Turetken, who provided the critical and constructive comments to aid me to develop the theory and research method for this study. Thanks also go to the many professors who have helped me to complete the data collection phase of the thesis.

I also am indebted to the participants who so enthusiastically contributed to this research and shared their time and expertise. I hope that the process of discovery and the findings from the research have been useful.

This research has also benefit from seminars and discussion in 2013 International Conference on Information Resources Management (IRM). I would also like to thank the organizers and participants of the IRM conference for valuable comments and discussion on earlier versions of this thesis presented at the research seminar.

Moreover, I am grateful for the encouragement from all of my friends during this journey. Special thanks go to my parents for the support and being healthy in China that I can concentrate on my study in Canada.

Last, but not least, thanks a million to my aunt, uncle and cousin, who provide meticulous care and assistance going throughout my study for completing this research. 


\section{TABLE OF CONTENTS}

CHAPTER 1: INTRODUCTION

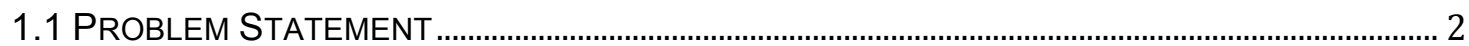

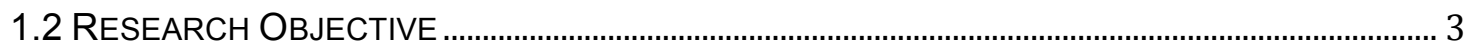

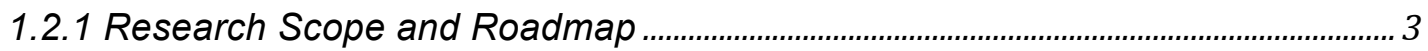

1.2.2 Research Questions.................................................................................................... 5

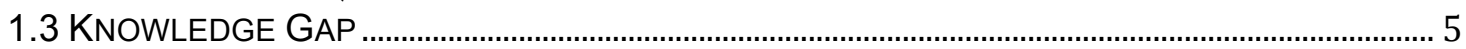

1.4 RESEARCH CONTRIBUTIONS TO THEORY AND PRACTICE...................................................... 6

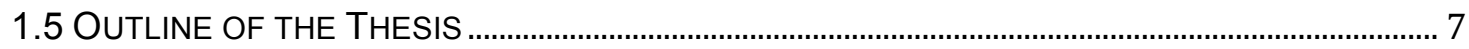

CHAPTER 2: LITERATURE REVIEW AND CONCEPTUAL FRAMEWORK .............................. 9

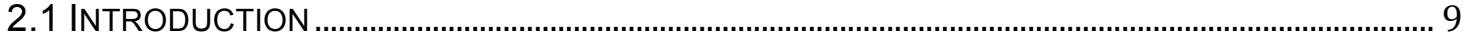

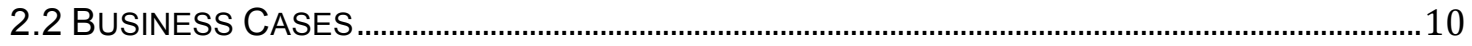

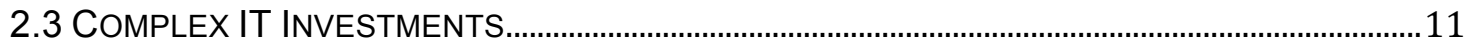

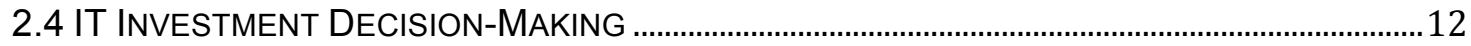

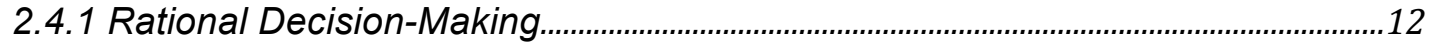

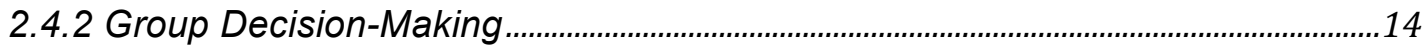

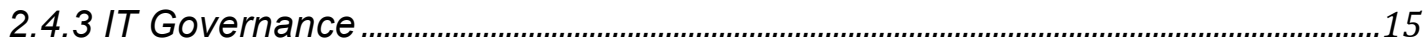

2.5 THE PROCESS OF CREATING AND EVALUATING BuSINESS CASES.....................................17

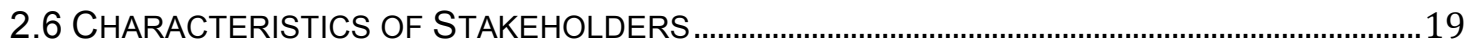

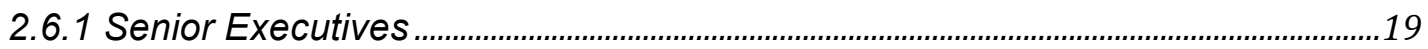

2.6.2 IT Project Managers ...........................................................................................................20

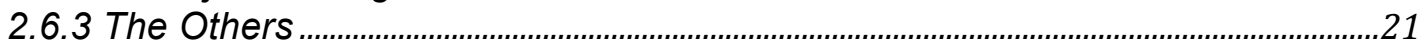

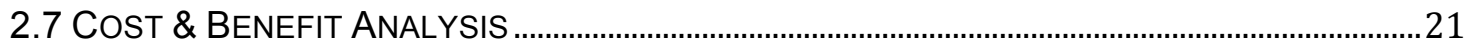

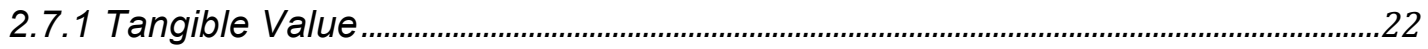

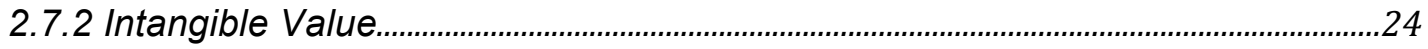

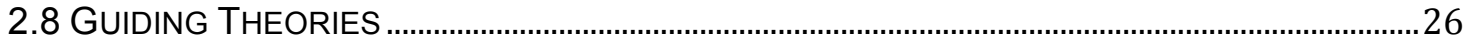

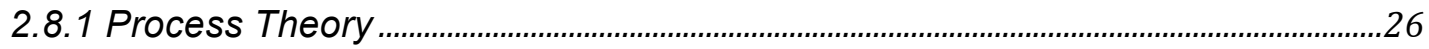

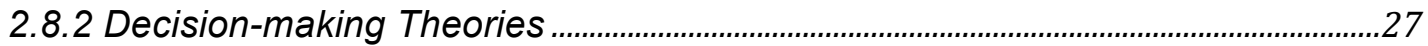

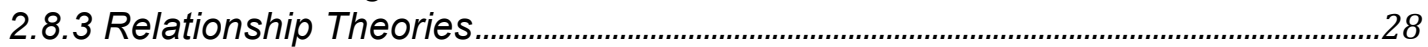

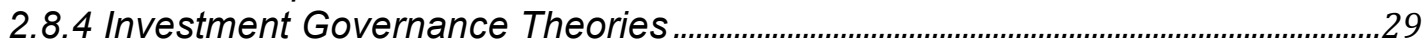

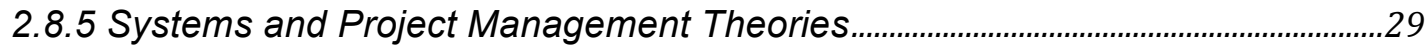

2.9 CONCEPTUAL FRAMEWORK

CHAPTER 3: RESEARCH METHODOLOGY

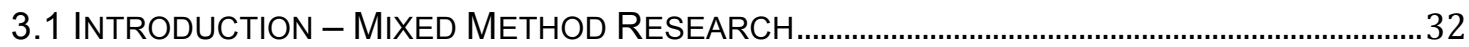

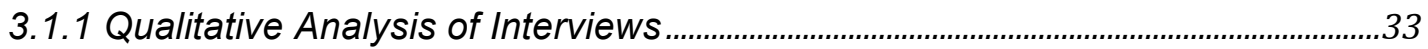

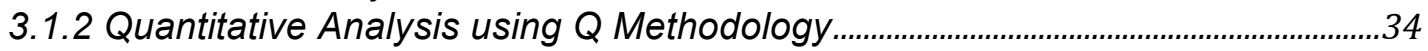

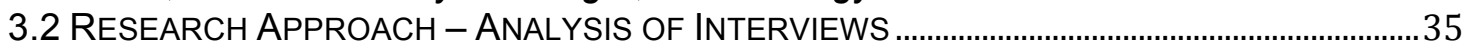

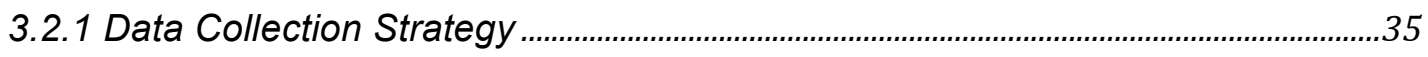

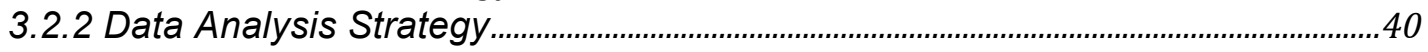

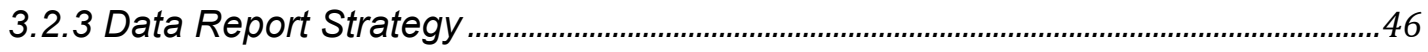

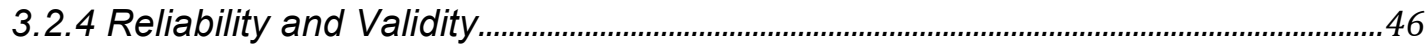

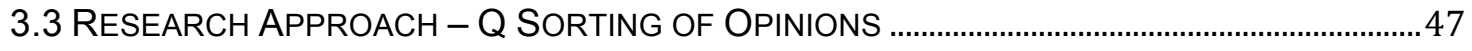

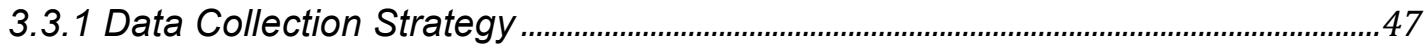

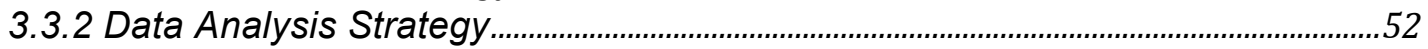

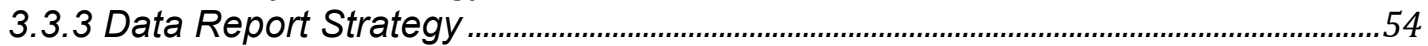

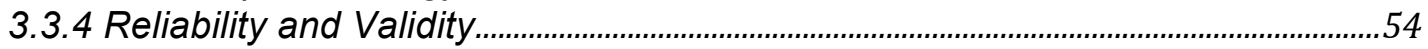

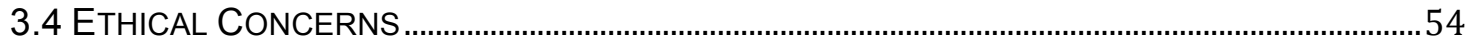




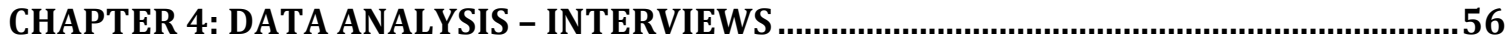

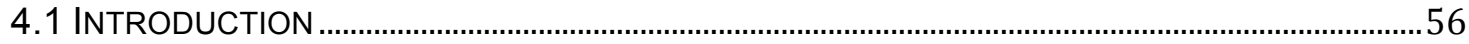

4.2 FINDINGS REGARDING THE PARTICIPANTS IN THE PROCESS ............................................56

4.3 FINDINGS REGARDING THE APPROACHES FOR SOCIALIZATION .........................................57

4.4 FINDINGS REGARDING THE APPROACHES FOR COST AND BENEFIT ANALYSIS ................58

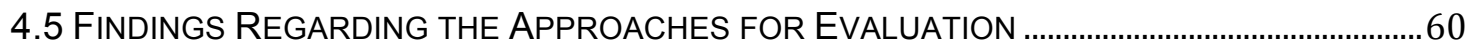

4.6 FINDINGS REGARDING THE CHALLENGES IN THE PROCESS .............................................. 61

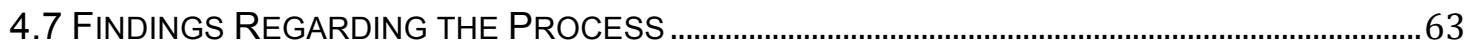

4.8 FINDINGS REGARDING SUGGESTIONS FOR IMPROVING BUSINESS CASES.........................64

CHAPTER 5: DATA ANALYSIS - Q METHODOLOGY

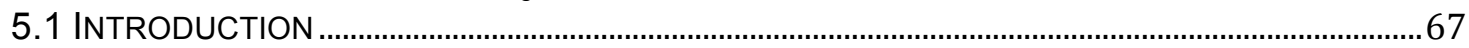

5.2 CONSENSUS RANKING ON THE IMPORTANCE OF EACH PRINCIPLE: THE ONE FACTOR

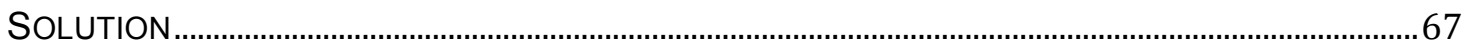

5.3 RANKING OF PRINCIPLES BY EACH OF THE TWO OPINION TYPES: THE TWO-FACTOR

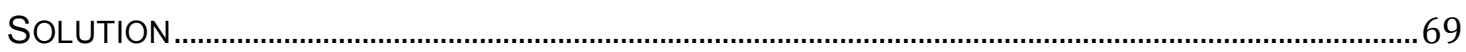

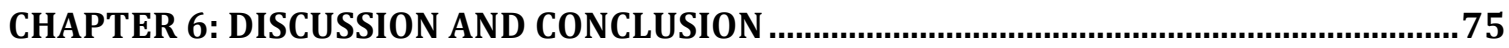

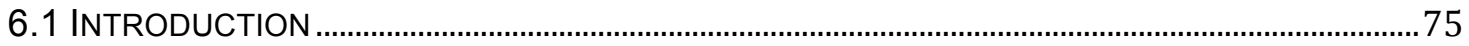

6.2 DISCUSSION OF FINDINGS FROM ANALYSIS OF INTERVIEWS ................................................75

6.3 DISCUSSION OF FINDINGS FROM ANALYSIS OF Q-SORTING EXERCISE ..............................76

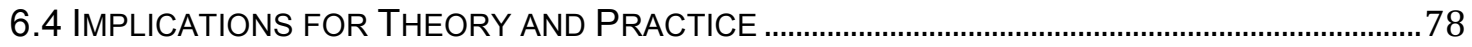

6.5 LIMITATIONS AND FUTURE WORK

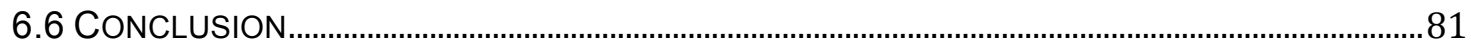

REFERENCES

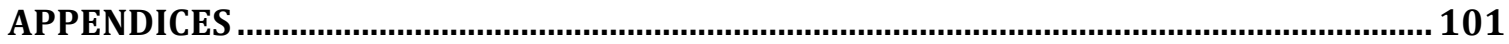

viii 


\section{List of Figures}

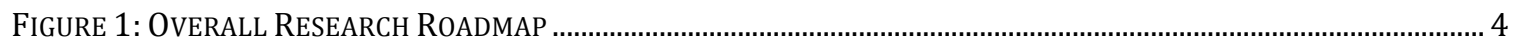

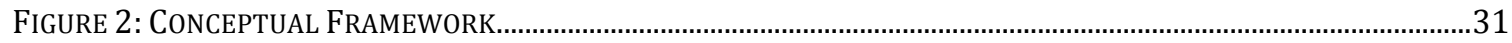

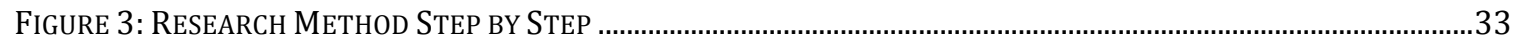

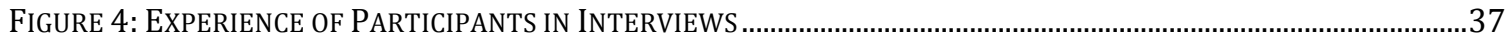

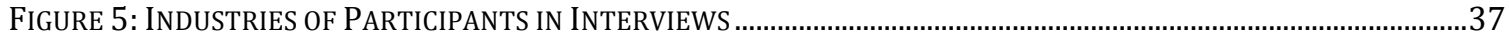

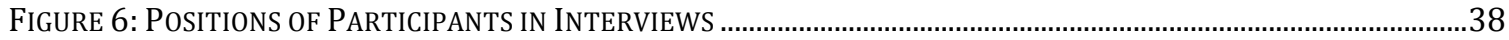

FIGURE 7: EXAMPLE OF CODING INTERVIEW TRANSCRIPTS IN NVIVO ......................................................................42

FIGURE 8: EXAMPLE OF FREE NODES (CODES) USED IN THE CODING .....................................................................44

FIGURE 9: EXAMPLE OF THE HIERARCHICAL CODES USED IN THE CODING .................................................................45

FIGURE 10: EXPERIENCE OF PARTICIPANTS IN THE Q-SORTING STUDY ........................................................................49

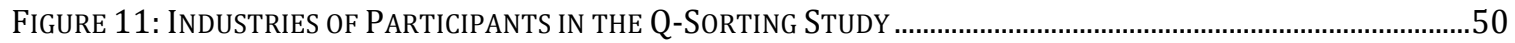

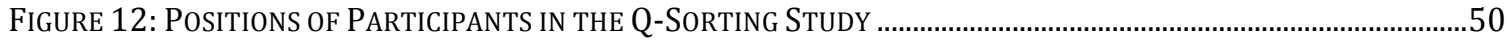

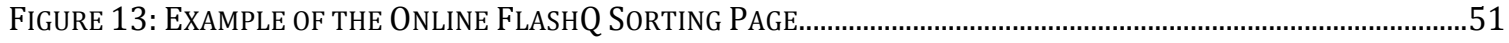

FIGURE 14: EXAMPLE OF THE QUASI-DISTRIBUTION GRID IN FLASHQ ....................................................................52

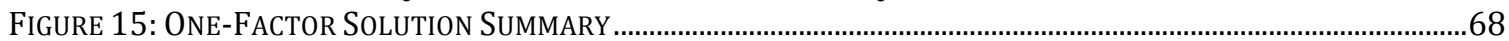

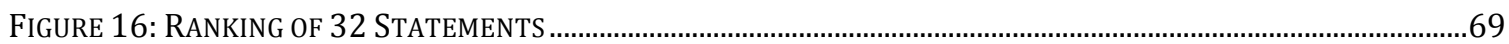

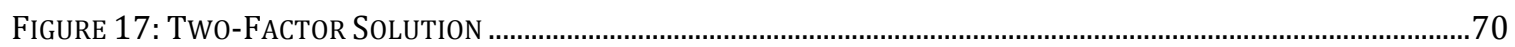

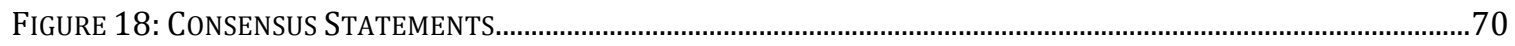

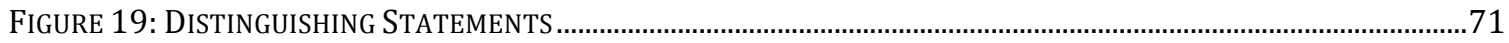

FIGURE 20: DifFERENCE BETWEEN OPINION TYPE A AND OPINION TYPE B .............................................................. 72

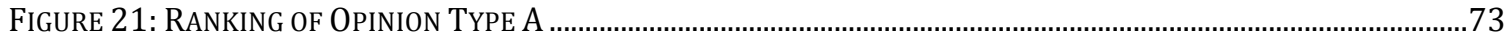

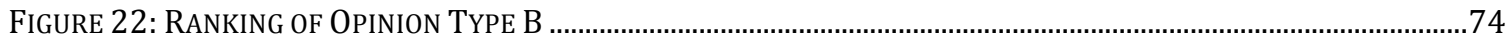

\section{List of Tables}

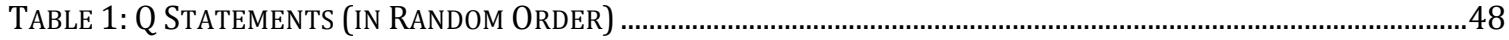

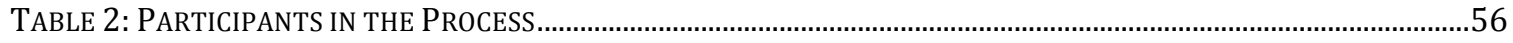

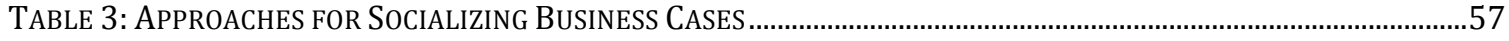

TABLE 4: APPROACHES FOR COST AND BENEFIT ANALYSIS.......................................................................................58

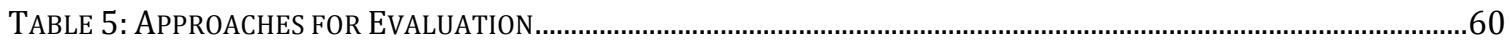

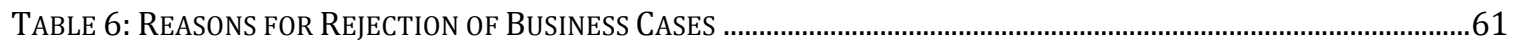

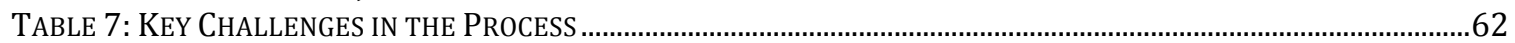

TABLE 8: CoMPARISON OF BuSINESS CASES For CoMPLEX IT vS GENERAL PROJECTS ..................................................63

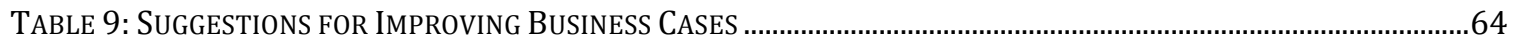




\section{CHAPTER 1: INTRODUCTION}

With the tremendous advancement of information technology (IT) and a rapidly changing market environment, enterprises increasingly adopt complex enterprise information systems such as enterprise resource planning (ERP) systems to manage their operations and supply chains. However, for the past thirty years, an uncomfortably high rate of failure has been experienced in IT projects (Doherty et al., 2011; Tesch, Kloppenborg and Frolick, 2007; Whittaker, 1999). Regarding a recent survey, IT projects always fail to deliver the expecting benefits of them (El Emam and Koru, 2008). Making an effective IT investment is a challenge for senior IT executives and IT project managers since it cannot be competently prospected and contains various uncertainties. Therefore, enterprises create and evaluate a business case document to guide the investment decisions (Gambles, 2009; Remenyi, 1999). A business case is a useful tool for decisionmaking and planning for IT investments, however, creating effective business cases is particularly hard for complex IT investments like ERPs. Failure to create and evaluate a business case effectively results in wasted organization resources in developing, managing and implementing IT projects that are short-lived and fail to produce adequate return on investment (ROI). Senior managers must understand the purpose and nature of a business case and be able to accurately interpret the business case to position their enterprises' high-value technology investments and to achieve success with emerging market opportunities.

Based on above situation, the objectives for this research are threefold: (1) to make a contribution to the theory and literature by better understanding the process of creating and evaluating business cases for complex IT investments, (2) to investigate the participants' experiences and current practices of creating and evaluating business cases for complex IT investments, and (3) to outline the criteria of effectively creating and evaluating a high-quality business case for complex IT investments. It is crucial to note that this research is based on the individual viewpoints of practitioners who are involved in the process of creating and evaluating business cases for complex IT investments and not from an organizational point of view.

In summary, the main idea of this exploratory mixed methods research is to investigate the process of creating and evaluating business cases for complex IT investments. Further, this research highlights practices that the expert participants felt would make the process of creating and evaluating business cases for complex IT investments more effective. While many other researches explain the traditional process for creating and evaluating business cases for IT projects (Keen, 2011; Schmidt, 2002), the purpose of this study is to identify the specific process for complex IT investments and the practices that could enhance the process by the exploration of practitioners' experiences and previous studies. 


\subsection{Problem Statement}

Over the past years, the failures of IT projects have been astonishingly high:

1. The late 1970s: no more than $20 \%$ of the projects accomplished benefits they intended to do (Eason, 1988);

2. The late 1980s: up to $70 \%$ of IS projects could be concluded as failures (Hochstrasser and Griffiths, 1991);

3. From 1994 to 1998: $31 \%$ of IT projects failed in 1994, only $25 \%$ of projects are completed on time and within budget, $40 \%$ were unsuccessful in 1996, and $28 \%$ were cancelled in 1998 (LaPlante, 1995; The Standish Group, 1999). The Standish Group report (1999) estimates that the cost of cancelled IT projects in 1998 alone to reach $\$ 75$ billion;

4. The end of 1990s: up to $90 \%$ of all IT projects fail to meet their aims (Clegg et al., 1997);

5. The last decade: $74 \%$ of IT projects from 1994 to 2002 fail to deliver expected benefits (Shpilberg et al., 2007);

6. 2004: only 16\% of IT projects can be considered truly successful (British Computer Society, 2004); and

7. 2009: $24 \%$ of IT projects were still considered as failures and further $44 \%$ of projects were viewed to be challenged since they are over time, over budget and do not fulfill the requirements (Levinson, 2009).

Although prior literature lists various IT project failures, the reasons that caused the failures and how to prevent these failures, the IT projects still fail as usual (Cobb, 1996). One of the possibilities is a weak, inaccurate and ineffective business case that is poor planning, inadequate risk management and lack of top management involvement and support. In recently years, the business case for IT projects is usually weak in several areas or missing several components, e.g., a lack of management involvement and support (Whittaker, 1999). The more complex the project is, the more adequate business case should be created.

Prior studies have identified the successes and limitations of current practices around creating and evaluating business cases for IT projects (IT Governance Institute, 2006; Remenyi, 1999). The traditional practices for creating and evaluating business cases to identify the needs, costs, benefits and risks are suitable for many simple and short-term IT investments such as the renewal investments that enhance the capability of existing IT infrastructure and retire outdated systems and technologies, the process improvements investment that improve operational performance by changing the existing operation flow. Yet, they may not be suitable for long-term IT projects that affect all business units and change the existing work flow since the projects are more complicated. Additionally, traditional business cases typically fail to adequately address intangible benefits and indirect costs in IT investments. They rely too heavily on the opinions and past experiences of influential decision-makers and consultants. The existing literature lacks an explanation for the inter-relationship among each element in a process of creating and evaluating business cases and also a lack of exploring different level of performance 
improvement targets and potential benefits in the combinations of IT enablers and business changes by the business cases (Ward, Daniel, and Peppard, 2008).

Moreover, rigid analysis in this domain has traditionally been intricate, primarily due to various IT projects and the complex inter-relationships of the different interests among decision-makers such as senior executives and IT project managers. Prior research recognizes that creating and evaluating business cases can be helpful in the decisionmaking process; however, without theoretical explanation and in-depth understanding, the previous document lack analysis of current situation especially for complex IT investments, i.e., enterprise systems implementations and complex IT-enabled process change.

\subsection{Research Objective}

The aim of this study is to gain a grounded understanding of the unique challenges in creating and evaluating business cases specifically for complex IT investments and to uncover prospective solutions to these challenges. The goal of this research is to explore the experiences of expert practitioners with the process of creating and evaluating effective business cases for complex IT investments. To achieve this goal, the research adopts exploratory mixed methods to obtain an in-depth understanding of the current practices and issues within the process. This research relies on data collected using interviews and online Q-sorting to examine the principles for effectively creating and evaluating business cases. Q-sorting is used to examine the opinions of practitioners on the relative importance of various principles for creating and evaluating business cases for complex IT investments. In contrast to traditional survey methods, Q-sorting enables statistical cluster analyses to be performed efficiently to identify groups or clusters of opinions using a relatively small number of expert participants. This research investigates the opinions of four groups of knowledgeable individuals: senior executives, senior IT project managers, business managers, and academic scholars all of whom had prior relevant experience with the creation and evaluation of business cases for complex IT investments. The theoretical insights generated from the analysis of prior theory and new empirical evidence are expected to have significant implications for practitioners and researchers.

\subsubsection{Research Scope and Roadmap}

IT in this thesis means all the technology that provides technology support for organizations including hardware (e.g., servers, storages), software (e.g., operating systems, applications), and telecommunication (e.g., networking device). Complex IT investments are investments on IT projects that require significant coordination across multiple functional areas of one or more organizations. An example of a complex IT investment would be an ERP implementation. In contrast, simple IT investments, such as 
for a standalone website or database are outside the focus of this research. Due to the complexity and scale of the ERP system implementation process, these IT projects have resulted in failures and implementation difficulties (Kanaracus, 2011). In order to make the best decision for complex IT investments, it is important to foresee what contents should be prepared in the first initial phase which is creating and evaluating a business case. Further, it is vital for practitioners to understand the principles that make the process more effective. Therefore, the scope of this research is limited to explore the ideas from practitioners who are involved in this process, i.e., senior executives, senior IT project managers, and business managers. It is also important to note that this research is based on the individual viewpoints of practitioners experienced with the process of creating and evaluating business cases for complex IT investments rather than any organizational point of view.

This research includes three phases: 1) Analyze prior literature; 2) Conduct interviews with expert participants; 3) Conduct Q-sorting with experts participants. First, the researcher reviewed the literature on business cases to identify the gap between general business cases and business cases for complex IT investments. As part of this discussion, the researcher drew distinctions between these two major types of business cases and tried to figure out how to make the process of creating and evaluating business cases more effective for complex IT investments. This is followed by a description of the research setting and the methodology used, i.e., field interviews. In the discussion of the interview results, the researcher integrated the predominant experiences of the participants and the literature in terms of the principles of creating and evaluating business cases for complex IT investments. Before drawing out the implications of these results, the researcher gathered insights from expert practitioners through online Qsorting on these principles that the expert participants felt would make the process of creating and evaluating business cases for complex IT investments more effective. The overall research roadmap (Figure 1) is as following:

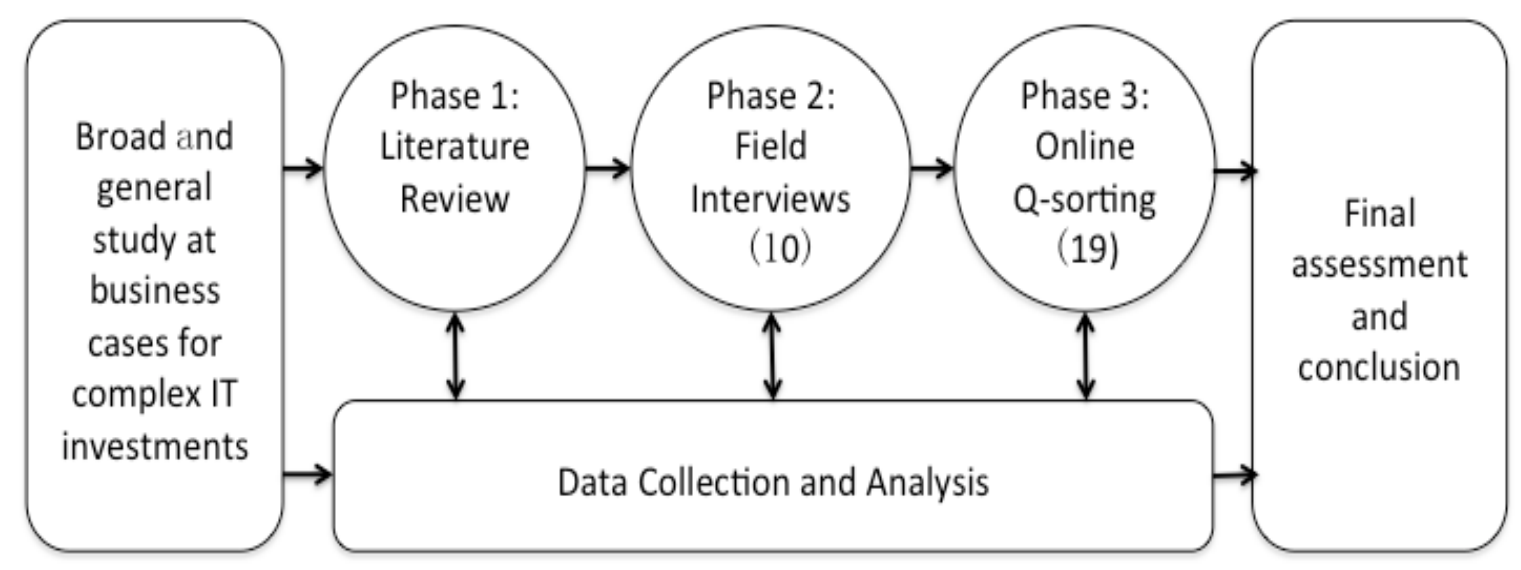

Figure 1: Overall Research Roadmap 


\subsubsection{Research Questions}

This research explores the gap in knowledge of the principles that help practitioners create and evaluate an effective business case for complex IT investments. Hence, the overall research question that provides direction for this research is: How can the process of creating a theoretically and empirically supported business case for complex IT project investments such as ERP implementations be done more effectively? The follow-up research question is how important are the principles for the creation and evaluation of a business case for a complex IT investment?

In order to acquire an in-depth understanding of creating and evaluating business cases and provide direction for this exploratory mixed methods research, the following additional guiding research questions are considered in the interviews:

(1) What elements does a business case comprise?;

(2) Why is a business case needed?;

(3) What types of IT projects or investments are not suitable for traditional business cases?;

(4) How can the business cases for these challenging projects be made better?; and

(5) How should the success of complex IT investments be defined?

\subsection{Knowledge Gap}

Decision-making and justification for complex IT investments are of strategic importance for modern firms and can be difficult for even the professional and knowledgeable managers in the presence of technological, organizational, and market complexity (Adomavicius et al., 2008). Many enterprises struggle with complex IT investments need to focus on business value, which is to maximize benefits while minimize cost. From a senior IT executive's perspective, the benefits and costs are the central considerations of a successful IT investment. In addition, risk and timeframe are also concerned. However, future costs, benefits, risks and competitive impact are difficult to forecast (Clemons and Weber, 1990). There is extensive research literature that highlights the need for a business case to be created prior to investments in process improvement projects in general and IT investments specifically (Gambles, 2009; Harvard Business School, 2011; IT Governance Institute, 2006; Remenyi, 1999).

Prior literature provides various definitions and descriptions of a business case, many benefits of a well-written business case have been speculated and claimed, and firms are adopting the approach. Notwithstanding, the business case literature is largely anecdotal and prescriptive, lacking formal analysis, empirical evidence and theoretical foundation to support the principles and practices of creating and evaluating a business case for complex IT investments. Little research has empirically examined the process construct in terms of its determinants, dimensions and effects on complex IT investment decisionmaking. As a result, there is a lack of understanding about how the process of creating and evaluating theoretically and empirically supported business cases for complex IT investments, especially for ERP implementations, can be done more effectively. Further, 
current studies did not explore different level of performance improvement targets and potential benefits in the combinations of IT enablers and business changes. For example, flexible choice for IT investors, like high-cost, high-benefit, high-risk, and longertimeframe versus another option that is lower-cost, lower-benefit, lower-risk, and shortertimeframe. More precisely, situations change during a project. Some technical aspects of the project might turn out to be much tougher than the technical team thought. On the other hand, the changes the business has to make might turn out to be more or less extensive, requiring a recalculation or the original logic that mapped the new system to the benefits might not be quite right, and needs recalculation (DellaVecchia, Scantlebury and Stevenson, 2007).

All of these issues expose the need of enterprises to create a suitable and effective business case model for complex IT investments. The literature is vague about the principles or "best practices" for creating and evaluating business cases for complex IT investments such as ERP implementations. Therefore, the purpose of this research is to fill the knowledge gap and further to explore our understanding of creating and evaluating business cases for complex IT investments. In addition, this research also aims to assist business and IT managers in ensuring the process of creating and evaluating business cases for complex IT investments is more effective.

\subsection{Research Contributions to Theory and Practice}

The contributions of this research are twofold. In terms of theoretical contribution, the research identifies several theoretical principles related to the creation and evaluation of business cases specifically for complex IT investments. This identification of theoretical principles lays the foundation for further research in an area that has seen little focus, but is of tremendous interest to IT decision-makers. In terms of practical contribution, several solutions and suggestions are provided for managers to address the challenges in the process thus make an effective decision. By understanding the factors that influence the process of creating and evaluating business cases and identifying the challenges that decision-makers face, this research provides practitioners and scholars the knowledge based on business cases for complex IT investments and by extension to the project management and investment governance domains. Moreover, this study provides practitioners with principles that could be applied into the process of creating and evaluating business cases to enhance its effectiveness. Additionally, the results of the Qmethod analysis help practitioners to understand various perspectives on the relative importance of different principles for creating and evaluating business cases for complex IT investments.

This research has three audiences. First, it should be of interest to those senior executives and stakeholders who have been considering their IT investments. They might be thinking of selecting a more effective business case. Second, it should be of interests to all those who are directly involved with IT investments and business case research. The guidelines provided in this thesis contribute to raising the aspirations for individual 
research projects. Third, many readers, while not being directly involved with business cases and IT investment research themselves, would like to better understand its foundations and value. Results and analysis of the findings will be shared with the participants, which enables them to gain new insights about creating and evaluating business cases and to provide them with a set of theoretically and empirically supported principles for creating and evaluating effective business cases for complex IT investments. This study not only enhances practitioners' conceptual understanding of the importance of creating and evaluating a business case and its outcomes in complex IT investments but also serves as a foundation for further theoretical and empirical investigations.

\subsection{Outline of the Thesis}

This thesis is divided into six chapters. Chapter 1 depicts the problem statement, research objectives, research scope, research roadmap and research questions. Further, it defines the knowledge gap between this research and the previous ones, and theoretical and practical implications of this research.

Chapter 2 reviews background and literature of the research. Further, the researcher outlines the theoretical foundation and a conceptual framework representatively that guides this research. It starts with a review of the literature that is focused on the constructs in the process of creating and evaluating business cases for complex IT investments. This is followed by a detail review in terms of business cases, complex IT investments, IT investment decision-making, the process of creating and evaluating business cases, characteristics of stakeholders, and cost and benefit analysis. Further, the researcher outlines the relevant theories that could be used as a theoretical lens to examine the activities in the process. The final section of this chapter provides a conceptual framework that guides this research.

Chapter 3 illustrates the research methodology. It begins with describing the philosophical basis that this study was conducted under and the rational for using exploratory mixed methods research methodology combing quantitative and qualitative approaches. This is followed by a detailed description of the design and development of interviews and Q methodology, which are served as research instruments in this study. These sections comprise the strategies of collecting data, analyzing data, and generating data reports, e.g., the usage of the coding and thematic analysis techniques. Further, the next section discusses the reliability and validity of the methodology. The last section of Chapter 3 outlines the ethical concerns and how to address them.

Chapter 4 and Chapter 5 provide the analysis of the empirical data gathered from interviews and online Q-sorting, representatively. The researcher interprets these data by providing tables and figures in terms of the challenges, suggestions, and theoretical recommendations for practitioners. The data analysis based on interviews is conducted by NVivo software. In addition, the results are further explored using online Q-sorting 
regarding the importance of several principles of creating and evaluating business cases for complex IT investments. This data analysis is conducted by PCQ software.

Finally, Chapter 6 discusses the implications of the research findings for theory and practice. It also outlines the limitations of this research and the opportunities for future research into business cases for complex IT investments. 


\section{CHAPTER 2: LITERATURE REVIEW AND CONCEPTUAL FRAMEWORK}

\subsection{Introduction}

The methodology used in this chapter involves a systematic literature review (Peloza, 2009), which examines relevant articles on business cases for complex IT investments, as well as business cases and investment decision-making in general. Academic articles were systematically reviewed using title and abstract searches in the domains of business cases, IT investments, and IT project management. Scholarly researched journals as MIS Quarterly, MIS Quarterly Executive, Journal of Information Technology, Journal of Management Information Systems, European Journal of Operational Research, as well as online search engines as ProQuest, EBSCO host, and Google Scholar were examined. To examine the practitioner literature systematically, Google searches were conducted based on the following search terms: business case, IT investment, decision-making, and management. Additional searches of several specialized online databases and websites were also conducted.

The literature review focused on the following areas:

1. What are the studies and practices in terms of creating and evaluating business cases for complex IT investments?;

2. What are the limitations of current practices in terms of creating and evaluating business cases for complex IT investments?;

3. What are the studies and the practices in terms of IT decision-making?;

4. Is there a perceived need for the effective process of creating and evaluating business cases for complex IT investments?;

5. How are the business cases used for complex IT investments?;

6. Does a gap exist between the perceived and the actual practice regarding creating and evaluating business cases for complex IT investments?;

7. Which theories can be applied to understand and explain the process of creating and evaluating business cases for complex IT investments?; and

8. What are the existing studies and theories contribute to more effective decisionmaking regarding the selection of complex IT investments?

This part of the thesis makes three principal contributions. First, drawing on the rich data of previous research, the paper generates a grounded understanding of the nature of business cases for complex IT investments and the constructs regarding the process of creating and evaluating these business cases. Second, the researcher provides relative theoretical foundations on the practices of creating and evaluating business cases for complex IT investments. Last, the researcher creates a conceptual framework to guide the future research on this topic. 


\subsection{Business Cases}

A business case is a decision support and planning tool for practitioners seeking finance supports from resources from an organization (Keen, 2011; Schmidt, 2002). It outlines the predicted financial results and other business consequences of a plan of action and is often a trigger for deciding whether or not to proceed with a project. A business case often assists with setting the scope and objectives of projects, determining the financial and technical feasibility a project, and assists in decision-making about the future (Hogbin and Thomas, 1994). It contains scenarios analyzed quantitatively and qualitatively with recommendations that are necessary in making an informed investment decision (Rottgers and Ritter, 2011).

Organizations are using business cases on the promise of increasing their effectiveness, efficiency, and competitiveness. These promises are based on an assumption or premise that business cases are good and that there are at worst negligible negative consequences of business cases. For complex IT investments in particular, creating and evaluating a business case document is particularly useful for establishing what resources are required and who govern the project and deliverables given that future ownership of IT investments is not always clear (IT Governance Institute, 2006; Remenyi, 1999). For example, a business case document for a planned ERP implementation can act as an initial clarification of which business unit or department funds the project and which stakeholders are responsible for governing the ERP system once it is implemented. Nevertheless, creating and evaluating an effective business case for complex IT investments is difficult due to the uncertainty around the expected benefits, costs, risks, and timing for these complicated organizational projects that typically involve significant technological and organizational change throughout the lifecycle of the IT system.

An accurate and concrete business case must meet the following four criteria:

1. The business objectives of a project including requirements;

2. The commitment of all the practitioners;

3. The operable and feasible of a project including time and human resource; and

4. The business impacts of a project including cost, benefit and risk.

Keen (2011) also provides practitioners tools regarding how to recognize a trustworthy business case. One of the tools is the Seven C's Content Audit Tool including the following qualitative factors:

1. Correct fit to the decision being made;

2. Concerns of decision participants fully identified and reflected in the decision criteria;

3. Complete analysis of all value areas, both tangible and intangible;

4. Connection from IT features to business goals;

5. Credibility of analysis;

6. Conciseness of expression; and

7. Compelling story usage. 
Making a better business cases for benefit realization is crucial. It is not only a document with numbers to acquire funding, but also the basis for reviewing the investment, the prioritization tool for IT investments, and the commitment from business managers (Ward et al., 2008). More than half of the IT executives in the US toughen their business cases when the benefit is not well (Duchessi et al, 2012). They review the IT plan and cost-benefit justification policies periodically. Most of business cases for IT projects are lack of logical link between how the systems will be built and the business changes to be made would lead to the promised benefits (DellaVechia, Scantlebury and Stevenson, 2007). Six additional considerations regarding business cases are outlined by Ward et al. (2008), i.e., non-financial benefits, benefit owners, evidence for the size of benefits, measures for all benefits, owners for the business change, benefit from the combination of IT, and business change. These are valuable concepts for practitioners to add them into a business case. Further, in light of the study of Duchessi et al. (2012), the CIOs suggest that IT executives should align the IT plans with business and endeavor to be as agile as possible. Therefore, they should not only focus on the business cases, but also adapt to new conditions as quickly as they can.

Executives or managers are influenced heavily by business cases. If the business case is not accurate such as putting not much contingency funds to cover overruns or overoptimistic regarding the forecasts, it will be especially pernicious to the projects (Lovallo and Kahneman, 2003). The managers tend to believe their original cost estimates and do not justify them sufficiently to cover the likelihood problems, e.g., the expansions in the scope of the projects (Lovallo and Kahneman, 2003). Therefore, the continually review of the business case is very crucial. It is an iterative process. Further, based on a literature review, Smart (2010) concludes that there has been a long-term issue with identifying business value from IT investments and in creating a business cases for IT investments. There are some problems of showing the influence of IT investments on organization performance such as measurement error. Therefore, a clearly stated business case is crucial for complex IT investments. Moreover, reviewing projects and the business cases after implementation and transferring the knowledge to new projects are important as well.

\subsection{Complex IT Investments}

Complex IT investments mean investments in IT projects that require significant coordination across multiple functional areas of one or more organizations. An example of a complex IT investment would be an ERP implementation. An ERP suite provides a single interface for controlling all major business processes and managing all the routine work flow from entering sales orders to coordinating shipping, as well as managing relationships with suppliers and vendors. The major objective of an EPR suite is to integrate all departments and functions across a company into a single computer system that can serve the entire enterprise's needs. It promises benefits from increased efficiency to improved quality, productivity, and profitability. ERP implementations are high monetary and resource investments, which are inherently complex and risk prone (Akkermans \& Van Helden, 2002; Chua et al., 2012; Ram et al., 2013). They are usually 
large, complex projects, involving large groups of people and other resources, working together under considerable time pressure and facing many unforeseen risks and challenges (Hitt et al., 2002). Davis (2004) outlines the particularly challenging characteristics of ERP systems include:

1. A vast increase in scale of organizational impacts because of integration;

2. Increased transactional intraorganizational interdependencies due to integrated business processes; and

3. Use of the system is not optional if the organizational benefits are to be achieved.

A typical ERP project cost multi million dollars and takes one to three years to accomplish since ERP systems integrate all management functions of an organization encompassing planning, coordinating, accounting and maintaining (Edelhauser, 2011). It can bring competitive advantages to organizations (Tsai et al., 2010). However, the benefits will start to accrue in an average 31 months. Grabski et al. (2011) outline the benefits and challenges of using ERP systems:

1. Implementing ERP system is costly and time-consuming;

2. ERP systems can provide competitive advantage, but this is short-lived;

3. Culture including internal and external context matters;

4. When people interact with technology and processes, outcomes are not predictable or easily determined; and

5. ERP systems continue to evolve.

Not surprisingly, many of these implementations turn out to be less successful than originally intended (Avnet, 1999; Buckhout et al., 1999; Davenport, 1998;). Topicos and Escolha (2011) delineate the principles of choosing a suitable ERP project for an organization and five macro-areas that should be assessed by practitioners: functional fit, flexibility, support, continuity, and maturity. Moreover, Harper and Utley (2001) employ an IT profile (ITP) instrument to define the success of IT projects. The measurement includes overall IT payoff, type of IT investments and evaluation of each, strategy, structural influence of IT, user involvement, performance metrics utilized, primary causes of failure, and IT benefits.

\subsection{IT Investment Decision-Making}

\subsubsection{Rational Decision-Making}

Decision-making is a rational, deliberate, purposeful action of choosing among alternative actions for the purpose of achieving a goal or goals (Tarter and Hoy, 1998; Turban and Aronson, 2001). Investment in modern IT is not optional to top management in this 21 st century and beyond (Hanson, 2007). Complex IT investments mean investing in the IT projects that influence major departments of the organization or the business. It is a critical practice for senior managers. They use decisions to make choices between two or more alternative options. Effective leaders get the right things done, while facing 
the challenges of gathering and interpreting data on which to form a decision (Drucker, 2004).

Ross and Beath (2002) characterize IT investments into four types: transformation, renewal, process improvement, and experiments. Peppard et al. (2007) define two types of IT investments, which are problem-based investments and innovation-based investments. Problem-based investments are focused on solving problems existed now or happen in the future (Peppard, Ward and Daniel, 2007). Innovation-based investments are focused on exploring new business opportunity by implementing IT (Peppard, Ward and Daniel, 2007). Irani (2010) proposes three types of investments, i.e., no choice option (no need to create a business case, compel to do it), infrastructure investments and research investments (next generation of technology). Further, the author defines the first phase of evaluation of IT investments, as ex-ante evaluation is the phase to make accurate decisions. The author divides the ex-ante evaluation into three facets: strategic decisionmaking, financial decision-making and integrated decision-making. Strategic decisionmaking is focused on technical importance, competitive advantage, and critical success factors (Irani, 2010). Financial decision-making is based on the assumptions of payback, return on capital, and cost-benefit analysis (Irani, 2010). Integrated decision-making uses scenario planning, balanced scorecard, and multi-criteria to scrutinize IT investments (Irani, 2010).

The generally spending guidelines managers have for IT investments are the spending levels of competing firms in their industry based on percentage of revenues, or a flat increment on last year's IT budget (Weill and Olson, 1989). Thus, much of this investment is based on blind faith that real returns will occur. Cyert and March (1963) ascribe five major goals of IT investments to contemporary organizations: production, sales, inventory, market share, and profit. Besides these goals, the decision makers must leverage IT investments to meet business requirements to sustain a competitive advantage. Further, decision-makers should also examine the past performance of the company and the dimensions and levels of the organization to make an accurate decision. They need to consider how to maintain competition position. Edelhauser (2011) recommends some advanced decision management methods and managerial decision tools. For example, the seven main advanced decision management methods which are dashboards, OLAP technology, Excel and so forth.

The process of decision-making comprises four principal phases: finding occasions for making a decision, finding possible courses of action, choosing among courses of action, and evaluating past choices (Simon, 1977). The decision-making effectiveness and efficiency are influenced by forecast accuracy, decision alternatives, decision time horizon, and decision speed (Teng and Calhoun, 1996). Further, Keen (2011) illustrates the current issues based on realities of technology investment decision-making:

1. Senior management does not aware that too many IT projects fail to achieve their required business goal and accomplish their required business value; 2. Many executives do not aware the fundamental reason of the failure of IT projects is ROI-based project management approaches; 
3. An inaccurate belief advocated by senior management is that minor adjustments to existing processes could resolve the issue of technology value shortfalls;

4. A lack of pragmatic knowledge of how to develop good business cases effectively; and

5. Many ROI business cases within organizations are unrealistically high, unknowingly low, or unconvincing.

Creating an effective business case is the fundamental step of making an accurate and precise decision. A business case gives the rational reason of making economic decisions including examine demand, estimate costs, specify objectives, and evaluate plan (Cyert and March, 1963). In organizations, the preferences are often problematic, technology is often unclear and participation is often fluid (March, Olsen and Christensen, 1979). Top management needs a business case that identifies problems, objectives, alternatives, tradeoffs and consequences to guide the smart decision-making (Hammond, Keeney and Raiffa, 1999).

Meanwhile, the strategic state of top management enables them to control the access to useful information and to restrict its availability for the other shareholders in the organization. Their investment and finance policies depend on the nature of their objective and they act in increasing the informational asymmetry towards the controllers to increase their discretionary behaviour (Dhaoui and Jouini, 2011).

\subsubsection{Group Decision-Making}

A group is a combinatorial mechanism that the members interact as the combinatorial process and act on individual preferences in the decision-making (Davis, 1973). Group composition is on three dimensions: interpersonal knowledge, interpersonal attraction, and member diversity (Gruenfeld et al., 1996). Many enterprises rely on groups or teams to making decisions since the diversity of the group members will increase product quality and the development of innovations (Chernyshenko et al., 2003). Group confidence is an important outcome of group decision-making process (Sniezek, 1992). Groups are more confident than individuals. However, if there is variance in the information owned by group members and all information is shared and discussed, a decrease in group confidence but an increase in decision quality would be raised (Sniezek, 1992).

Hollingshead (1996) illustrates the pros and cons of group decision-making than individuals' decision-making. In terms of advantage, it can gather all the members' perspectives, expertise and information. In terms of disadvantage, considerable evidence shows that group discussion tends to reflect common information that is known by all group members than unique information. The reason is the probability of recalling the information, which indicates common information is more likely to be recalled since 
group members have better memory for it than unique information (Hollingshead, 1996). Moreover, the pre-discussion preferences can affect group judgment as well.

Some researches indicate that common information is formed before the group discussion (Chernyshenko et al., 2003). Gruenfeld et al. (1996) also argue that information held in common prior to discussion dominates the group decision and group judgments. Unaware information has less influence on group decision and judgments. According to the study of Chernyshenko et al. (2003), group discussion gathers both common information and unique information only if the group members bring up the unique information to discussion. Otherwise, common information will dominate the group decision-making. Further, discussed-common information is weighted considerable more than discussedunique information in terms of group decision-making. In addition, groups composed with familiar members are more effective with respect to pooling information and integrating alternatives than groups composed with unfamiliar individuals (Gruenfeld et al., 1996). However, they are less likely to generate unique knowledge or points of view.

Thus, based on the context, group discussion impedes the exchange of individuals' unique information (Chernyshenko et al., 2003). Therefore, not only group discussion, but also face-to-face interviews or one on one conversations have the probability to gain unique or insightful opinions for decision-making of complex IT investments. On the other hand, interaction with others, which is a rational construction than an information collection, increases the confidence of decision-making but not the quality (Heath and Gonzalez, 1995). The reason is during the interaction, group members are forced to construct a rational explanation to the others. After articulating a coherent rationale, individuals will feel more confident in their decision (Heath and Gonzalez, 1995).

Hollingshead (1996) recommends a rank-order decision procedure. This procedure can compel group members to consider all of the alternatives, which lead to a comprehensive and consistent result. Furthermore, the group members tend to share and discuss all the information including unique and common information. This tendency leads to better group decision-making. Based on this research, the rank-order method for decisionmaking is more effective than choosing the best alternative, however, it only effects on face-to-face conditions, not in computer-mediated groups. Further, the spread of information during group discussion only increase the common and unique information but not harm to the quality of group discussion (Hollingshead, 1996).

\subsubsection{IT Governance}

IT governance is a valuable means to avoid risks and protect organizations from technology-related losses (Mohamed, 2012). It is a crucial factor for complex IT investments decision-making. Business executives perceive that IT importance for strategic alignment is contingent upon IT management sophistication (Huang, 2012). IT management sophistication is how IT management activities expand in planning, control, organization, and integration in terms of identifying and responding to changing and 
dynamic business threats and opportunities (Huang, 2012). It enhances the relationships between IT and business and facilitates practitioners to collect and analyze market information (Huang, 2012). There is no standard IT governance for all of the practices (Bart and Turel, 2010). IT governance includes three major activities, which are managing IT risk, strategic oversight, and control. IT governance dimensions contain structure, process, and relational mechanisms refer to strategic decision-making (Mohamed, 2012). There are five factors (Mohamed, 2012) that work as determinants of IT governance: organizational demographics, information intensity, organizational culture, external environment characteristics, and IT functional characteristics. The organizational demographics such as the size of the organization increase the possibility of the approval of IT investments. The information intensity means that the business is more dependent on IT, therefore, they more tend to use IT to manage business operations.

Adequate IT governance leads to better return on IT investments (Nfuka and Rusu, 2011). Numerous studies incur the need for effective board-level IT governance in order to realize value from IT (e.g., Andriole, 2009; Buckby, Best \& Stewart, 2005; IT Governance Institute, 2003; Nolan \& McFarlan, 2005; Trites, 2004). Board IT governance has a positive impact on the contribution of IT to organizational performance (Bart and Turel, 2010; Jewer and McKay, 2012). Further, proportion of insiders, IT competency of directors, role of IT, organizational age, and board size influence the board's level of involvement in IT governance (Jewer and McKay, 2012). Bart and Turel (2010) recommend a list of IT governance questions that board members should ask before making decisions for IT investments in terms of organizations' strategic use of IT and the requirements for IT reliability.

The critical success factors (CSF), which are project planning, project management, leadership, user support, and executive and upper management support, are crucial for cost effective IT investments (Grabski et al., 2011). Nfuka and Rusu (2011) investigate five areas (i.e., strategic alignment, value delivery, risk management, resource management and performance management) and 11 CSFs included in these areas. According to Nfuka and Rusu (2011), the following CSFs should be considered when making a decision for IT investments:

1. IT leadership to understand the business goals and IT contribution and bring it to the management attention;

2. Involve and get support of senior management;

3. Encourage and support IT/Business communication and partnership;

4. Engage key stakeholders;

5. Define and align IT strategies to corporate strategies and cascade them down in an organization;

6. Consolidate IT structures to ensure responsiveness and accountability;

7. Consolidate, communicate and enforce policies and guidelines for costeffective acquisition and use of IT across the organization;

8. Consolidate, standardize and manage IT infrastructure and application to optimize costs and information flow across the organization;

9. Provide IT governance awareness and training for optimal IT use;

10. Attract, develop \& retain competitive IT professionals; and 
11. Consolidate performance measures and benchmarks to track and demonstrate success.

\subsection{The Process of Creating and Evaluating Business Cases}

The traditional practice for creating and evaluating a business case involves identifying the business needs and projecting costs, benefits and risks of a project. This traditional approach is well suited for most simple and short-term IT investments such as upgrading existing IT infrastructure only when the forthcoming changes from the status quo (e.g., individual, processes, and technology) are well understood and easy to predict. However, it is inherently difficult to create an effective business case for more complex IT investments where the potential benefits, costs, and risks over the lifecycle of the system are difficult to predict. Additionally, traditional business cases typically fail to adequately address intangible benefits and indirect costs in IT investments (Ward, Daniel, and Peppard, 2008). They may rely too heavily on the opinions and past experiences of influential decision-makers and consultants. The existing literature lacks an explanation for the inter-relationship among each element in the process of creating and evaluating business cases and also a lack of exploring different level of performance improvement targets and potential benefits in the combinations of IT enablers and business changes by the business cases.

Keen (2011) delineates the process of building better business cases. These approaches facilitate the researcher to gain a fundamental understanding of the process of creating and evaluating business cases for complex IT investments:

1. Scope- who expects what;

2. Criteria- who cares about what;

3. Align- connect the dots;

4. Calculate- show the money;

5. Prove - who says so;

6. Analyze- find the winner; and

7. Story tell- explain it.

Further, the process of creating and evaluating business cases is a part of decision-making process. The process for decision-making is well discussed by scholars in the past years. Schwab and Kallman (1991) outline the general process of making an IT decision including the steps of finding the vendors, evaluating the offerings, involving the users in definition and selection, and making the final decision. Besides the technology consideration, they point out that political and human factors have a significant impact on the decision-making. In order to make an effective decision, an organization should first identify the capabilities required to execute a business imperative and then understand how to use the appropriate information or technology (Kohli and Grover, 2008). Stewart and Mohamed (2002) argue that the investment management process should have the following three phases:

1. IT/Information system (IS) project selection (benefits, risks and costs); 
2. IT/IS implementation and monitoring (applications, deficiencies and reviews); and

3. IT/IS performance evaluation (measurements, corrective actions and lessons learned).

Mohsen et al. (2011) identify four factors that have impact on decision-making process, which are availability of required technologies, capabilities of individuals, coordination between departments, and acceptance and trust of decision makers. Besides the last one, there is a significant relationship between the former three factors with the effectiveness of decision-making (Mohsen et al., 2011).

Ward et al. (2008) propose a six-stage approach in terms of building better business cases for IT investments based on surveying over 100 European organizations. The result derived from this study indicates that the more the benefits are encompassed in a business case, especially benefits generated from innovation and improved co-operation, both internally and with trading partners, the more successful the organization is (Ward et al., 2008). The proposed and validated six-steps approach (Ward et al., 2008) for creating and evaluating a business case for IT investments is in the following ways:

1. Define business drivers and investment objectives;

2. Identify benefits, measures, and owners;

3. Structure the benefits;

4. Identify organizational changes enabling benefits;

5. Determine the explicit value of each benefit; and

6. Identify costs and risks.

Ahadi (2004) identifies the factors that positively associated with the successful implementation of business process redesign (BPR). The factors are: top management supports, change management, centralization of decision-making, formalization of procedure, organizational culture, and customer involvement. The egalitarian culture of organization is crucial for the success of BPR implementation (Ahadi, 2004). The egalitarian culture is depicted by Grover et al. (1995) as the following: (1) shared organizational vision and information; (2) open communication; (3) strong leadership style; (4) employee participation in decision-making. Further, the capabilities of IT infrastructure have a significant impact on the efficiency of business process change. A fundamental IT infrastructure competency regarding implement BPR is required. Based on the study of Broadbent et al. (1999), the higher level of IT infrastructure the firms have, the more efficient the business process redesign will be. Process simplification requires less infrastructure capabilities while process innovation requires more infrastructure capabilities (Broadbent, Weill and St.Clair, 1999). In respect to decisionmaking for complex IT investments, the scrutiny of IT infrastructure is crucial. Most of complex IT investments are relevant to business process redesign. Therefore, the examination of IT infrastructure should be done before the decision-making. Practitioners can apply the three measures provided by Broadbent et al. (1999) to assess the capability of IT infrastructure in their organizations. The measures are: (1) The extent of the firm's infrastructure services; (2) The provision of boundary-crossing infrastructure services; (3) The firm's reach and range. 


\subsection{Characteristics of Stakeholders}

IT investments are more complex than other investments since more departments and practitioners are involved in the process and all values, desires, and motivations of each participant have to be considered (Rottgers and Ritter, 2011). It is commonplace that senior executives, high-level managers from the finance department, IT project managers as well as other practitioners participate in the process of creating and evaluating business cases for complex IT investments. This core team provides cross-functional and crossorganizational input, and spreads the sense of ownership (Schmidt, 2002). Each practitioner has his/her own characteristics related with their role since they have their own perspectives on business cases.

\subsubsection{Senior Executives}

Senior executives such as Chief Executive Officer (CEO), Chief Information Officer (CIO), Chief Financial Officer (CFO) are the top management of an organization who consider the future direction and the long-term strategy of the firm that is not focused on one business case but the management of the whole resources. The role of CEO is essential in underpinning the new prioritization of projects in a firm (Kearns, 2004). Meanwhile, CIOs concern about the technology trend and the whole IT landscape of the firm. They take charge of information technology department in most enterprises in today's dynamic competitive business environment. They manage rapidly changing internal customer needs, agilely changing technology and internal or external context changes. The leadership of these senior managers affects the process of creating and evaluating business cases for complex IT investments.

Leadership is regard as dealing with change. Most of important decisions in an organization are made by upper-level management (Ahadi, 2004). The characteristics of executives and entrepreneurs that their self-confidence could affect them to believe that they have competency to avoid or overcome potential problems in executing a project (Lovallo and Kahneman, 2003). An effective team is crucial to effective implementation and deployment of IT projects (Fickenscher and Bakerman, 2011).

Executives and entrepreneurs tend to exaggerate the talent of themselves and the degree of control more than other individuals (Lovallo and Kahneman, 2003). Therefore, it is easily to misperceive the causes of events, overstate the influence of their actions and discount the role of luck. The over optimism of executives raised from cognitive biases (i.e., anchoring and competitors neglect) and organizational pressures ruins the accuracy of decisions (Lovallo and Kahneman, 2003). In terms of cognitive biases, managers tend to accentuate the positive plan such as a business case. Moreover, executives are inclined to focus on their own business and thus tend to ignore the ability and activities of rivals. In terms of organizational pressures, managers eagerly to obtain the funding since every organization have only a limited amount of resources (e.g., money and time) to invest in new projects (Lovallo and Kahneman, 2003). In respect to complex IT investments, 
managers should generate realistic forecasts especially for large capital projects and balance the optimism and realism-between goals and forecasts.

According to Ross and Weill' research (2002), the most successful organization in terms of IT investments has senior managers take a leadership role in the decision-making process. While transit their responsibility to IT executives, it always ends with failures, especially CRM and ERP fiascoes (Ross and Weill, 2002). Therefore, IT executives should not be left to make decisions that determine the influence of IT on a company's business strategy. Further, the authors outline six decisions for which senior managers should take leadership responsibility, but not the job for IT people:

1. How much should we spend on IT?

In general, many executives use industry benchmark to determine the proper spending levels. However, the business strategic role of IT is the appropriate foundation for IT investments;

2. Which business processes should receive out IT dollars?

The prioritization of IT projects should not leave to IT department. The senior managers should choose an accurate set of IT priorities;

3. Which IT capabilities need to be companywide?

Senior managers should play the role in weighing the crucial trade-offs;

4. How good do our IT services really need to be?

The decision should be made based on the suggestions from IT people;

5 . What security and privacy risks will we accept?

Security becomes new importance in an organization. However, the viewpoint

from IT units is totally different from marketing executives; and

6. Whom do we blame if an IT initiative fails?

The value of a new system is from new or redesigned business processes.

Therefore, business executives should be assigned to realize the business benefits from an IT project.

\subsubsection{IT Project Managers}

Hoving (2007) delineates four key talents for IT project managers to succeed: (a) inherent knowledge of the technologies and natural instinct to know which ones will pay off; (b) business agility and the courage to demand measurable returns; (c) the competency to manage a diverse set of internal and external resources; (d) an accurate sense of what it takes to achieve right things. These challenges force them to make an accurate and concrete business case for complex IT investments in order to succeed in competitions. Proactive IT project managers who take advantage of a stable environment are outperforming reactive IT leaders and obtain performance advantage ( $\mathrm{Lu}$ and Ramamurthy, 2010).

From IT project managers' viewpoints, technology such as the function of the system is one of the important aspects in terms of complex IT investments. IT project managers put effort on the business case because they eager to get the funding for their projects. They are specialized in the function of information systems. However, the firm's managerial 
skills by IT project managers are important for the firm to gain competitive advantages. Karanja and Zaveri (2012) dispute that IT project managers should be skilled at strategic thinking and planning. Further, they should have good communication skills and a good sense of business operations and processes. According to the research (Karanja and Zaveri, 2012), most of the IT leaders have a MBA or EMBA graduate degree. The higher level of education the managers have, the more they tend to be innovative that is open minded, risk takers, creative, and easily tolerant to ambiguity (Karanja and Zaveri, 2012). A business case is to aid them to manage change and prepare for uncertainty.

\subsubsection{The Others}

Business managers are focused on the business value derived from IT investments. From senior managers' viewpoints, they are focused on perceived benefits, costs, and risks (Fink, 1998; Thong and Yap, 1995). Since IT is one of the business enables, business managers concern how IT facilitates their business.

Financial managers are part of the top management who take effort to achieve the maximum of benefits. They analyze and examine the costs and benefits that a project will bring to the corporation in the future. Although they do not have IT knowledge, they are very sensitive to the numbers and the revenue.

Indeed, these practitioners have different characteristics and working relationships. Communications among them play a vital role on the effectiveness of creating and evaluating a business case, which is a cross-functional activity. To ensure that a business case achieves its objectives, it needs to have the commitment of all practitioners involved, through their participation in its preparation and implementation.

\subsection{Cost \& Benefit Analysis}

Prior studies have established that IT contributes to a firm's financial performance through improved productivity, higher profitability, and enhanced consumer value (Dewan and Ren, 2011; Ramirez et al., 2010; Ravichandran and Lertwongsatien, 2005). IT investments that have a positive impact on a firm's market value and the subsequent increases in a firm's market value are vital to sustaining corporate viability and prosperity (Bacon, 1992; Chou, Chou \& Tzeng, 2006; Kohli, Devaraj and Ow, 2012). It is an outcome that is of considerable interest to senior managers and other stakeholders. As recent evidence indicates, failures to invest in IT can influence a firm's operations in ways that adversely affects its market value (Yayla and $\mathrm{Hu}, 2011$ ). Nowadays, more than 76 percent of all IT project investments fail to meet their financial goals and over 50 percent of funded IT projects still use no formal ROI guidance (Keen, 2011). The failure of projects is presented in three ways: overrunning its budget, overrunning its schedule or failing to demonstrate the planned benefits (Whittaker, 1999). It seems many practitioners are unsure about the most effective ways to get investment back. 
From a senior manager's perspective, the business value (risk-adjusted net benefit) is the central consideration for a potential IT investment. IT investments generate business value (Kohli and Grover, 2008; Soh and Markus, 1995). IT value including potential value and realized value can be assessed in process level and market level (Chircu and Kauffman, 2000). Besides technology, there are many things that are necessary for acquiring benefits such as a new business process, work routines, and organizational knowledge. However, many IT investments lack of realization of expected business benefits (Peppard, Ward and Daniel, 2007). Organizations spend an increasing amount on IT without a better return and fail to realize the value of IT (Computer Economics, 2010; Jewer and McKay, 2012). It is easy to underestimate or overestimate the huge value penalty of current management practices since there are tangible and intangible costs and benefits.

Schryen (2013) illustrates a new IS business value model to explain the causal relationship between IS investments and business value, especially the economic relevance of IS, i.e., how IS investments create business value, what is the particular outcome of IT investments and how these outcomes are interpreted. IT investments should be examined if appropriate IT assets and impacts were measured (Kohli and Devaraj, 2003). Hitt et al. (2002) conclude that large organizations tend to adopt ERP systems although the performance and the productivity will be slow down after the implementation in a short period of time. Devaraj and Kohli (2000) identify that there is a relationship between IT and organizational performance after a time period. Kearns (2004) also points out the measurement issues in terms of IT investments, one of which is the time issue between investments and realized benefits. Besides these issues, the researcher discusses the cost and benefit analysis in terms of tangible value and intangible value in the next sections.

\subsubsection{Tangible Value}

Cost and benefit analysis including the concepts of Total Cost of Ownership (TCO) and Total Benefits of Ownership (TBO) is considered in this research. TCO goes beyond the simple purchase price and is the total cost of procuring, implementing, maintaining, and changing work practices in a project over an extended period of time. TBO is a similar concept involving the total monetary benefits that accrue from a project, rather than merely the most obvious revenue increases. Cost and benefit analysis is needed in planning, decision-making and proposal evaluation. The sheer size of ERP projects requires centralized control, strict discipline and extensive monitoring of project outcomes (Sumner, 2000). Rottgers and Ritter (2011) propose three steps to explore the insights of cost and benefit analysis:

1. Quantify qualitative values by visualizing the decision problem with an influence matrix;

2. Quantify the elements of the decision problem by creating the financial model; and

3. Analyze the results of the financial model by performing a sensitivity analysis. 
The costs of an IT project are often perceived to be easier to estimate than the benefits such as hardware and its installation, software provision and its customization, development and maintenance of hardware and software, running and operating, training, staff, consultancy (Hogbin and Thomas, 1994). On the other hand, benefits can be calculated by some key business ratios such as expense, profitability, working capital and return on assets. In addition, it is operable to use some experts with the relevant accountability and authority to facilitate making the estimate of benefits.

Here are some key ratios used for cost and benefit analysis:

1. Net present value (NPV) is defined as the sum of the present values (PVs) of the individual cash flows of the same entity. It is used for capital budgeting and is a central tool in discounted cash flow (DCF) analysis;

2. Internal rate of return (IRR) is a ratio of return used in capital budgeting to measure and compare the profitability of investments;

3. ROI is used when deciding whether or not to invest in something, or make an acquisition. Sometimes, it is also used as Return on asset (ROA);

4. TCO is the total cost of acquiring installing, using, maintaining, changing, and getting rid of something across an extended period of time. It is a life cycle cost estimate; and

5. TBO is used when summarizing the positive effects of acquisition of new computer components.

Peppard et al. (2007) develop an approach to clearly identify the expected benefits and a detailed plan of how the practitioners can realize these benefits. The central element of this approach is to involve key stakeholders in the development and execution of this benefits identification plan. Therefore, not only the success of the project, but also the relationship among participants will be improved. Further, they propose Benefit Dependency Network (BDN) model, which is a good fit for contemporary organizations to optimize ROI from IT expenditures. Stevenson endorses the BDN approach, which could be the guideline for determining and tracking ROI of IT projects (DellaVechia, Scantlebury and Stevenson, 2007). In addition, DellaVecchia, a former CIO, points out that BDN model should be further explored for portfolio-based approaches to high-level corporate governance (DellaVechia, Scantlebury and Stevenson, 2007).

Few organizations conduct ROI-based analysis for IT projects and the business cases are usually defective. Thus, Keen (2011) suggests managers to employ ROI-based business case analyses. Further, he recommends practitioners to use Balanced Scorecard, which is Kaplan and Norton (1996)'s globally popular performance measure methodology for aligning organizational effort to enterprise strategies. Also, Edelhauser (2011) argues that it is one of the methods, which every manager should have it. Mohamed (2012) defines the balanced scorecard that complements the historical perspectives using financial measurement to evaluate the IT performance. The author suggests business executives to identify financial perspective, customer, internal business processes, and learning and growth when investigating IT performance. The users of Balanced Scorecard can benefit 
from a more reliable and tightly integrated business case process for identifying the true business value of strategies (Leckson-Leckey et al., 2011).

\subsubsection{Intangible Value}

IT investments are increasingly made to provide benefits, the value of which is difficult to identify. A lack of foresight in the IT investment decision processes causes a significant loss (Schniederjans and Hamaker, 2003). The nature of IT investments embraces financial elements and technological issues. Besides cost and benefit, decision makers consider more regarding organization's strategies, priorities and other intangibles (Schniederjans and Hamaker, 2003). Most studies regarding IT investments are focused on the financial value of information technology investments. For example, using cash flows and tangible assets to measure the impact of investments in the organization's outputs. However, intangible benefits from complex IT investments are also important. Intangible benefit in terms of IT projects is a benefit incurring from a proposed investment that is not or cannot be expressed in monetary terms (Jack and Bonnie, 2003). For example, better customer services, improved quality and enhanced agility to an increased variety of customer needs (Jurison, 1996). To measure intangible benefits such as customer/user satisfaction related with trust and loyalty, competitive advantage, or investor confidence, it is crucial to quantify qualitative values in monetary terms using business case analysis to get the budget approved. The intangible element if it matters at all, it can be detectable and observable by putting the numbers into a range: minimum, most likely, maximum (Rottgers and Ritter, 2011).

Benefits from IT projects are generated from organizational change instead of a technical artifact (Doherty et al., 2011). Organizational performance is one type of intangible benefits that should be considered into benefits realization management (BRM). The practitioners should identify the meaningful benefits, rather than fulfill the on time and on budget or the technical requirements. Stewart and Mohamed (2002) recommend decision makers to adopt the ranking approach based on value and risk to select the most viable projects. The weighting factors may be employed to the ranking criteria, especially for the intangible things. The most benefit of adopting IT is it goes beyond the traditional business value (e.g., NPV, IRR) but focuses on the concepts of risks and value (Stewart and Mohamed, 2002). IT/IS projects are difficult to identify hard benefits in the short term but will definitely impact the future of the firm (Stewart and Mohamed, 2002). Decision makers could adopt the ranking approach based on value and risk to select the most viable projects.

Cintrón et al. (2008) conducted a research aims at examining the knowledge of employees and their technological capabilities gained from information technology investments. They distinguish intangible assets into two categories, one is legal intangible such as trademarks, patent and goodwill and another is competitive intangible including knowledge activities as well as structural activities and collaboration. These knowledge assets are generally overlooked by traditional financial analysis, which should be taken into account as the organizations' market value. The authors suggest using Knowledge 
Value-Added, which depicts that the value of the knowledge applied into a process determines the benefits and costs of a business process. Knowledge management is an organization strategic effort to collect knowledge and experience from employees and customers which are stored in a database, documentation or in individuals' intellect thus distribute it to obtain more benefits (Mohsen et al., 2011). There are three types of knowledge: explicit (tangible), implicit (tangible), and tacit (intangible) (Mohsen et al., 2011). The availability of knowledge management technique can bring great benefit to various business operating activities (Mohsen et al., 2011).

In addition, many successful decisions are driven by the gut feel of experience and intuition (Jack and Bonnie, 2003). Mostly, intangibles are included into business cases on an exception basis (Jack and Bonnie, 2003). The research conducted by Jack and Bonnie (2003) outlines the five typical ways organizations handle intangibles:

1. Ban intangibles;

2. Allow intangibles on a case-by-case basis;

3. Use individual intangibles as scorable items;

4. Group intangibles together; and

5. Convert as many intangibles to tangibles as possible.

They also provide approaches to address intangibles as the following:

1. Convert intangible factors into tangible;

2. Managing intangibles with a score sheet; and

3. Develop a policy for intangibles management such as upgrade research skills, interviewing individuals, take time, open minded, and be prepared for pushback.

Keen (2011) proposes how to deal with intangible things. For example, turn intangible view (e.g., increase shareholder value, increase customer satisfaction, increase competitive advantage, improve marketplace image) into tangibility theme (e.g., encourage larger and more frequent purchases, reduce turnover costs, improve acquisition expenses).

In addition, Analytic Hierarchy Process (AHP) and Analytic Network Process (ANP) are mathematically based multi-criteria decision-making tools proposed by Saaty $(1980$, 1996). They can be used to deal with the benefits, opportunities, costs, and risks (the BOCR merits) of a decision. AHP is aimed at intra-functional factors. ANP is a complement of AHP to solve the difficulties in appraising compatibility (Sarkis and Sundarraj, 2003). The four steps of AHP (Sarkis and Sundarraj, 2003) are the following:

1. Develop a hierarchy of factors influencing the final decision;

2. Elicit pairwise comparisons (PWCs) between the factors, using inputs from users/managers;

3. Calculate the relative ranking of factors in step 2; and

4. The overall importance weight of the EIT alternatives.

Kearns (2004) recommends AHP as a multi-objective, multi-criteria (MOMC) approach which can improve the alignment of IS plan with organization goals. Since AHP only investigates hierarchical relationships, ANP is needed for inter-functional compatibility 
issues (Sarkis and Sundarraj, 2003). The five steps of ANP (Sarkis and Sundarraj, 2003) are the following:

1. Develop a decision model;

2. Elicit pairwise comparisons among the factors influencing the decision;

3. Calculate relative-importance-weight vectors of the factors;

4. Form a two-dimensional matrix and normalize this super matrix; and

5. Raise the normalized super matrix to a large power to calculate the converged weights for the alternatives.

\subsection{Guiding Theories}

Familiarity with prior theories can help sensitize a researcher to understand and interpret management phenomena (Weick, 2007). This research examines the patterns that emerge from a thematic analysis of interviews exploring the creation and evaluation of business cases for complex IT investments. The analysis described in Chapter 4 compares and contrasts new insights from the interviews with prior theory from the areas of process design, relationship management, decision-making, investment governance, and systems and project management (see Appendix B for an overview of these theories). For example, concepts from sensemaking theory (Klein et al., 2006), theory of inventive problem solving (Hua et al., 2006), theory of decision-making (Cohen, March and Olson, 1972; March, Olsen and Christensen, 1979), structuration theory (Giddens, 1984), actor network theory, and agency theory (Eisenhardt, 1989; Fama, 1980; Jensen and Meckling, 1976; Long and Walkling, 1984) may all contribute important concepts in developing the new process theory. However, knowing which guiding theories will be relevant will not be known until the initial patterns or themes begin to emerge from the analysis of the data gathered by interviews and Q-sorting.

\subsubsection{Process Theory}

This research seeks to develop a process theory (Langley, 1999) to better inform the creation and evaluation of business cases for complex IT investments. The process theory approach has been used extensively in IS research, most notably as a base for structuration analysis and for modeling sequences of events (Adomavicius et al., 2008; Markus and Robey, 1988). This research combines the principles of process theory (Langley and Truax, 1994) with the formal guidelines of theory building using exploratory mixed methods. A process is a set of activities and comes out with an artifact (Walls et al., 1992). Also, a process is a set of constructs that refer to actions of individuals or organizations and a sequence of events that demonstrates how things change over time (Van de Ven, 1992). Process theory is seen as offering an explanation of the temporal order in which a discrete set of events occurred, based on a story or historical narrative and encompass three components that are a set of starting conditions, a functional end-point, and an emergent process of change (Huber and Van de Ven, 1995; Van de Ven, 1992). Furthermore, process theorization needs to go beyond surface 
description to penetrate the logic behind observed temporal progressions - whether simple or complex (Van de Ven, 1992). In this research, the process is how to create an effective business case and describe the causal relationship among the constructs such as IT projects, practitioners and so forth. Moreover, the theory of inventive problem solving (Altshuller, 1988; Altshuller, 1996; Hua et al., 2006) is a useful tool that can guide the process design process. It is known as a powerful method in solutions generation in the design problem-solving process. Besides, the Failure Mode and Effects Analysis (FMEA) is an analysis tool facilitating individuals to identify weakens and makes improvement for a design or a process (Frenklach and Savransky, 1998). This tool answers the question "What might be wrong with a system?" (Cavallucci and Lutz, 2000; Mazur, 2000; Pevzner and Katsman, 2001; Terninko, 2000; Zeidner and Wood, 2000).

\subsubsection{Decision-making Theories}

Since the purpose of a business case is to support decision-making, the researcher also looked for guidance in decision-making theories such as the garbage can theory of organizational choice. First, garbage can theory suggests that decisions result from the random collisions of participants, choice opportunities and solutions (Cohen, March and Olson, 1972; March, Olsen and Christensen, 1979; Tarter and Hoy, 1998). From this point of view, an organization is a collection of choices looking for feasible solutions and decisions to solve the issues and problems in various kinds of context. To understand processes within organizations, individuals can take a choice opportunity as a garbage can into where problems and solutions are dumped by participants as they are generated (Cohen, March and Olson, 1972). In this research, the garbage can theory can guide the practitioners to understand the decision-making under possible organizational structure, moreover, to understand the determination of the energy required and effective energy applied to make such choice.

Second, behaviour decision theory (Carter, 1971; Cyert and March, 1963) is a theory of human decision-making in an organization. It is based on Bayesian decision-making and tries to incorporate decision-making patterns of individuals such as underweighting or overweighting of probabilities, decision or choice framing, and trade-offs. It complements garbage can theory to better understand the human actions. Prospect theory that is a behavioural economic theory is utilized to make decisions that involve risks in terms of loss and gain between alternatives, where the probabilities of outcomes are known (Kahneman, Slovic and Tversky, 1982; Thomas and Fernandez, 2008). Since this theory emphases risks management in decision-making, it can be utilized to analyze risk part in a business case.

In addition, contingency theory is a class of behavioural theory that claims that there is no best way to organize a corporation, to lead a company, or to make decisions. On the contrary, the most favourable course of action is contingent in terms of internal and external situation (Ferrell and Gresham, 1985; Tarter and Hoy, 1998; Woodward, 1958). Contingency theory is focused on the efforts of individuals to respond to environmental pressures and is based on values that are important to the institution (Leaptrott, 2005). 
Some important contingencies for organizations are technology, customers, and competitors. These contingency elements could also be examined in future research.

Concepts from sensemaking theory (Klein, Moon and Hoffman, 2006; Snowden, 2005; Weick, Sutcliffe and Obstfeld, 2005) such as creativity, comprehension, curiosity, mental modelling, explanation and situational awareness can help understand connections among individuals, contexts and events in order to anticipate their trajectories and act effectively. Institutional theory suggests that organizational governance and decision-making are significantly influenced by the need for institutional legitimacy (Tolbert and Zucker, 1999; Xue, Liang and Boulton, 2008). Even when a top management approval is required, a wide variety of IT governance archetypes may be used that IT organization is not involved in the initiation or development stages of the IT investment decision process, while other IT organizational actors involved in by initiating and developing IT investment proposals.

\subsubsection{Relationship Theories}

The process of creating and evaluating business cases for complex IT investments involves diverse departments and each of them reacts by their own characteristics, roles and the context. Therefore, theories related with agency and structure are considered in the preliminary research phase. First, structuration theory provides the relationship between agency and structure in terms of the activities and context (Brugha, 2005; Orlikowski and Robey, 1991). Structure is what gives form and shape to social life and agency does not refer to individual's intentions in doing things but rather to the flow or pattern of individual's action (Giddens, 1984). They interact with each other since actions are conditioned by structures while structures are recreated by actions. According to this study, the structure is the culture of organizations and departments. The agency is the flow or pattern of participations' actions in the process of creating and evaluating business cases for complex IT investments. In addition, IT project dimension including function, time-scale is also be considered into the research. Second, actor network theory is a method of thoroughly exploring the relational ties within a network (Latour, 2005; Nagm and Cecez-Kecmanovic, 2008). The actors that can be human or non-human in a network form an apparently coherent whole while contain conflicts as well. The practitioners and IT projects are the actors in this research. They act as a whole within the network of the process of creating and evaluating business cases. There are conflicts among the practitioners depending on their own preference and priority. In addition, other elements including context and strategy also influence the network.

Agency theory can be used to explain the relationship between principals and agents in business (Eisenhardt, 1989; Fama, 1980; Jensen and Meckling, 1976; Long and Walkling, 1984). A principal is pervasively considered as shareholders who are represented by differentiated groups within or outside the organization (Jensen \& Meckling, 1976). An agent represents the principal in transactions with a third party such as managers or company executives (Eisenhardt, 1989). The fundamental assumption of agency theory is the presence of asymmetric information and divergent risk perceptions between 
principals and agents. Therefore, agency theory can explain the conflicts between principals and agents in order to solve problems that exist in the relationship between these two parties. The practitioners such as senior executives, senior project managers are the agents in this research and other stakeholders such as senior IT project managers are the principals. They have different goals and different risk tolerances that incline to take different actions in the process of creating and evaluating business cases for complex IT investments. In addition, without the efficient communication and inaccurate information, the process will be ineffective and mislead the decision-making.

\subsubsection{Investment Governance Theories}

Investment governance theories may also play an important role. Entrenchment theory (Shleifer and Vishny, 1989) can be used to interpret the behaviour of corporate managers in terms of investing in businesses and making contracts. Finance operations such as the free cash flows can permit managers to increase arbitrary actions in decision-making that expand their authority towards the shareholders (Dhaoui and Jouini, 2011). Real options theory can supplement concepts such as NPV to incorporate uncertainty about future cash flows (Benaroch, 2002; Leiblein, 2003). This theory is composed with five categories of real options: Waiting-to-Invest option, Growth option, Flexibility option, Exit option and Learning option ("Real options theory", 2011).

\subsubsection{Systems and Project Management Theories}

IT project management is one of the main concepts related with creating and evaluating business cases for complex IT investments. The following theories could enhance the understanding of elements in IT project management. The first, complexity theory explains how complex adaptive systems function, and thus suggests the project manager needs tools and techniques that can model both linear and nonlinear behaviour and is applicable to IT project management (Curlee and Gordon, 2010). Complexity "is formed by interweaving, interconnecting, and folding together different parts, elements, or components ... it is an intricate process of implication; complication implicates and implication complicates" (Taylor, 2001). It is commonly interpreted to describe the condition of something that is other than simple. Since complexity is a key attribute of project behaviour comprised of both linear and nonlinear activity, project managers learn to look at their project organizations as complex adaptive systems, they become more adept to not only to manage the internal, short-term, linear aspects of a project, but also to plan and better integrate capabilities focused on the nonlinear nature of projects (McKinnie, 2007). Second, systems theory is the bridge facilitating the complementary analysis by complexity theory. It has a well-established history in explaining organizational behaviour. Both projects and organizations are complex adaptive systems. The foundation of systems theory is discussed and systems are classified as hard and soft, a perspective that points to the issue of flexibility as found in social science (Banathy, 1996; Haslett and Shankar, 2009). Systems are also frequently classified as the following 
hierarchy: simple systems, static systems, complex dynamic systems, self-organizing systems, complex adaptive systems, and autopoietic complex adaptive systems.

Third, chaos theory, refers to an apparent lack of order in a system that nevertheless obeys particular laws or rules, is the study of nonlinear dynamics, in which seemingly random events are actually predictable from simple deterministic equations (Singh and Singh, 2002). The main ideas of chaos theory are that systems - no matter how complex they may be - rely upon an underlying order, and that very simple or small systems and events can cause very complex behaviours or events. From a process perspective, a definition of chaos is somewhat less complicated. Chaos is the "unstable, aperiodic behaviour in deterministic nonlinear dynamical systems" (Taylor, 2001).

\subsection{Conceptual Framework}

A conceptual framework is the central part of research and facilitates the researcher establish concrete organization of the study (Maxwell, 1998; Miles, 1979; Miles and Huberman, 1994). The following preliminary framework that guides the research during the investigation of the process of creating and evaluating business cases for complex IT investments. This framework emerges from previously discussed relevant concept identified from the existing literature. The main purpose of this framework is not to be validated by hypothesis testing but rather to offer a visual representation of the proposed relationships among constructs and provide guidance for exploring understanding and the research questions.

As shown in Figure 2, there are five main categories of research constructs: guiding theories, processes, IT projects, stakeholders, and decision variables (e.g., costs, benefits, and risks). Guiding theories is the main part of this framework that is the foundation of the study. This research further highlights the fundamental theories underlying the practice. Since creating and evaluating business cases for complex IT investments focuses on effective decision-making, the theories related with decision-making are the most relevant to this study. The guiding decision-making theories, e.g., behavioral decision theory, have primarily been concerned with the rationality of making a choice. For example, managers often scrutinize "hard" information, i.e., costs, benefits and risks as the fundamental variables to direct their decisions. Notwithstanding, the subsequent analysis of interviews described in this thesis highlights the importance of human dynamics (e.g., emotional components, resistance from stakeholders, the preferences of decision-makers), which influences the effectiveness of creating and evaluating high quality business cases for complex IT investments.

The processes of creating and evaluating an IT business case includes elements such as identifying a need for an IT project, defining scenarios and alternatives, and estimating and evaluating costs, benefits, and risks. A business case should be complete, accurate, objective and balanced. In general, creating an IT business case comprises of elements such as requisition of an IT project, communication between practitioners, estimation and evaluation of costs, risks and benefits. Each element has its own characteristics, for 
example, there are various types of complex IT projects such as enterprise systems implementation and complex IT-enabled process change. Each project is different in terms of requisition for IT function, the impact to the majority of practitioners in an organization and long-term or short-term time scale. The practitioners involved in the process of creating and evaluating a business case for complex IT investments typically are senior executives, IT project managers, financial managers, project team members, end users, and other stakeholders. They act or interact upon their job roles, personalities and characteristics. Furthermore, one of the most important parts of creating and evaluating a business case is to estimate costs, benefits and risks of an IT project. The costs of an IT project are often perceived to be easier to estimate than the benefits such as hardware and its installation, software provision and its customization, development and maintenance of hardware and software, running and operating, training, staff, consultancy (Hogbin and Thomas, 1994). On the other hand, TCO, TBO and risks are decision variables for complex IT investments.

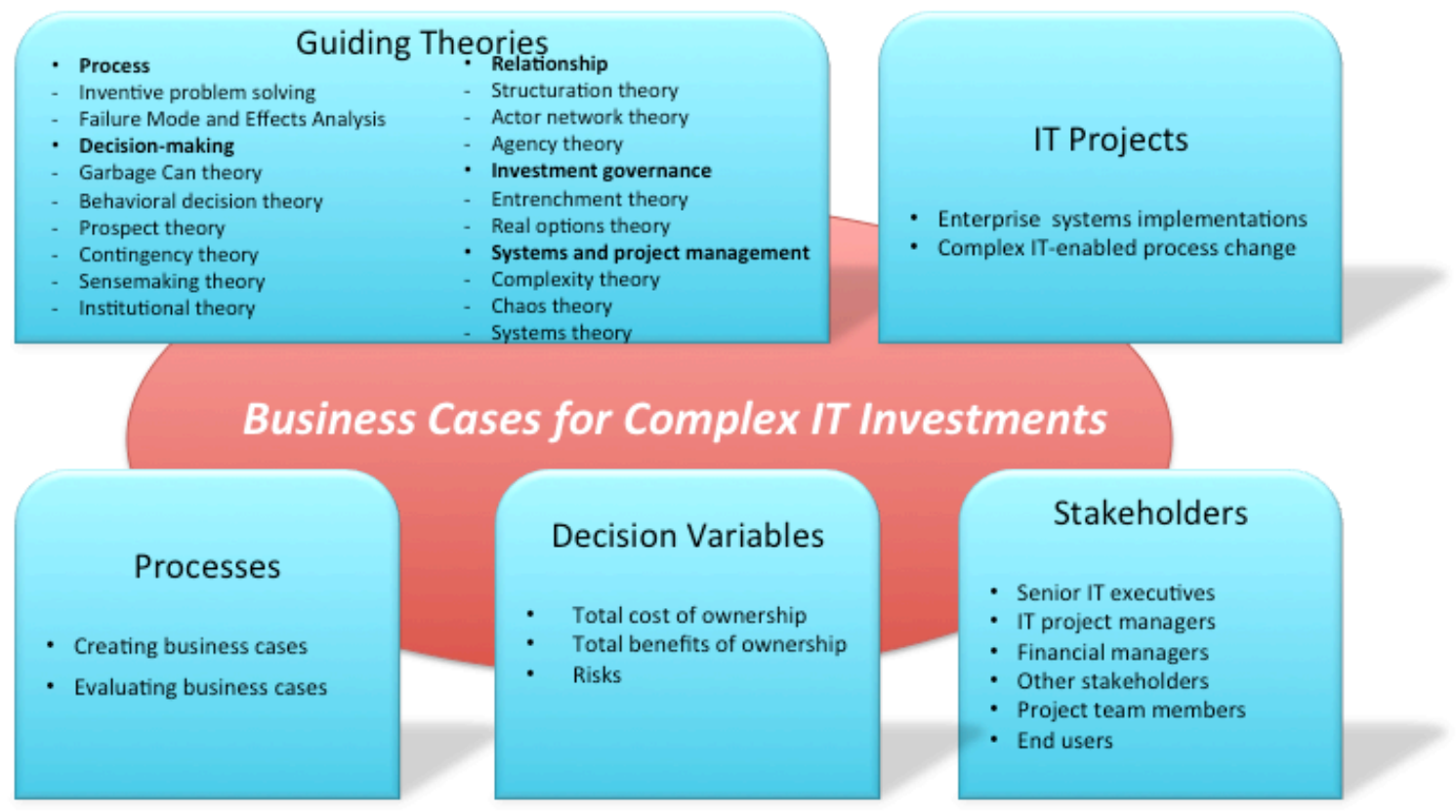

Figure 2: Conceptual Framework 


\section{CHAPTER 3: RESEARCH METHODOLOGY}

\subsection{Introduction - Mixed Method Research}

Since research on business cases for complex IT investments is still in its infancy and very little has been written about how to effectively create and evaluate business cases for complex IT investments such as ERP, the researcher followed an exploratory research approach (i.e., Eisenhardt, 1989) rather than a theory or hypothesis testing approach. The researcher conducted an exploratory mixed methods field study based on interviews with IT investment practitioners to look for empirical process that would benefit the decisionmaking of the investment in IT projects and followed up with an online Q-sorting to further explore the level of the importance of principles for creating and evaluating business cases for complex IT investments.

The philosophical basis of this proposed approach is pragmatism that understands the real world phenomena and learns from it in order to explore the knowledge and generate an empirical theory (Creswell, 2012). This study is a problem-centered, exploratory research, which, aims to find a solution for the problem of how the process of creating and evaluating business cases for complex IT investments, such as ERP implementations, can be done more effectively. Pragmatism means to provide creative and innovative through analysis and conceptualizations that best meets needs and purposes of this research. The purpose of this research is not to generate and develop hypothesis about the role and impact of business cases in a 'positivist' viewpoint but to explore a rich understanding and new insights of creating and evaluating business cases for complex IT investments, which is useful for practitioners in theoretical and empirical way (Eisenhardt, 1989).

Qualitative research is argued to be the most "adequate" and "efficient" way to obtain the type of rich contextual information required to examine new situations (Glaser and Strauss, 1967; Johnson and Christensen, 2007; Maxwell, 1998; Miles, 1979; Strauss and Corbin, 1998). Qualitative data are rich, full, earthy, holistic, real, their face validity seems unimpeachable and they tend to reduce a researcher's trained incapacity, bias, narrowness, and arrogance (Robson, 2002; Yin, 1981). The researcher is creative, openminded, flexible, and explore all sources of information in this study.

Quantitative research using statistics to analyze and interpret data can increase the accuracy and validity of findings (Creswell, 2012). Moreover, using quantitative data provides objective sustentation. However, quantitative research sometimes needs large samples to obtain a significant result, but dealing with large samples cost human resources and time (Boeije, 2010). In addition, misusing sampling and weighting can completely undermine the accuracy and validity of a quantitative research (Boeije, 2010). Last but not least, confirmation bias may exist in quantitative research since the researcher might omit phenomena because of the focus on theory or hypothesis testing rather than on theory or hypothesis generation (Boeije, 2010). While quantitative and qualitative research approaches have their own strengths and weaknesses, they can be 
extremely effective in combination with one another that is mixed methods approach (Creswell, 2012).

Exploratory research as one of mixed methods research addresses what question (Neuman, 2011). Although exploratory mixed methods are in general used to motivate research questions or illustrate conceptual arguments, one of the most effective ways of using them is in the inductive derivation of new theories. Guiding by the conceptual framework (Figure 3), data for this research were generated from two sources: (1) semistructured interviews and (2) online Q-sorting data to help the researcher find the answers of research questions and fulfill the purpose of this study. First, the researcher conducted interviews with expert participants to examine the practices in the process of creating and evaluating business cases for complex IT investments. Then, the researcher used the interview results combined with literature to execute an online Q-sorting to explore the opinions across a number of expert participants with respect to principles that make the process more effective. The overall approach of this exploratory mixed methods study follows a theory-building paradigm rather than a theory testing one. The step by step of conducting the research is presented as the following Figure 3:

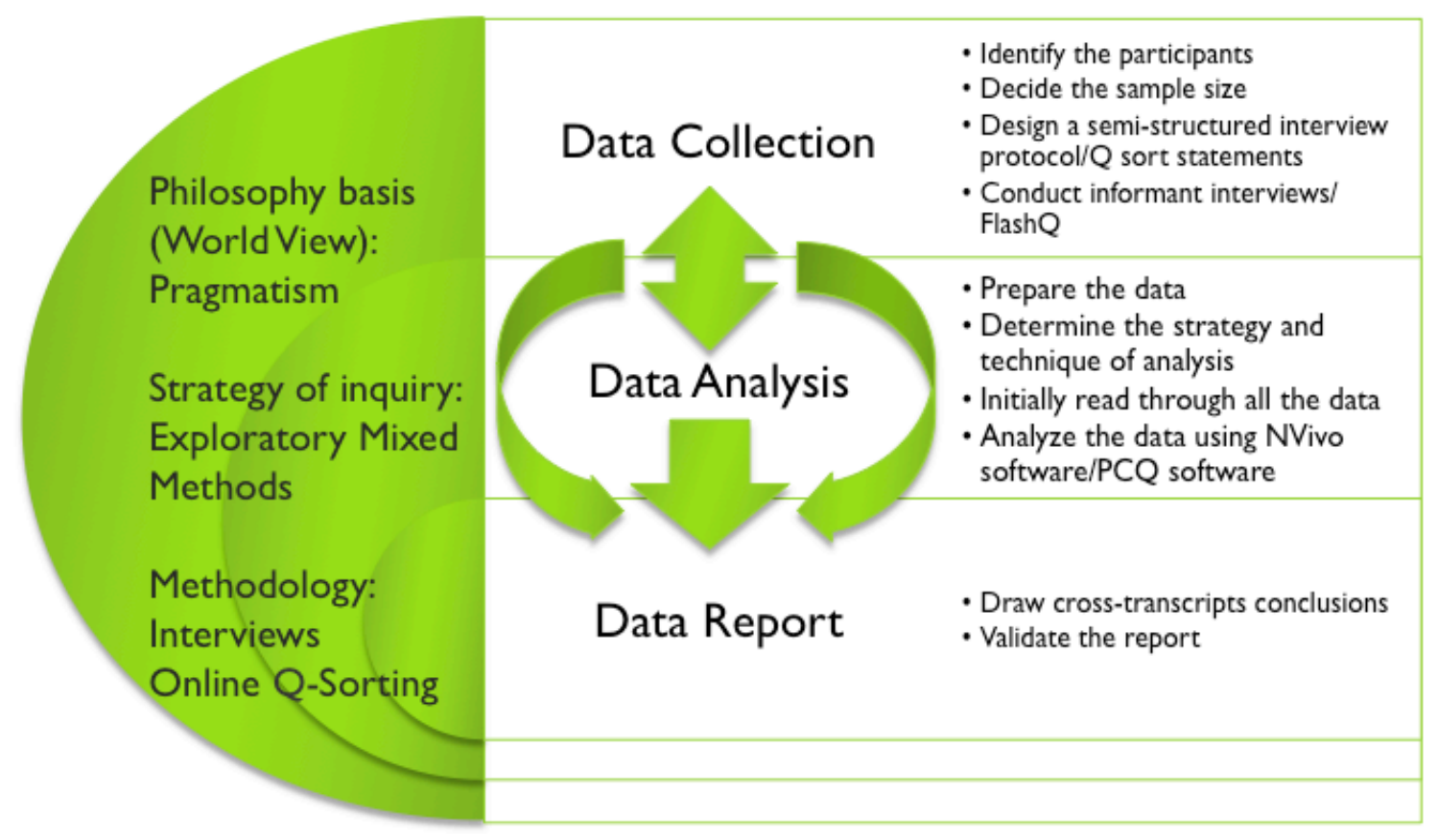

Figure 3: Research Method Step by Step

\subsubsection{Qualitative Analysis of Interviews}

This study uses exploratory mixed methods. The first step is a qualitative analysis of interviews that facilitates the researcher to develop a practical process theory by taking the individuals as a series of independent experiments. The rationality for using this 
approach is that an understanding of creating and evaluating business cases could best be developed only after useful interviews. Furthermore, since this research investigates the influences that impact the process of creating and evaluating business cases, it utilizes the viewpoints from individuals in attempt to generalize the results to an individual level and not restrict the findings to one particular type of organization. This study is focused on the contexts in which these principles would lead to the effective complex IT investments.

The data collection instrument of primary data is the semi-structure interview, which has a high degree of flexibility. The transcripts and notes made during each interview were reviewed and typed up immediately after the interviews. Guiding by the conceptual framework, the researcher first conducted ten in-depth interviews with senior executives, senior project managers and business managers to probe how they create and evaluate business cases for complex IT investments. Then, using the results from the interviews and combining with findings from literature, the researcher summarized a list of principles as the basis for the follow up online Q-sorting to further concrete and assess the opinions from expert participants. The follow up Q-sorting invited up 19 participants including $\mathrm{CEO}, \mathrm{CFO}$, senior IT project managers, business managers, and scholars to evaluate 32 principles based on their experiences on creating and evaluating business cases for complex IT investments.

\subsubsection{Quantitative Analysis using Q Methodology}

Q methodology comprises both qualitative and quantitative research methods (Klaus et al., 2007). The most significant difference between $Q$ methodology and general survey and questionnaire methods is that all the statements in a Q sort are treated as dependent on each other, while each item in a questionnaire or survey is treated as independent on each other (Klaus et al., 2007). In general, a Q methodology study aims to uncover dimensions of individual subjective points of views, statistically identify different dimensions of those viewpoints, and scrutinize characteristics of groups of individuals who share common viewpoints (Brown, 1993). Q methodology is a structured inductive exploratory means to organizational research (Davis, 2004). In the study of business cases, the viewpoints under investigation comprise of senior executives, IT project managers, and other participants perceptions regarding the principles of how to create and evaluate business cases for complex IT investments more effective.

Q methodology focuses on the collective insights and experience of practitioners. William Stephenson (1935) argues that individual could invert normal factor analysis, using the participants as the variables and a set of subjective measurements as the sample. Q methodology demonstrates the approach for illustrating how practitioners consider the ranking of the vast list of critical principles in terms of creating and evaluating business cases for complex IT investments. It formed a "systematic and rigorously quantitative means for examining human subjectivity" (McKeown \& Thomas, 1988, p. 7).

One potential limitation in terms of using Q methodology is that Q methodology tends to concern about the degree to which the concourse is represented rather than the general 
population of individuals (Klaus, Wingreen and Blanton, 2007). In the context of this research, the analysis of the concourse and its factors is relative with the viewpoints of expert participants who provide the information rather than the relative proportions of types of individuals in the general population. However, if the respondents are also representative of the general population of individuals, thus generalizations may additionally be made based on the relative proportions of viewpoints in the general population.

Q methodology benefits this research from several facets. It can facilitate exploratory research (Thomas and Watson, 2002). The major benefit is that it provides a means for an in-depth study of the opinions from a small sample population. It is not usual that generalize Q samples to populations. In general, Q-sorting is applied in small samples that are not randomly chosen, which is the analysis assesses a given behavioural pattern exists in a given context (Thomas and Watson, 2002).

\subsection{Research Approach - Analysis of Interviews}

\subsubsection{Data Collection Strategy}

In qualitative data collection phase, the first step is to identify the individuals that can best help the researcher understand the central phenomenon. To provide rich, robust and critical new insights into the business cases for complex IT investments, the researcher needs to obtain a high degree of access to senior managers, IT professionals and business stakeholders working on a variety of complex IT projects. Regardless of public sector organizations and private sector organizations, the researcher focused on the individuals who have the richness experience in creating and evaluating business cases for complex IT investments.

The researcher carried out guided interviews with the following participants from three distinct populations: senior executives, senior IT project managers, and business managers. The researcher chose these groups to represent the comprehensive set of perspectives of experts typically involved in the process of creating and evaluating a business case. Using local industry contacts, the study invited up to ten individuals to participate in the interview process given research time constrains. All participants have over five years of IT industry experience, and over five years of experience in a management or senior decision-making role. To qualify as a participant, he/she needs to have business cases practices for complex IT investments such as ERP implementations in place. The participants chosen to assist in understanding the phenomena were intentionally selected in terms of their various positions.

The primary goal of this study is to assess the effective process for practitioners in terms of creating and evaluating business cases for complex IT investments. The senior executives provided managerial viewpoints, while IT project managers illuminated technology perspective, and business managers offered the view of point from business 
perspective. Strauss and Corbin (1998) note that there is no set number with respect to population sample size. The intent is to interview as many qualified individuals as time allows. The sample size is focused on reflecting adequate view of the factors related to the process of creating and evaluating business cases for complex IT investments. The sample size for this qualitative research could be addressed by 'theoretical saturation' (Glaser \& Strauss, 1967; Strauss \& Corbin, 1998). Theoretical saturation is satisfied when (a) no new or relevant information is emerged from a category, (b) the category is well formed in terms of its properties and dimensions manifesting variation, and (c) the relationships among categories are well developed and validated (Strauss \& Corbin, p. 212.) A large number of participants is not necessary for a qualitative research, only if the research is very complex (Marshall, 1996). Marshall stated, "the number of required subjects usually becomes obvious as the study progresses, as new categories, themes or explanations stop emerging from the data" (p. 523). Further, scholars recommend continuing with the expansion of the sample size until there is no new data (Douglas, 2003; Goulding, 2002; Locke, 2001). These recommendations proved useful. For this study, the researcher continued interviewing practitioners until gathered data became reduplicative. This meant that there was no new information collected. A sample size of ten participants was found as beneficial as a larger sample for the context of the current research study.

The researcher interviewed selected individuals who were accessible and were known to have a background in working on complex IT projects. Part of the selection strategy is to identify potential participants that come from both diverse applications of the project management industry and different levels and roles within the industry (McKinnie, 2007). The recruitment was conducted by emails. There are a few constraints related with the length of time it takes to complete this process: (a) the research requires participants with specific working experience such as creating and evaluating business cases for complex IT investments; (b) it takes some time to obtain connect to acceptable participants and get appointments set up; (c) interviewees have to be accordance with the researcher's request for time off from work; and (d) most of the interviewees are senior managers who are very busy. The interviews conducted are of sufficient quality to meet the requirements of this research. The demographic information of participants is summarized through the following charts (Figures $4-6$ ): 


\section{The Experience of Participants}

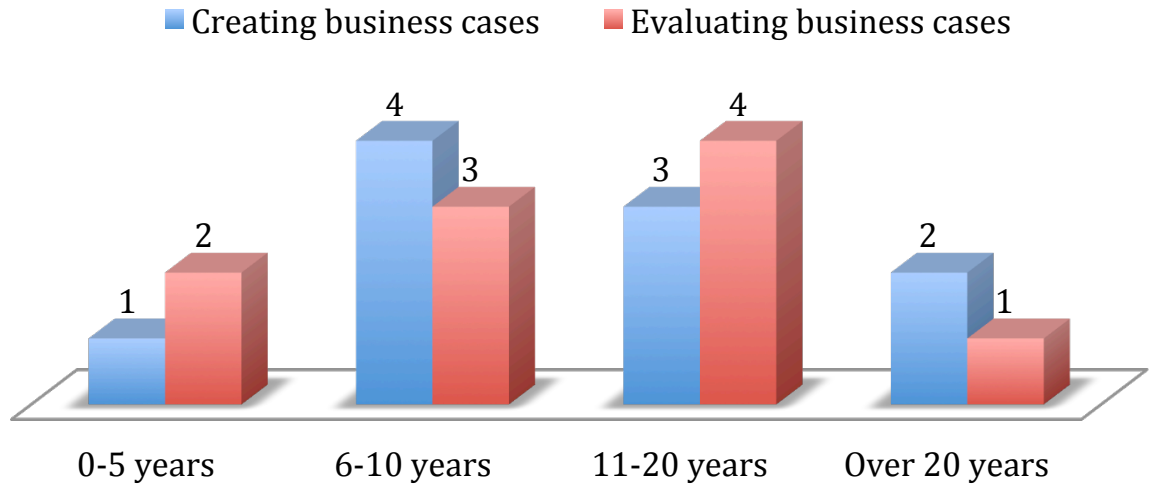

Figure 4: Experience of Participants in Interviews

\section{Industries of Participants}

IT consulting Education $\square$ Financial service
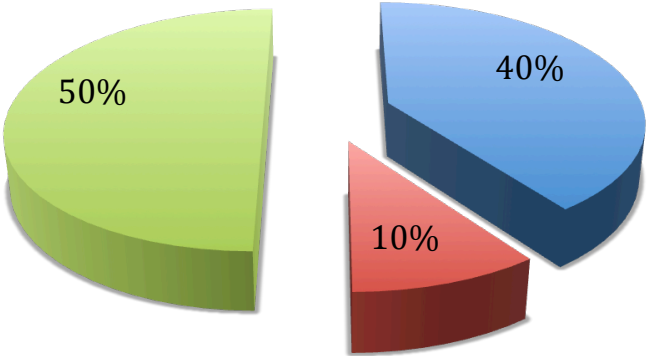

Figure 5: Industries of Participants in Interviews 


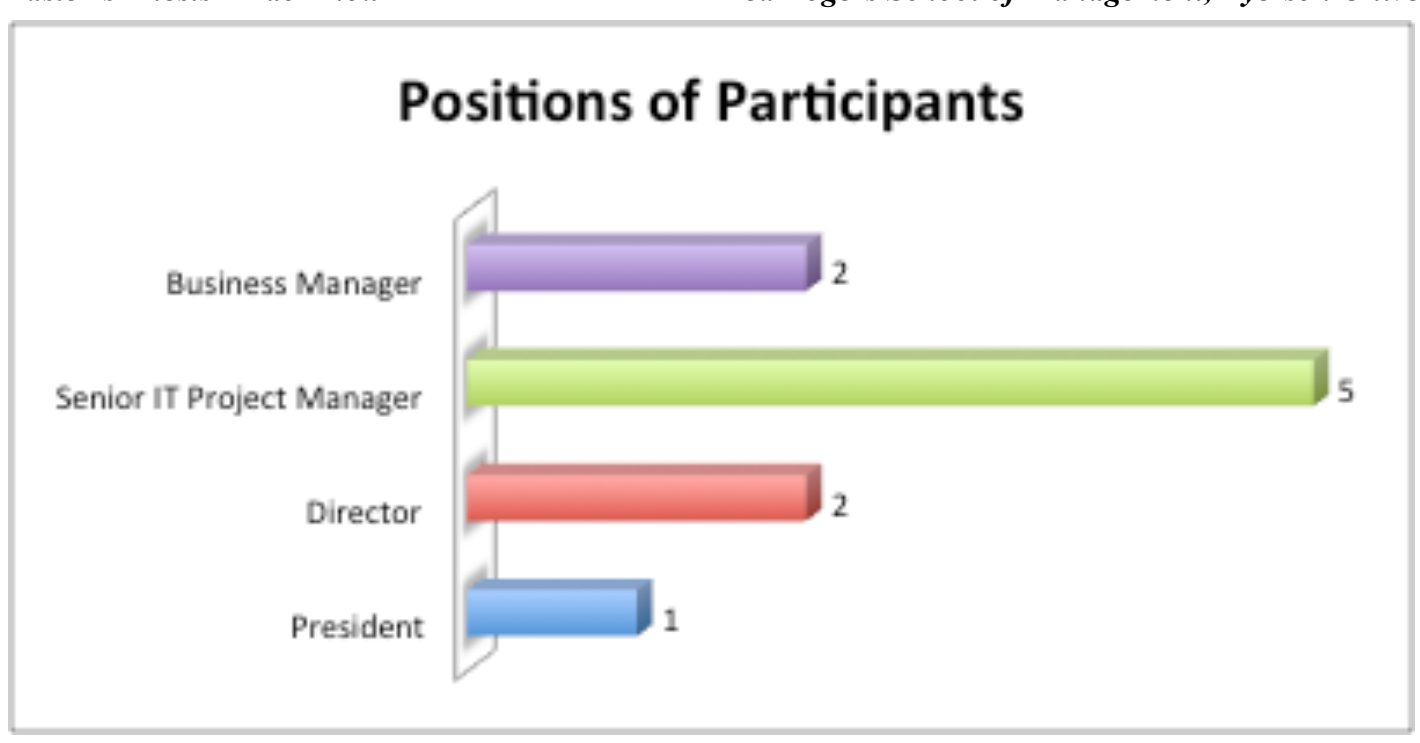

\section{Figure 6: Positions of Participants in Interviews}

The second step of data collection is to design semi-structured interviews with openended questions and conduct the interviews. The qualitative interview is the most common and one of the most important data gathering tools in qualitative research (Myers and Newman, 2007). Initial contact with perspective research participants was by e-mail with a recruitment form. A copy of recruitment form was also provided to each of the participants, which included the summary of the research, the purpose of the research as well as the researcher, the supervisor and Ryerson University Research Ethics Board (REB) contact information in case they had any questions regarding the research. At this time the researcher prequalified the study participants using the criteria discussed above. Then, a personal meeting was arranged to conduct the interview.

Each interview was scheduled to last between 45 to 60 minutes at the convenience of participants. To minimize distractions and limit background noise, interviews were conducted in a confidential meeting room in the working place of the participant or a meeting room in the library of Ryerson University. Participants in this research were recruited on a volunteer basis. At the first beginning of each interview, the researcher asked participants to sign a 'Consent Form'. This consent form stated the content of the interview and verified that the participants volunteered, i.e., they understand the purpose of the research and how the information they provided is handled and protected. Participants were confirmed the permission to record the interviews for future analysis. Along with this information, the consent form stated the right of the subjects as a participant. The participants were informed that this study was voluntary. There is a space in the consent form for the participants to sign their names. If the participants are willing to accept the interview and to be tape-recorded then they sign their name on the signature line. The signed consent forms were collected before conducting the interviews. The signing of the consent forms indicated participants' agreements to allow the utilization of information in the study. A copy of consent form was given to each of the participants. 
The researcher used an interview protocol approved by REB to delineate the interview questions and clarify how these questions might be reframed in the field. The semistructured interviews are based on an interview script with open-ended questions that are well understood and properly interpreted and surrendered the appropriate kinds of insights. The interviewer ensured that all questions in the script were covered during the interview and related topics of discussion were permitted in order to increase the richness of the information gathered. Conducting interviews is a key approach for implementing IS research and is one of the most important data gathering tools in qualitative research (Donnelly and Trochim, 2007; May, 2011; Myers and Newman, 2007). Interviews provide a means for capturing extremely rich data and, in this study, can be used to understand the existing challenges in creating and evaluating business cases for complex IT investments.

The interviewees were asked questions according to a pre-defined, semi-structured protocol (Appendix A). During the interviews, the researcher endeavored to lead the conversation and talked less. This meant that the researcher encouraged the participants to talk more about their understanding of the questions. The researcher believed that this would provide more constructive insight with respect to the topic. The interview included an opening for capturing basic background information, and an introduction to explain the purpose of the interview, key questions, and a closing to provide a debriefing (Adomavicius et al., 2008). The interview protocol form was maintained throughout the interview collection process in order to write notes and responses from participants in case of any occasional technical failure of the tape recording equipment.

The first step of iterative interview process was to identify the categories of the research interest. The research categories were identified from the literature review before the implementation of interviews. Additional categories were emerged as the analysis of the interview starts. These categories were integrated into the semi-structured interview protocol. As can be seen from Appendix A, the interview protocol consists of 10 openended questions in three different categories: the value of business case, the process of creating and evaluating business case, and the decision-making. These questions are organized to first briefly introduce the topic to the interviewee and explain the interview process. Next, a few questions establish the interviewee's qualifications and demographics. At this point, the questions are grouped into the three broad topic areas. Each area begins with a leadoff question with several possible follow-on questions should the interviewee need additional guidance.

The questions asked during the interviews were open-ended questions that allow the participants to provided in-depth responses. The same questions were used for each interview. Also, if the questions were not answered fully, the researcher used probe questions for further confirmation. Some example questions that were asked during the interviews included "What do you think about the role of business cases?" "How do you estimate cost, benefit and risk?" and "What steps do you think should be included into the process of creating business cases?" The semi-structured interview format allows the researcher to do exploratory discussion with probing and open-ended questions. Based on 
confidentiality, the participants felt free to speak about their experiences with using business cases. Consequently, the interviewers were reasonably blind to the theoretical model that frames the current study. Although not systematically planned, each interviewee agreed to a follow-up e-mail or phone conversation if necessary.

The first interview, in particular, was with an informant who can provide an overview of the phenomenon under study. This allows the researcher to validate and, if necessary, modify the mental concept of the phenomenon at the earliest available opportunity (Pan and Tan, 2011). While the first informant does not need to have detailed knowledge of all aspects of the phenomenon under study, the informant has a good idea of whom the researcher can interview subsequently to obtain the required pieces of information. Data was collected during the interview by using a digital recording device to full record every interview. As a complement, the researcher made rough but extensive notes during interviews, and to write them up in full as soon as possible after the interview into a laptop computer. The advantage is that it provides a full description of what was said. Note taking supplemented by tape-recording where appropriate is one sensible approach (Walsham, 1995). Following the interview, each recording was transcribed into a Microsoft Word ${ }^{\mathrm{TM}}$ file stored in a laptop. The laptop requires a primary password and user I.D. to access the data. Both the laptop and the audio tapes are kept in secure physical confinement when not being actively utilized by the researcher.

After the first interview, the researcher began to organize the data to prepare for subsequent analyses and theory building. The very interviews or field notes were entirely transcribed and analyzed before going on to the next interviews or field observations. This early coding gives guidance to the next field observations and/or interviews (Strauss and Corbin, 1998). Besides of in-depth interviews, retrospective data like books and journal articles were examined as well. Concepts derived from literature provide a source for making comparisons to data at the dimensional level. If a concept emerges from the data that seems similar or opposite to one recalled from literature, then the concepts can be compared in terms of their properties and dimensions. This enables an analyst to differentiate and give specificity to the emergent concept.

In summary, the researcher opted for data collection techniques that would not jeopardize the ability to identify in-the-moment reactions and behaviours. The researcher therefore relied mainly on semi-structured interviews as a data collection strategy. In total, the researcher conducted ten interviews and all were taped. The researcher transcribed the content as soon as after an interview as possible and stored interview transcripts into a notebook computer. Each transcript was confirmed more than three times in order to check the miss content exists or not.

\subsubsection{Data Analysis Strategy}

The data collection and analysis occurred iteratively. As interviews were transcribed, they were coded. Throughout the data collection, the researcher was engaged in data 
analysis. To summarize the data and clarify the researcher's thinking, the researcher experimented with constructs and themes by drawing tables and diagrams. The researcher also shared the initial interpretations with the supervisor. The researcher reported weekly to the supervisor to make sense of the research, to confirm the results of interviews, to identify themes and constructs, and to strategize how to interpret those themes and constructs. A more methodical data analysis is described in more detail later in this thesis.

Data analysis started by first preparing the data for analysis including organize and transcribe qualitative data. When it came to analyzing the interview transcripts, the primary activity involved reading the transcripts over and over again in order to categorize events and to inductively construct themes. This typically implies manipulating the transcripts by cutting the content apart and reassembling them into coherent patterns that apparently 'emerge' from the data themselves (Schultze, 2000). The researcher read through all the data to acquire a general idea. This iterative process required frequently revisiting the data as important features of creating and evaluating business cases may emerge within each transcript. Once the individual transcript was completed, the researcher executed a detailed analysis to identify the similarities and differences between the transcripts. Since this study relies on a preliminary research framework that reflects the major constructs the researcher studies, initially, the researcher compared the transcripts to identify common dilemmas and refined the unique aspects of each particular transcript. This approach enables the researcher to identify and to reconfirm the framework's constituent elements.

This research used NVivo software as a transcript-based content analysis to identify emergent themes and categories from the raw data across semi-structured interview. The NVivo software allows the transcript of interviews to be categorized, coded, and manipulated to identify themes (Agosto, 2002). The researcher typed the content of a .mp3 audio into documents and then load these documents into Nvivo software to help with the searching, coding and comparisons of the interviews. All transcribed interview responses were input into NVivo database indexed by transcript numbers. The researcher gathered response to the same question to form a single response. Strauss and Corbin (1998) stress that carefully following the coding process is essential to the quality of the research artifact. This research utilized a combination of three coding structures to organize and analyze data: open, axial, and selective coding (Miles and Huberman, 1994; Pan and Tan, 2011). The researcher followed Strauss's recommendations of doing axial coding after open coding, but utilized this technique as a method through which to discover relationships in the data, and not as an overly restrictive set of rules (Urquhart, 2007).

Open coding is a process by which the researcher extracts conceptual ideas and inferred meanings from various textural materials and places them in suitable categories for further analysis. This step helped the researcher to establish and discover contextual relationships. The researcher used content analysis to examine responses to the openended research questions. It facilitates the data to be coded into established patterns, themes, and categories to underpin the generation of thoughts (Harwood and Garry, 2003). Content analysis is inductive and can only be used when the content is 
manipulated in a manner that permits recurring examination (Krippendorff, 2004). The codes were extracted from the themes and categories derived from the interviews (Figure 7). In the research, the interview questions were grouped into three basic conceptual categories that this study encompasses - process, business case and decision-making. Axial coding is the process of establishing relationships between the researcher's open code categories. It is a process that the varying range of a category's properties is examined in relation to the varying range of another category's characteristics. This process allows both the interviewees and the researcher to arrive at a correlation determination together, if there is one. With the completion of axial coding process, the researcher looked for an implied central core concept. Selective coding, this core concept is back checked to confirm its relationship to all categories to extract processes and reasonable explanations for probable mechanisms that explain the behaviour in questions. If a theoretical lens is conceptualized as an incomplete data table, then selective coding can be understood as the process of filling in the table with at least two sources of data (Yin, 2011) for every category.

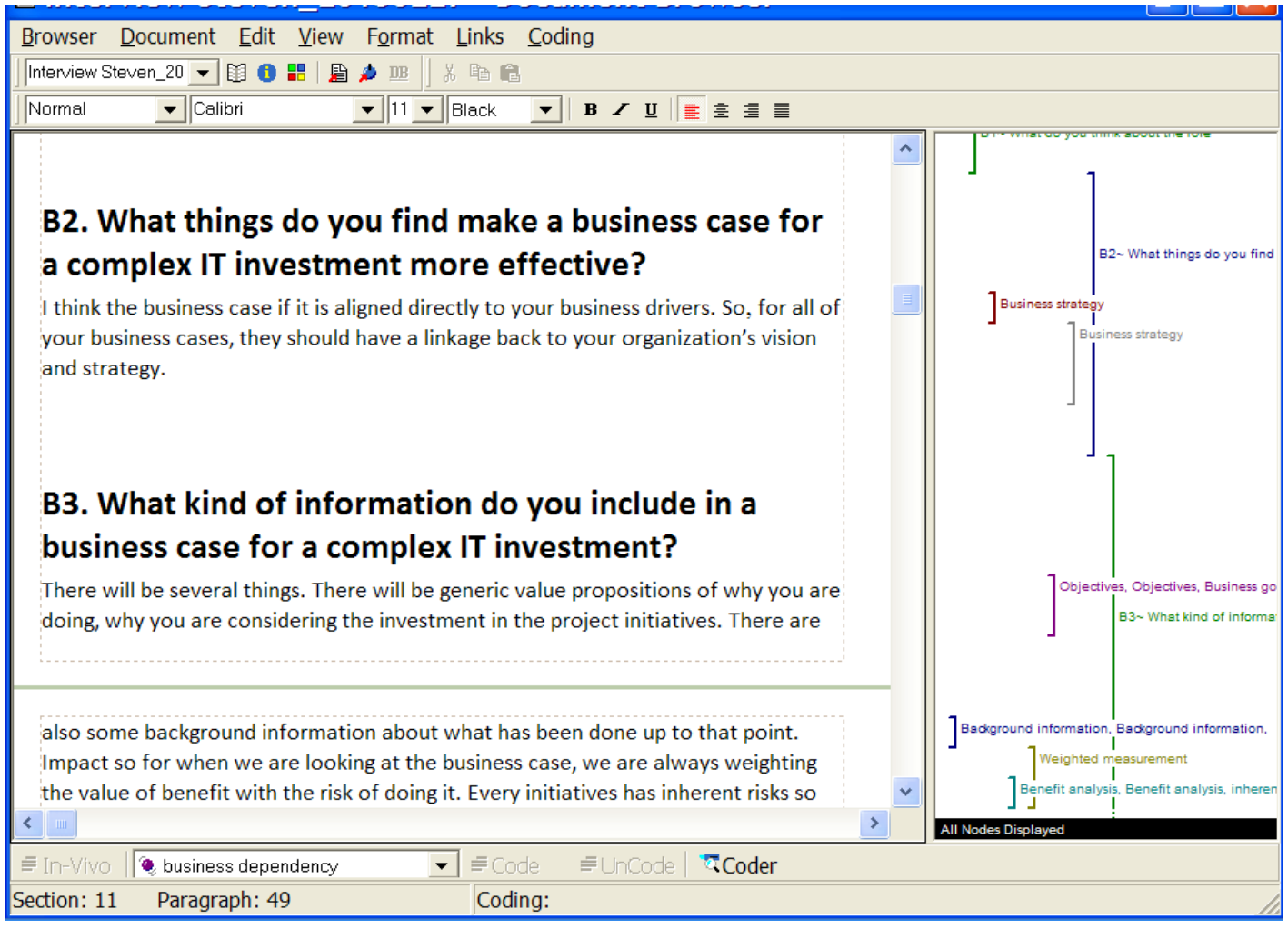

Figure 7: Example of Coding Interview Transcripts in NVivo

In detail, the following step by step coding process was used to organize the data into categories and label those categories with a term: (1) divide the text into segments of information; (2) label the segments of information with codes; (3) reduce overlap and redundancy of codes; (4) collapse codes into themes. While developing the coding schemes, basic coding dimensions (construct types) include: (1) process components such as decision-makers, business cases, technologies and tools; (2) business case 
competencies such as perspective benefits, costs and risks; (3) contextual factors that influence the process like management support, stakeholder interests. The bottom-up development of the coding scheme by the researcher ensured a higher degree of reliability.

There are many controversies regarding qualitative data analysis in terms of using computer program to analyze data (Bergin, 2011). NVivo is one of the most popular computer data analysis software packages. Bazeley (2007) outlines five principal ways in terms of analyzing qualitative data by NVivo: organizing data, managing ideas, querying data, graphically modeling the ideas and concepts that are being built from the data, and reporting from the data. Thus, this research was using NVivo to manage, organize, and report data. Based on the nature of small or large volumes of qualitative data, NVivo software package facilitated the researcher to achieve deep levels of analysis. All the interview transcripts can be installed in one location.

The main functionality of NVivo is coding the data by the creation of nodes. A node is a reference of a specific theme, activity, individual or other specific interests (Bazeley, 2007). NVivo allows researchers to create different types of nodes including free nodes, tree nodes, relationship nodes and so forth. In this research, the researcher use free nodes and tree nodes as the major tools of the data analysis. A free node is a stand-alone node that has no explicit logical connection with other nodes (Bergin, 2011). Free nodes are very useful when the research is at the beginning of the coding and uncover the potential node structure in a whole. Thus, after importing all the interview transcripts into NVivo, the researcher created free nodes during a coding process by reading through the entire interview transcripts as the first step of data analysis. Then, the researcher coded the references to broad free nodes, creating 165 free nodes in total (Figure 8). A characteristic of qualitative analysis by NVivo is that the creation of nodes becomes less frequent when the researcher progresses because references begin to fit free nodes that already exist (Bergin, 2011). The number of references coded to each free node varied from 42 coded to free node 'stakeholders' to one coded to 'business dependency'.

Multiple nodes were coded in a passage or a transcript in order to capture the main ideas in it. The codes were emerged from the transcripts imported into NVivo database. The similar text or words were grouped in the same particular category. The final results were derived from the computer-assisted content analysis. Detailed coding was quite slow at first. The researcher needed to orient the thoughts to the issues raised by the data. However, after the first two or three transcripts, the number of new nodes decreased markedly. Thus, as the text referenced by free nodes creates, a clearer structure was developed. Free nodes help researchers capture ideas without organizing structure too early (Bazeley, 2007). 


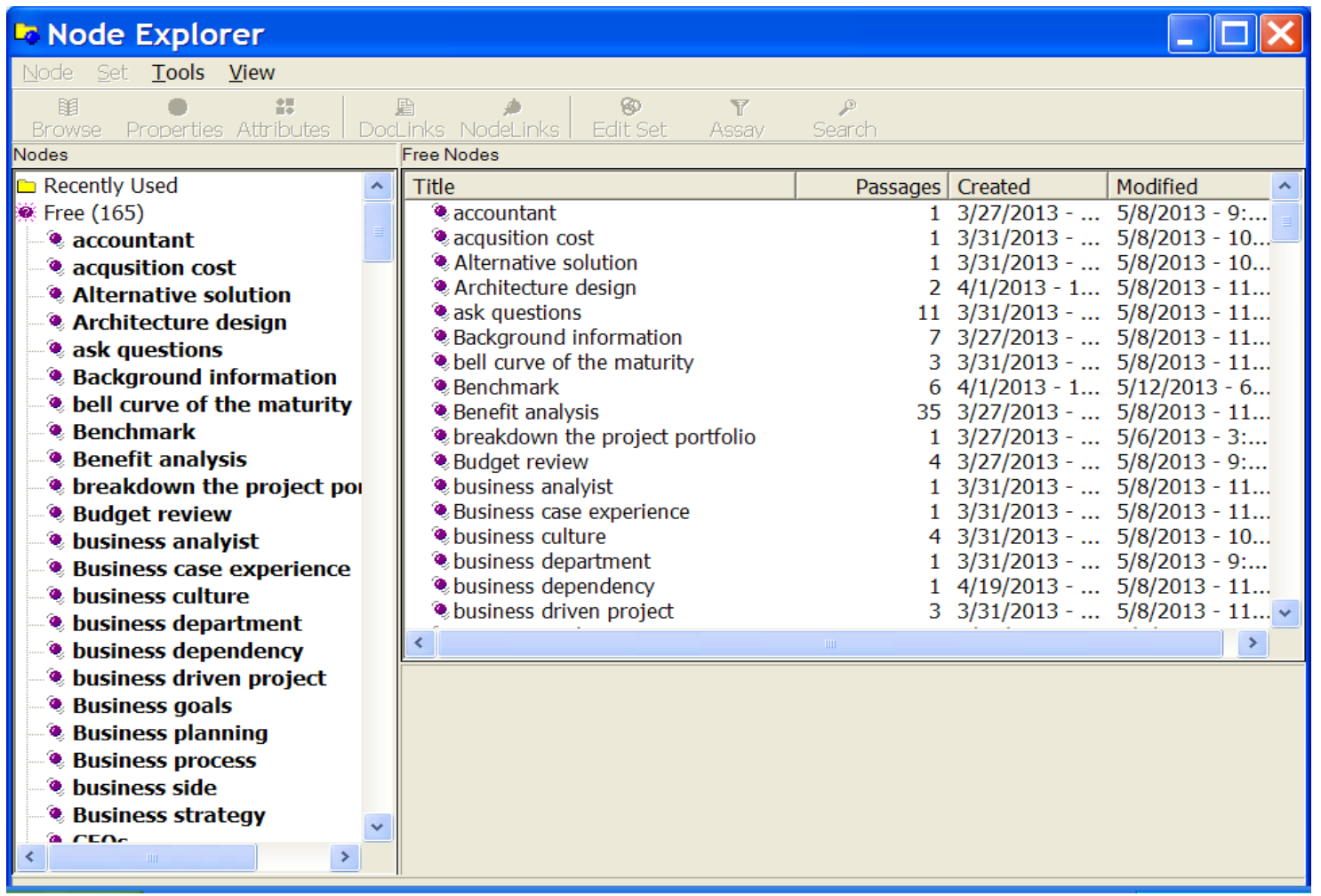

\section{Figure 8: Example of Free Nodes (Codes) Used in the Coding}

After all the free nodes were coded, the tree structure was emerged (Figure 9). Tree nodes are more organized in a hierarchical structure comprising the parent node at the top and several child nodes belong to it. The researcher developed a node structure by dragging free nodes into tree nodes. Of the original 165 free nodes the researcher coded, all of them were used to create a hierarchical structure of tree nodes organized into several key areas for business cases: the value of business cases, the content of business cases, the process of creating and evaluating business cases, the participants, the practices of collecting information, decision-making, the reasons of rejections, challenges, and suggestions. NVivo facilitates the researcher to identify free and tree nodes efficiently and does not limit the ability of researchers to create categories and sub-categories (Bergin, 2011). The hierarchical structure illustrates an overall view of the findings. Once completed the coding, the researcher wrote a summary for each category. 


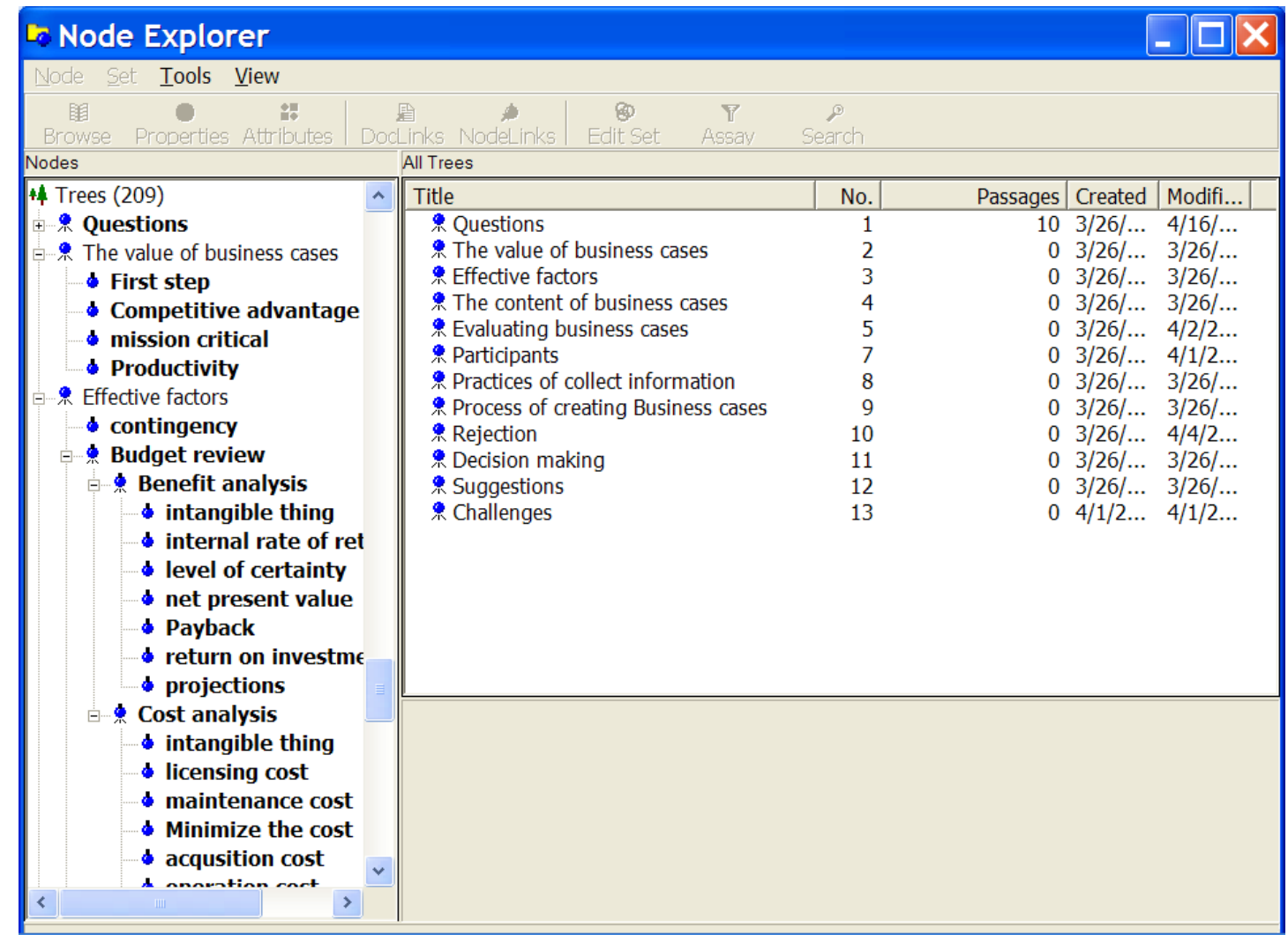

\section{Figure 9: Example of the Hierarchical Codes Used in the Coding}

The analysis of the data collected from the various sources reflected the analytical framework in trying to identify important content, context, and process elements of creating and evaluating business cases as perceived by different individuals and interest groups (Walsham and Waema, 1994). Furthermore, the steps of data collection and data analysis were iterative that allowed the researcher to take advantage of emergent themes and unique case features (Eisenhardt, 1989). As new evidence was analyzed, the research iterated between data analysis and searching for insights from the prior literature. Further, the researcher collected additional evidence to fully explore the emerging theory until theoretical saturation is achieved. In addition, the researcher did not yield any new insights until gathering new evidence.

In summary, the coding process is a systematic process. The transcribed data was analyzed and coded by NVivo software. This software is well used for qualitative research in order to interpret data. The researcher understood how to use this software accurately through reading the instruction and manipulating it for pre-tests. The researcher's supervisor independently analyzed and coded the qualitative evidence. The findings were compared for consistency. Moreover, data collection and data analysis process were reported in detail in order to provide the audiences with an explicit and accurate figure of the method used in this research. 


\subsubsection{Data Report Strategy}

The researcher experienced the research as a constant writing and reading. The researcher began to compose the report even before data collection and analysis have been completed. The researcher compared the interview transcripts and draw cross-transcripts conclusions to make a report. The cross-transcripts report contains tables and figures to be cited by the narrative. The cross-transcripts report was confirmed by the supervisor for inaccuracies or researcher bias. Based on this report, the researcher generated the new process for creating and evaluating business cases for complex IT investments. While theory generally is thought of as devoid of context, the new process theory what is expected to emerge from this study is contextual information that shed light on the application of the theory more than define the theory itself.

\subsubsection{Reliability and Validity}

As this phase of research was based on qualitative method and data, it maybe arise internal validity concerns. For ensuring internal validity, the researcher's supervisor serves as a peer examiner. Furthermore, in attempt to strengthen the internal validity of this research, guidelines for the qualitative research by Myers and Newman (2006) facilitate the researcher to develop the interview guide, frame questions and structure interview protocols.

Since this research does not investigate based on organizational level, it maybe arise concerns about the external validity, which is the possibility of generalizing this theory to industries or populations. This research is using an exploratory study approach that the results are not to be generalized to a population but rather to some theories. It enhances external validity by providing an opportunity to verify the emerging process in a variety of different circumstances (Eisenhardt, 1989; Yin, 2009). Furthermore, the study is focus on complex IT investments such as ERP implementations that not only has central research question but also has additional research questions to provide complement.

According to construct validity, data was collected through multiple sources including interviews and documents. The results from multiple respondents were constantly compared. The interviews were coded by the researcher who conducted it, on the assumption that being present at the interview provided information about the speakers' intentions that were not available from simply reading a transcription. Later, the interviews were coded by a supervisor to ensure consistent coding. The supervisor independently analyzed and coded the qualitative evidence. The findings were compared for consistency.

Lastly, the research process followed was designed to minimize personal bias as much as possible. The researcher selected peer-reviewed literary references and data sources and posed objective, pre-approved questions to carefully selected qualified individuals to minimize individual favouritism. However, whenever one investigates into a problem that 
affects individuals on a personal level, inevitably some bias form in conjunction with that experience. Whatever bias may exist from this study is considered negligible.

\subsection{Research Approach - Q Sorting of Opinions}

\subsubsection{Data Collection Strategy}

Due to the nature of exploratory study, a quantitative approach is useful to complement the qualitative data and yield more effective and meaningful results on the research question. Empirical data collected in preliminary interviews extended the fields to principles of creating and evaluating business cases more effective. The researcher adopted Stephenson's Q methodology (1953) to further empirically identify the participants' viewpoints of the findings through interviews. Q methodology is a statistical method to study human behaviour or opinions regarding a subject (Stephenson, 1953). It is an innovative method combined quantitative and qualitative approach for business and management research (Krivokapic-Skoko and O'Neill, 2011). It has been used by a number of qualitative researchers as a hybrid approach including qualitative and quantitative features (Krivokapic-Skoko and O’Neill, 2011). Recent years, Q methodology gained numerous recognitions, however it is not used in most IT investments research. The researcher aimed at exploring the utility of Q methodology to analyze the preference of expert participants in terms of the principles of effectively creating and evaluating business cases for complex IT investments.

Q methodology is used to conduct in-depth study of situations in which the judgments of the research participants are of primary importance (Tractinsky and Jarvenpaa, 1995). It is more focused on the degree to which the concourse is represented rather than the generalization of population. Previous research has manifested that the highest probability of acquiring a representative sample of Q-sort statements is achieved by generating the statements from: literature on the subject, interviews with people involved with the concourse, and feedback from domain experts regarding the content of the Qsort instrument (Dennis, 1988). These criteria were fulfilled in this research by: 1) generating a set of Q-sort statements based on a review of literature and interviews with practitioners; 2) obtaining feedback from experts in the concourse of principles for creating and evaluating business cases.

The final 32 statements (Table 1) of this research were draw from an initial concourse of 60 statements collected from interviews, journal articles, professional publications, conference proceedings, and dissertations suggesting principles for creating and evaluating business cases for complex IT investments. The concourse was defined using interview transcripts of ten interviewees and the literature review. The researcher chose 24 statements from interview data mentioned by more than three participants and eight statements from literature review. The research question for Q-sorting is: How important is the following principal for the creation and evaluation of a business case for a complex IT investment? 
Table 1: Q Statements (in Random Order)

\begin{tabular}{r|l|} 
No. & \multicolumn{1}{|l|}{ Principles that make the process of creating and evaluating business cases for } \\
complex IT investments more effective
\end{tabular}

The study invited up to 19 individuals to participate in the Q-sorting process given research time constrains. The researcher carried out Q-sorting with the following participants from four distinct populations: senior executives, senior IT project managers, business managers, and scholars. Besides the ten interviewees in the previous interview 
phase, the researcher recruited nine additional professionals into the Q-sorting. The same with the recruiting strategy of interviewees, all participants have over five years of IT industry experience, and over five years of experience in a management or senior decision-making role. To qualify as a participant, he/she needs to have business cases practices for complex IT investments such as ERP implementations in place. The participants chosen to assist in understanding the phenomena were intentionally selected in terms of their various positions. The researcher sent a recruitment email to obtain the agreement from participants.

In addition, the same with the data collection strategy of interviews, there were a few constraints related with the length of time it takes to complete this process: (a) the research requires participants with specific working experience such as complex IT investments; (b) it takes some time to obtain connect to acceptable participants and get appointments set up; (c) interviewees have to be accordance with the researcher's request for time off from work; and (d) most of the respondents are managers that are very busy. While a few of the potential participants are an acquaintance of the supervisor, effort was made to identify individuals who are referred to the researcher by their credentials. The demographic information of participants is summarized through the following charts (Figures $10-12$ ):

\section{The Experience of Participants}

Creating business cases Evaluating business cases

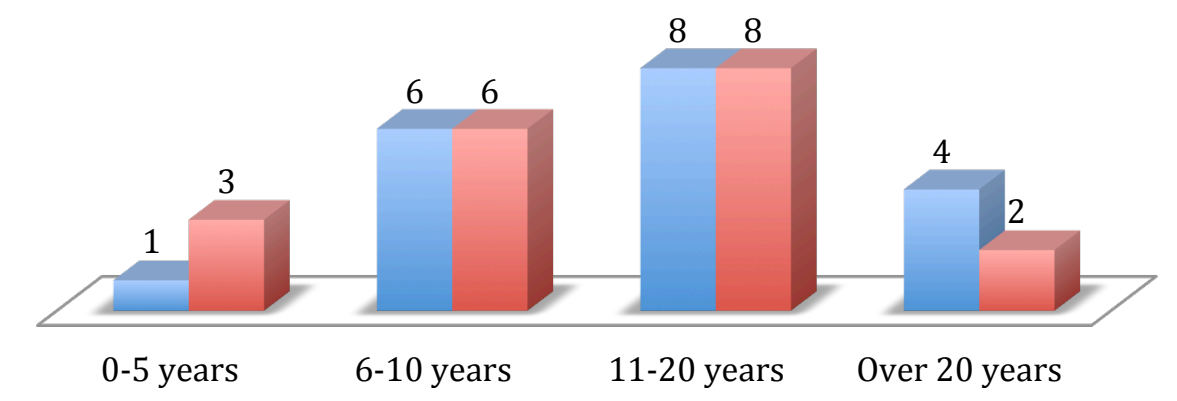

Figure 10: Experience of Participants in the Q-Sorting Study 


\section{Industries of Participants}

$\square$ IT consulting $\square$ Education $\square$ Financial service $\square$ Manufacturing $\square$ Retail

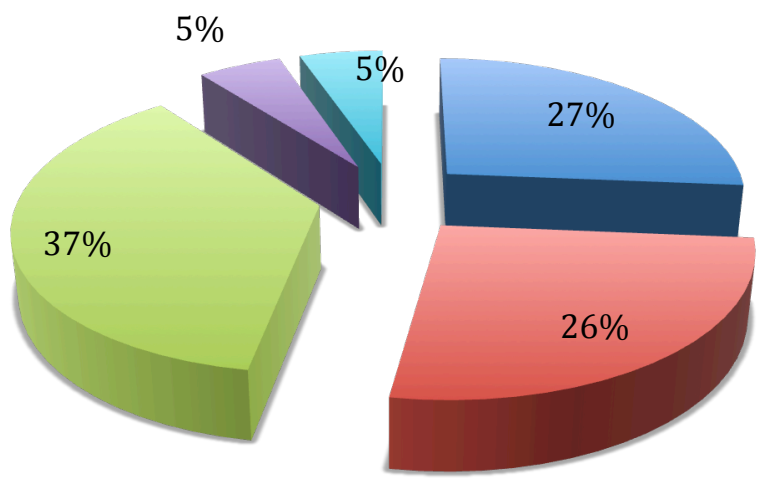

Figure 11: Industries of Participants in the Q-Sorting Study

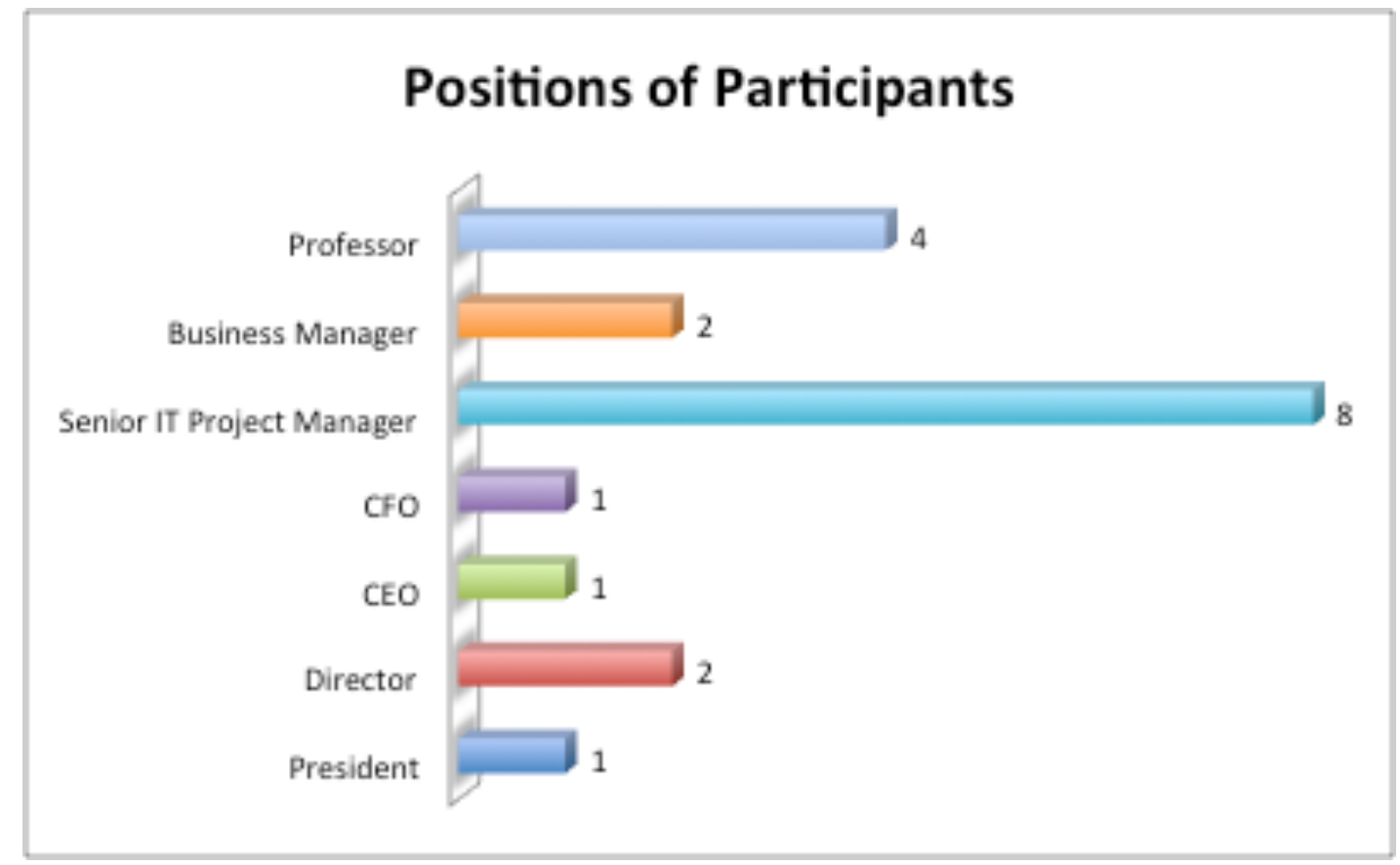

Figure 12: Positions of Participants in the Q-Sorting Study

The data collection of Q-methodology is by an email sent to participants with a link of the FlashQ, which is a web application. It is used to gather the data and store the results. 
The participants first were required to agree with the consent form in the first web page of FlashQ.

Before every step, there was a detail instruction, which guides the participants about what to do and the question showed on the top of the web page reminds them the purpose of this Q-sorting whilst conducting it. The FlashQ software randomly presented each statement from the Q sample to the participant who initially distributes the statements into one of three categories, statements representing principles most important for creating and evaluating business cases, statements reflecting principles least important for creating and evaluating business cases, and statements somewhere between most important and least important into a third category, labeled neutral (Figure 13). As a typical study adopting Q methodology, the participants were asked to start the online Qsorting by dragging each principle into three different piles: least important, neutral, most important.

\section{How important is the following principal for the creation and evaluation of a business case for a} complex IT investment?

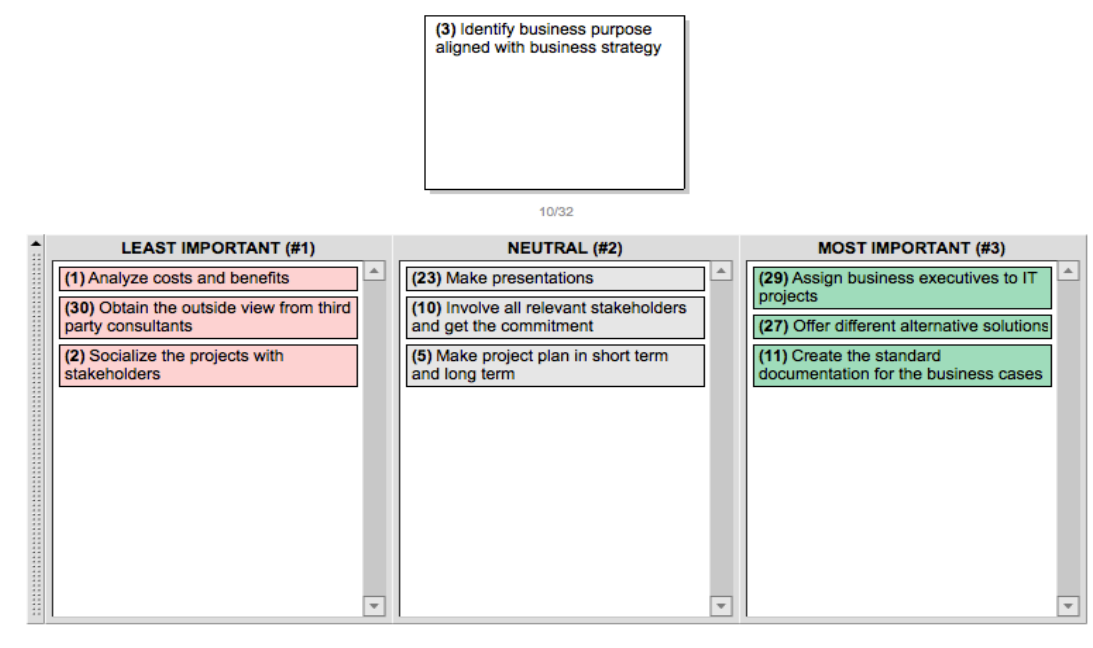

Figure 13: Example of the Online FlashQ Sorting Page

After completion of the initial sort, the participants were provided with additional instructions for completing a quasi-normal distribution grid with the previously categorized statements. Figure 14 presents an illustration of a grid for a 32 items Q sample. After sorting the statements, the FlashQ software asked the respondents to complete a brief survey regarding the years of experience they involve into the creation and evaluation of business cases for complex IT investments, the industry they are in, and the position of their jobs. The FlashQ software stored the participant sorting arrangements from the grid, the justification for statements at the extremes, survey responses, and any additional comments in the server provided by Ryerson University. 


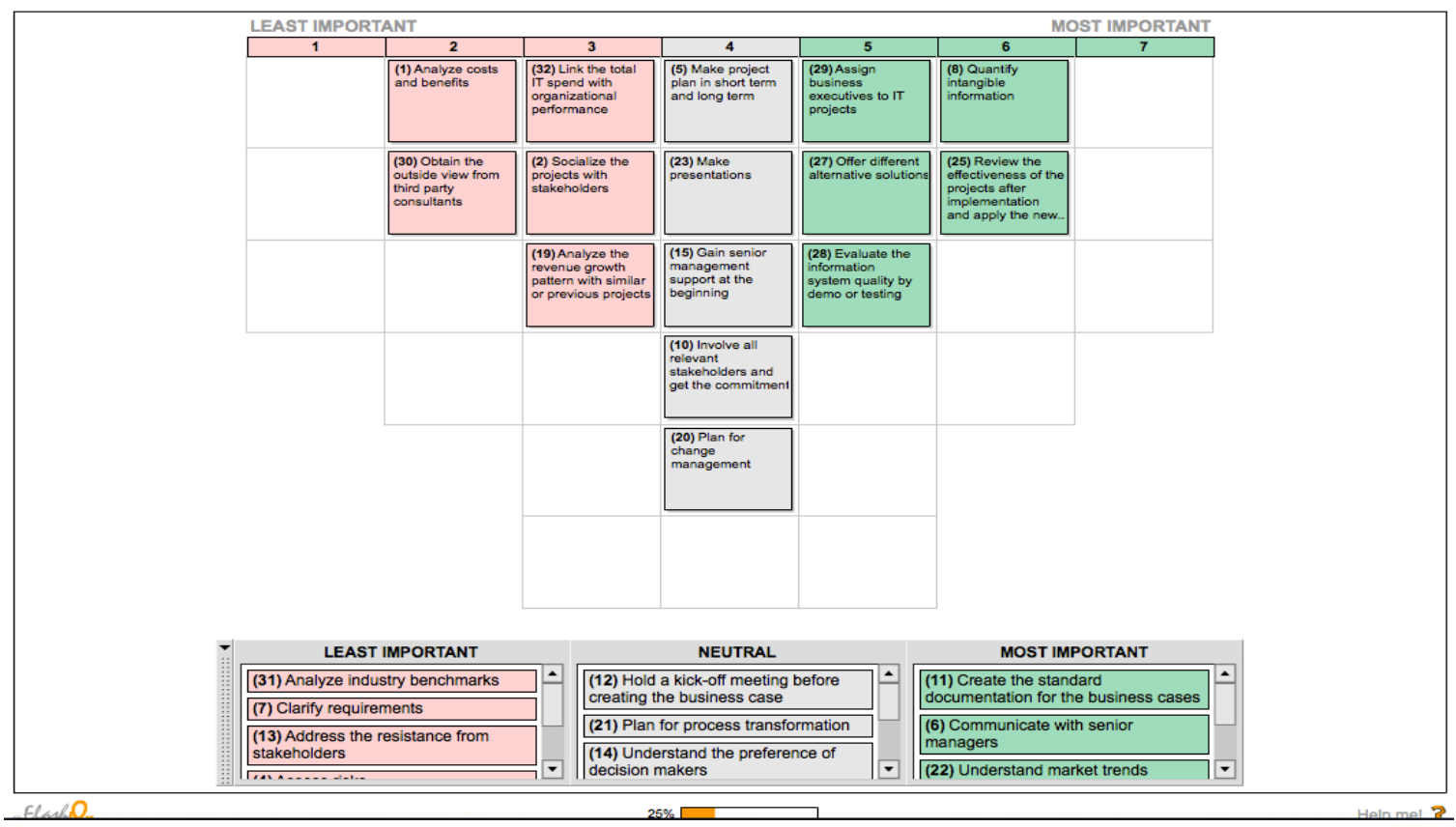

Figure 14: Example of the Quasi-Distribution Grid in FlashQ

\subsubsection{Data Analysis Strategy}

In this thesis, the data analysis was conducted in two steps: calculation and interpretation. First, the researcher employed PCQ software to calculate the correlation matrix of all Q sorts by one, two, three, four, and five factors. There are some dedicated Q methodological software packages for data analysis, such as PQMethod and PCQ for Windows, which are user-friendly for non-experts in statistical manipulation, and automatically generate the correlation report. This research chose PCQ to analyze the data gathered from FlashQ because of the convenience of obtain the software and the easy use. PCQ software is a well-used tool for Q methodology research. It is often used to analyze Q sort data and provides comprehensive statistical support for Q methodology studies, including factor analysis. Subsequently, the researcher input the data and examined the ranking results by PCQ.

The analysis uses centroid Q-factor analysis to extract factors based on an analysis of the among-individuals correlation matrix (Klaus, Wingreen and Blanton, 2007). Furthermore, varimax rotation (Thomas and Watson, 2002) is used in order to analyze the degree of perceived importance of 32 statements regarding the creation and evaluation of business cases for complex IT investments. The varimax rotation facilitates the researcher to more clearly identify factors by optimizing the scaling of the factor loadings to maximize the amount of variance (Klaus, Wingreen and Blanton, 2007). Individual Q sorts were factor analyzed to identify common patterns of rank ordering, representing shared viewpoints about the importance of these statements (Davis, 2004). Each factor represents points of view of a group, since the factors are generated from inter-correlated groups of Q-sorts 
(Klaus, Wingreen and Blanton, 2007). Inasmuch as the varimax rotation method insures that each viewpoint is orthogonal to the others, it facilitates the researcher to evaluate both the differentiation between groups and homogeneity within groups (Klaus, Wingreen and Blanton, 2007; Tractinsky and Jarvenpaa, 1995).

The Q-sorting instrumentation of this research was created according to the guidelines depicted by prior research (Brown, 1980; Thomas and Watson, 2002). Typically, it encompassed the following steps: (1) definition of the concourse; (2) development of the Q sample; (3) selection of the P set; (4) Q sorting; and (5) analysis and interpretation. The concourse is a comprehensive set of items with respect to the research topic. It is filled with statements be gathered by complementary communicability such as interview data and literature (Klaus et al., 2007). The Q samples are statements that represent the participants' experience on the topic (Previte, Pini \& Mc-Kenzie, 2007). The P set is a set of participants. The Q-sorting is the action of sorting the statements and the distribution of establishing a Q-sort. The selection of Q samples and P set and the technique of analyzing data are three determinant factors to Q methodology (Webler, Danielson, \& Tuler, 2009). The interdependence of Q samples in a Q-sort is the operational means by which each individual's coherent point-of-view is captured (Brown, 1980). Q methodology could facilitate the practitioners to do the ranking based on their own experience.

The researcher input all the FlashQ data gathered from the server into PCQ software to generate reports. First, the researcher input each Q sort replied by participants into PCQ software to build a database for the further analysis. Then, the researcher input the $32 \mathrm{Q}$ statements, i.e., principles of creating and evaluating business cases for complex IT investments, into PCQ software to link with the numbers in Q sorts.

The researcher scrutinized the results from these rotations and judged whether the factor solution contributed significantly to the research question. The researcher interpreted the results with few factors but including most of the $\mathrm{Q}$ sorts. Therefore, based on the results of rotation, one factor analysis best established a ranking of importance of all 32 statements in terms of the importance through Z-values. It satisfied one of the purposes of this research, which is to identify the degree of the importance of these 32 principles. Meanwhile, two-factor solution was selected for further analysis. One of the reasons is the other factor solution (e.g., three-factor, four-factor and five-factor) did not provide any more useful information than can be seen in the two-factor solution and its correlations was slightly weaker. Thus, the two-factor solution had the most significant results and useful information. It divided most of the sorts into two groups and indicated the consensus and different opinions from both groups. Another reason is that two is a sufficient number of groups to analyze the Q sorts based on respondent demographics, since the aim of the research is to explain the main groups that abstract from the data analysis, rather than every group that exists. 


\subsubsection{Data Report Strategy}

The findings from the data are reported based on the recommendations from Thomas and Watson (2002) that the analysis and interpretation of the Q sorts should contain: 1) Factor loading arrays; 2) normalized factor scores; 3 ) the statements on which arrays load. Thus, the readers are able to examine and reinterpret with these information. The Chapter 5 describes the detail results of data reports.

\subsubsection{Reliability and Validity}

Q methodology is a growing controversial subject with respect to its importance and role of validity (Klaus, Wingreen and Blanton, 2007). In terms of the reliability and validity, it lies in the data rather than the measurement (Dennis, 1988). Further, the construct validity is irrelevant since the methodology is striving to understand the relative pointsof-view of respondents (Klaus, Wingreen and Blanton, 2007). Q methodology concentrates on the correlation among individuals rather than any other. Thus, it tends to be related with qualitative research that there is no substitute to a participant's viewpoint (Dennis, 1988). Lincoln and Guba (1985) assess that in acquiring a person's viewpoint, "since there can be no validity without reliability, a demonstration of the former validity is sufficient to establish the latter reliability" (p. 316). On the other hand, the statistic results of Q-sorting provide quantitative characteristics to Q Methodology. Quantitative data explores qualitative viewpoints from respondents.

Q methodology allowed for a rich description of a range of creating and evaluating business cases experience from a number of expert participants. The highest probability of acquiring a representative sample of Q-sort statements is achieved by generating the statements from literature on the topic, interviews with individuals involved with the concourse, and the feedback from domain experts in respect to the content of the Q-sort instrument (Dennis, 1988). This research satisfied these criteria by: 1) deriving a set of Qsort statements according to the literature review and interviews with domain experts; 2) the supervisor who is a domain expert examining the Q-sort instrument.

\subsection{Ethical Concerns}

To address ethical concerns, this study passed an ethical review by Ryerson University REB. Since this research involved individuals whose participations were voluntary, the researcher guarantees the participants confidentiality and assures the identifying information such as IT projects and company names are not be made available to anyone who is not directly involved in this study. This study keeps all of the participants in interviews anonymity by a sequential numbering system (e.g., participant A1, etc.). All of the information regarding participants are disguised in all the written records and audiotapes, and will not be released. The real names are only known by the researcher 
and the supervisor. The researcher maintains confidentiality and will not disclose identifying information about participants or organizations in any report or publication. The letter of consent form comprised of relevant details on confidentiality for conducting semi-structured, open-ended and in-depth interviews. The consent form clarified that individual participants' identity, enterprise names, or any other identifying information would remain confidential.

Further, after the transcript of each interview was done, the raw data were imported into computer programs for data analysis (NVivo and PCQ). The information imported into the computer programs was on the researcher's password-protected computer. Any thesis-based materials, such as the consent forms were stored at school under lock by the researcher. The data and consent form will be retained by the researcher under lock for a period of three years after the study where the thesis-based materials will then be discarded by shredding them. 


\section{CHAPTER 4: DATA ANALYSIS - INTERVIEWS}

\subsection{Introduction}

This chapter describes the findings from interviews involving experienced practitioners to explore the process of creating and evaluating business cases for complex IT investments. The findings are organized into the following subsections: The Process; Participants; Approaches for Socialization; Approaches for Cost and Benefit Analysis; Approaches for Evaluation; Challenges; and Suggestions. Further, the researcher went back to the participants to gather feedback on the list of statements to help establish whether the findings from the interview analysis were credible.

\subsection{Findings Regarding the Participants in the Process}

After an iterative process of coding the interview transcripts using NVivo, eight categories of participants were identified that should be involved in the process of creating and evaluating business cases for complex IT investments (see Table 2).

\section{Table 2: Participants in the Process}

\begin{tabular}{|l|l|}
\hline No. & Participants in the Process \\
\hline 1 & Marketing/procurement/business analysts \\
\hline 2 & $\begin{array}{l}\text { Corporate audit/finance/legal/security/risk } \\
\text { analysts }\end{array}$ \\
\hline 3 & IT department: developers/infrastructure analysts \\
\hline 4 & CEO/CFO/CIO \\
\hline 5 & External consultants \\
\hline 6 & Suppliers \\
\hline 7 & Influencers \\
\hline 8 & Innovators \\
\hline
\end{tabular}

Marketing, procurement and business analysts tend to focus more on the business requirements rather than technical requirements in a business case. Corporate audit, finance, legal, security and risk analysts tend to focus on the investment governance requirements in a business case as do the senior management $(\mathrm{CEO} / \mathrm{CFO} / \mathrm{CIO})$ who do so with a higher level strategic focus. The IT department comprising developers and infrastructure analysts tend to focus on the technology requirements in a business case. In addition, individuals who are innovators or influencers can also have a distinct and notable contribution to the process of creating and evaluating complex IT investments. An innovator is an individual who has creative thoughts and considers things from various views. As stated by one of the participants who is a CEO of a financial company, the innovators facilitate decision-makers to understand the requirements 
from different viewpoints. In addition, influencers, who usually heavily affect the others' judgment, are trusted by decision-makers. Their opinions influence other participants and decision-makers because of their experience and knowledge on the topic.

\subsection{Findings Regarding the Approaches for Socialization}

Analysis of the interview transcripts suggested that engaging participants in the process and "socializing" or circulating the business case were seen as important. Socializing a business case is a concept that has not been discussed in detail in the prior literature. It refers to the process of communicating, explaining, and gathering feedback and/or consensus on the elements within a business case. As one respondent noted:

F1: "For the creating business case, we have to engage as more as possible about the owners and stakeholders. And also for evaluating a business case, not only have engage those stakeholders, but also have the proposal that can have the perspective of evaluating the case."

Several approaches were uncovered which were used by the interview participants for socializing or "shopping the business case around" (see Table 3).

\section{Table 3: Approaches for Socializing Business Cases}

\begin{tabular}{|l|l|}
\hline No. & Approaches for Socializing Business Cases \\
\hline 1 & E-mail \\
\hline 2 & Survey \\
\hline 3 & Face to face Interview \\
\hline 4 & Kick-off meeting \\
\hline 5 & Regular meetings \\
\hline 6 & Coffee with the right person \\
\hline 7 & Joint application design (JAD) sessions \\
\hline
\end{tabular}

Socialization has a positive impact on the success of IT projects in the conceptual phase, i.e., idea generation, research, and analysis (Lee et al., 2008). As the following statement from the participant, the socialization (i.e., social validation) of the information of IT projects is very important.

D1: "So the emphasis, the most important part of the business case is the socialization of it, not be actual quantitative analysis." "You never want present a business case and then somebody else say hey what about this? You should want that objection deal before you get to the executive team."

Based on the interview data, some of the participants prefer to use emails or surveys, which are convenient to collect mass information from a large population. Some of the participants choose face-to-face interviews because of the direct interaction. Besides these means, a kickoff meeting or regular meetings with participants are useful for the socialization. Participants can share and explore their ideas and opinions through these meetings. 
F1: "I put a lot of value on kick off meetings and during these meetings which is normally the first phase of sitting with stakeholders and project managers."

11: "Depending on the size of the project, there will be several meetings. This will make the process of making business case more efficient and effective."

In addition, some of the interviewees point out that coffee with the right person (e.g., top management) is an effective approach that enhances the socialization and understanding of the business cases. Further, complex IT projects are always associated with application design. Joint application design (JAD) sessions are used to gather participants (i.e., business side and IT side) together, which help to achieve the consistency of the utility design of the applications. Similar

\subsection{Findings Regarding the Approaches for Cost and Benefit Analysis}

The analysis of interviews indicated that the participants were using financial cost-benefit and tax write-off techniques for evaluating the tangible costs and benefits and weighted measurement scale and bell curve techniques for evaluating the intangible costs and benefits (see Table 4).

\section{Table 4: Approaches for Cost and Benefit Analysis}

\begin{tabular}{|l|l|}
\hline Category & Approaches for Cost and Benefit Analysis \\
\hline \multirow{4}{*}{ Tangible } & Internal rate of return (IRR) \\
\cline { 2 - 2 } & Net present value (NPV) \\
\cline { 2 - 2 } & Return on investment (ROI) \\
\cline { 2 - 2 } & Payback \\
\cline { 2 - 2 } & Tax write off \\
\hline Intangible & Weighted measurement scale \\
\cline { 2 - 2 } & Bell curve \\
\hline
\end{tabular}

The majority of the expert participants seemed to take cost and benefit analysis very seriously in their approach to creating and evaluating business cases for complex IT investments. They seemed well aware of how to deal with intangible costs and benefits according to the following responses:

A1: "The cost and benefits fairly easy to see the projections that you know the amount of people they are doing the job now and how you can reduce it." "At very least something as simple, you know all the benefits are intangible, and you just put them on scale, one to five, one to be the least important and five to be the most important. And you know if you find that this procurement would not satisfied anything that is five. But it satisfies a bunch of one. Then maybe it is not worthy...... At least, you would assign some sort of scale to the intangible benefit." 
D1: "I'd like to use a kind of weighted system or sort of weighted value."

G1: "the three dollar values we are trying to get to is what is the incremental revenue, what is the cost savings and what is the cost avoidance."

11: "How to address the intangible things is really most rely on experience and mostly thinking basically asking a lot of questions. And more questions you ask, the more answers you get and the more questions are being raised."

J1: "We write numbers you know in the business case. It is a really number driven exercise rather than creating a PowerPoint presentation, but mostly are number driven exercise to show the benefits that related hard benefits like numbers, dollars. And the soft benefits, the perceptions, the customer service, you know the non-tangible benefit is also important in coming up with the business case." "Don't under estimate the non technical component in IT implementation project, specifically for ERP projects. You need to include that new estimates. That's one of the important thing. Training is another important thing. And the process transformation is another important thing. Don't just put on the system without understanding, without transform the process in the place."

Furthermore, some participants emphasized that IT spending should not only focus on technology but also the business and operation side. There is on going cost that should be taken into consideration.

B1: "The business case has to do with how the organization views IT. So if the organization is old and traditional views IT as a cost centre. It becomes difficult to justify the cost just on the technology or pure money, benefits." "The issue is sometimes like I said IT people like to spend money on technology maybe there is no benefits. So in this case, we have to also include the executives on the business side and the operation side to see if we save you this much operationally, would it help the business."

E1: "There are a lot of other variables that should be accounted for over time. Refreshing the equipment for example, maintenance cost and operation cost. Some solutions require additional new staffing or partial staffing. There could be software applications. And other things that people don't think through but there are on going costs. And if you do not account for all the costs, after when there is an implication down the road because the budget hasn't been planned for. So doing the business case, if it has done properly. It helps you to identify all the different costs that would incur."

In addition, one of the interviewees described that engaging top management to scale the importance of each component was useful and effective for creating and evaluating business cases. Further, Bell curve is another method to estimate the benefits of intangible factors. For example, if the software were largely adopted by most of the organizations in the industry, the later adopter of this software would gain less benefit from it since there is no difference with other companies in terms of technology from the customers' viewpoints. On contrast, if one organization is the pioneer of the adoption of software, it can gain more interests from customers and has competitive advantage in the market. 
11: "So our philosophy is we are not big enough to be able to invent things. But we are big enough to innovate things. And the difference is somebody invents something and we look at it and we say yah that fits what we need. Thank you very much inventor. We recognize you and we want to buy what you have and incorporate into what we do. Therefore, our involvement if it starts, it will start at the early adoption area type. So as the curve is going up that we are the best. That's what we really thrive. And once we are at the top and is going to late adopters, we usually get out of the market place. It's something we don't do. So if I have something that the maturity level is at the late adoption area. Usually at that point it has been commoditized."

\subsection{Findings Regarding the Approaches for Evaluation}

The evaluation of business cases is a critical step. The expert participants usually utilize the following approaches to conduct it (see Table 5).

\section{Table 5: Approaches for Evaluation}

\begin{tabular}{|l|l|}
\hline No. & Approaches for Evaluation \\
\hline 1 & Budget review \\
\hline 2 & Risk mitigation strategy \\
\hline 3 & Stability of vendors \\
\hline 4 & Level of certainty \\
\hline 5 & Projections/Forecast \\
\hline 6 & Perception management \\
\hline 7 & Gap analysis \\
\hline 8 & Contingency/scenario planning \\
\hline
\end{tabular}

The most and the foremost is budget review in terms of costs and benefits. Further, risk is another important factor that needs to be mitigated. Therefore, risk mitigation strategy is very important. Similarly, the level of certainty regarding using the IT systems and the stability of vendors should be carefully examined as well according to the following statement:

A1: "So just say you are in a situation that everyone said it is worth well, starting to pressure, then what I could recommend doing is looking at the solution is available in the actual market place. I think I would get into contacts with vendors immediately. I would be saying we are not close to the procurement phase but we are just looking to build a business case."

The level of certainty indicates how many things that managers know they would happen but how many contingencies that managers do not know. How to manage the contingencies or the uncertainties could be a useful means to evaluate business cases. The projection or forecast is another important part of business cases. The perception management is used to deal with the 
organizational threatening events and organizational reputation. The gap analysis is the analysis between the existing process and the new process or the existing system and the new system would be explicitly evaluated. It includes the quality of the system and the capability of IT infrastructure. Furthermore, contingency/scenario planning can be utilized to scrutinize the availability of the IT projects.

\subsection{Findings Regarding the Challenges in the Process}

The challenges facing by practitioners are based on the rejections of business cases. The expert participants uncovered their failures of obtaining the approval of business cases (see Table 6).

\section{Table 6: Reasons for Rejection of Business Cases}

\begin{tabular}{|l|l|}
\hline No. & Reasons for Rejection of Business Cases \\
\hline 1 & Poor business case \\
\hline 2 & Misunderstanding the strategy \\
\hline 3 & Re-prioritization \\
\hline 4 & No budget \\
\hline 5 & Reject part of the plan \\
\hline 6 & Market trends \\
\hline 7 & Technology trends \\
\hline
\end{tabular}

One of the reasons of rejections is that they are simply poor business cases. This kind of business cases does not satisfy the requirements from decision-makers or has missing parts. Similarly, misunderstanding the strategy is another reason of rejection that leads to poor business cases. Besides these, the re-prioritization across several IT projects can drop off the business cases. Further, because of the limited resources (e.g., budget, human resources), entirely or only a part planning of the business case would be rejected by decision-makers. In addition to this internal reasons, the external factors such as market trends and technology trends influence the final decision-making since the IT investments should align with the long term business trends and technology trends in the industry.

Based on the reasons of rejections, the challenges to practitioners are identified by interviewees as stated in the following Table 7. 
Table 7: Key Challenges in the Process

\begin{tabular}{|l|l|}
\hline No. & Key Challenges in the Process \\
\hline 1 & Misunderstanding \\
\hline 2 & Miscommunication \\
\hline 3 & Resistance from stakeholders \\
\hline 4 & Emotional component \\
\hline 5 & Change management \\
\hline 6 & Limited time \\
\hline 7 & Human dynamics \\
\hline 8 & Presentation \\
\hline 9 & Dependencies \\
\hline 10 & Business cases experience \\
\hline 11 & Process transformation \\
\hline
\end{tabular}

Misunderstanding the requirements or the business strategy would harm the validity of business cases. Miscommunication is critical to understand the requirements from customers. Moreover, the resistance from stakeholders hinders the progress of creating and evaluating business cases for complex IT investments. The emotional component inherent in stakeholders such as afraid of loosing job because of the new IT system impede the business cases maker to obtain useful and accurate information for creating and evaluating business cases based on the following feedback. It is difficult to control and manage human dynamics.

B1: "The issue becomes business process for engineering and that is a big problem than the technology side. So like anything in technology, if you want to make a big project or small project, you have to look at the people resistant to change, you have to look at process, business processes, can we change it, can it be better. And the technology that can support it."

F1: "There is always conflicts especially some stakeholders are not comfortable to changes, especially comes to IT projects. If the stakeholders are not convinced, they will reject or they will resist. Some of them they think that, for example, they may loose their job and they resist. Some of them may think that they have to go through headache to train with the new system."

J1: "The emotional component will due to impact doing a business case. The second thing is we talked about some of the mistakes a lot of people do. They don't take certain factors into consideration. They come out of these benchmark without proper benchmark data. They trust gut feeling."

The accurate estimation of change management is another challenge for practitioners. The implementation of information technology involves a process of organizational change over time, and not merely the installation of a new technology. They are agile and flexible, which means hard to predict. Change management is crucial within implementation phase. Therefore, it should be taken into account when creating and evaluating business cases for complex IT investments. Time limited for complex IT projects is another challenge for managers to fulfill all the requirements. In terms of the final decision-making phase, how to synthesize all the 
information regarding the business case and make a comprehensive presentation to decisionmakers is challenging to practitioners. As one of the participants pointed out:

11: "Don't lecture. Make it a conversation."

\subsection{Findings Regarding the Process}

Drawing on the rich data of practitioners' experiences, this thesis generates a grounded understanding of business cases and the process of creating and evaluating business cases for complex IT investments. According to the following opinions from participants, business cases are very important, especially for complex IT investments.

E1: "ERP systems tend to be more complex because of their nature -- security and risks are a lot higher. So a lot of attention needs to be paid to the detail and the planning has to be done a lot better than there are some other projects that are required more standard approach than typical ERP system project."

Further, based on the interviews, the process of creating and evaluating business cases for general business projects and for complex IT investments are different in nuance (see Table 8):

\section{Table 8: Comparison of Business Cases for Complex IT vs General Projects}

\begin{tabular}{|c|c|c|}
\hline Step & General Business Projects & Complex IT Projects \\
\hline 1 & $\begin{array}{l}\text { Business requirements generate from business } \\
\text { department. }\end{array}$ & $\begin{array}{l}\text { Technology requirements generated from business or IT departments- } \\
\text { Business purpose or IT purpose. }\end{array}$ \\
\hline 2 & $\begin{array}{l}\text { Gather information from different stakeholders on } \\
\text { business requirements, budget, timeframe and so } \\
\text { forth. }\end{array}$ & $\begin{array}{l}\text { Socialize the project with stakeholders by several meetings that are on } \\
\text { going to identify the business strategy, technology requirements } \\
\text { (requirement for proposal), budget, timeframe and so forth; Define what } \\
\text { they are going to satisfy that strategy and what initiatives are required for } \\
\text { that strategy in business term. }\end{array}$ \\
\hline 3 & $\begin{array}{l}\text { Initiate a statement of the deliverable business } \\
\text { value that the project should create. }\end{array}$ & $\begin{array}{l}\text { Initiate a statement of the deliverable business value that the project } \\
\text { should create; Put the team together in charge of creating the business } \\
\text { case and choose the coordinator or the facilitator who will deliver the } \\
\text { business case. }\end{array}$ \\
\hline 4 & $\begin{array}{l}\text { Outline the alternative solutions for satisfying the } \\
\text { requirements such as procure versus developing } \\
\text { something, execute the key business needs versus } \\
\text { implement the full plan, etc. }\end{array}$ & $\begin{array}{l}\text { Outline the alternative solutions for satisfying the requirements such as } \\
\text { procure versus developing something, execute the key functionality } \\
\text { versus implement the full version, etc. Explore different level of } \\
\text { performance improvement targets and potential benefits in the } \\
\text { combinations of IT enablers and business changes by the business cases. } \\
\text { For example, flexible choice for IT investors, like high-cost, high-benefit, } \\
\text { high-risk, and longer-timeframe versus another option that is lower-cost, } \\
\text { lower-benefit, lower-risk, and shorter-timeframe. }\end{array}$ \\
\hline 5 & $\begin{array}{l}\text { Estimate cost, benefit and risk of the alternative } \\
\text { solutions. }\end{array}$ & $\begin{array}{l}\text { Estimate cost, benefit and risk of the alternative solutions, especially } \\
\text { which may accrue from change management. Compare proposals from } \\
\text { different vendors. }\end{array}$ \\
\hline 6 & $\begin{array}{l}\text { Identify the recommendations and summarize the } \\
\text { business case. }\end{array}$ & $\begin{array}{l}\text { Identify the recommendations by demo testing. Create the final version of } \\
\text { the business case. Everything have a agreement with stakeholders. }\end{array}$ \\
\hline 7 & $\begin{array}{l}\text { Present the business case for decision makers in } \\
\text { order to get the funding of IT investment. }\end{array}$ & $\begin{array}{l}\text { Present the business case for decision makers in order to get funding of IT } \\
\text { investment. Understand what the management needs and ask questions. }\end{array}$ \\
\hline 8 & Final review & Final review: revise the business case or postpone the business case. \\
\hline
\end{tabular}


The requirements of general projects and complex IT projects are different. General projects emphasize the needs from business department, while complex IT projects are focused on both business side and technology side. The elementary component of complex IT projects is technology requirements, which are generated from business departments. Since complex IT projects impact many areas of the organization, socialization is an important step in the initial phase. Several meetings are needed to identify the business strategy, technology requirements, budget, timeframe and people issues. In contrast with general business projects, complex IT projects usually require creation of a larger and more cross-functional project team whose mandate is the creation and evaluation of the business case.

Business cases for both general business projects and complex IT projects need to outline alternative solutions. But complex IT projects typically need to focus more on how IT systems satisfy the more complex business requirements and explore complicated procurement decisions such as whether to purchase a system, develop software, and integrate or replace separate information systems.

For business cases for complex IT investments, the decision-makers also are usually presented with more complicated combinations of choices or trade-offs that impact the costs and benefits of the investment. For example, decision-makers are often presented with more flexible choices for a complex IT investment using a combination of cost, benefit, risk, and timeframe tradeoffs. As with general business cases, the business case would estimate cost, benefit and risk of the alternative solutions. However, in terms of complex IT projects, the contingencies which may accrue from change management is emphasized in the process.

\subsection{Findings Regarding Suggestions for Improving Business Cases}

In order to avoid problems with the creation and evaluation of business cases for complex IT investments, several suggestions were provided by interview participants (see Table 9).

Table 9: Suggestions for Improving Business Cases

\begin{tabular}{|l|l|}
\hline No. & Suggestions for Improving Business Cases \\
\hline 1 & Ask more questions \\
\hline 2 & Communicate \\
\hline 3 & Focus on business strategy \\
\hline 4 & Consider human dynamics \\
\hline 5 & Senior management support \\
\hline
\end{tabular}

First, as noticed by most interviewees, asking more questions would help both decision-makers and business cases makers to achieve a high level and comprehensive understanding of complex IT investments. Second, communication is the central activity in an organization 
(Orlikowski and Yates, 1994). According to the interviews, many participants point out the importance of communication.

E1: "I think a good communication is a good thing. Sometimes we don't do enough of it. People often ignore types of things like that security or the needs for backups or there are all types of variables like that, that they do not factor in initially. And you need that collaboration at front or as soon as possible. That would avoid disappointment later on or budget issues." "Don't be afraid to ask questions."

Third, the practitioners should focus more on business strategy more than technology based on the following suggestions:

B1: "First of all is business goals and strategies." "The process for ERP is different with the others since ERP affects every aspects of the company especially it implement the company wide."

C1: "I think the business case if it is aligned directly to your business drivers. So, for all of your business cases, they should have a linkage back to your organization's vision and strategy." "The first step is several meetings that are on-going with the senior leader team to identify the strategy. That always has to take place. Then there will be different lines with business. They would define what they are going to satisfy that strategy."

Fourth, IT technology does not mainly dominate the final decision-making. In contrast, human dynamics plays a vital role in the process of decision-making.

D1: "The main message I would have is that the world is not nearly interested in quantification things as your engineering background might let you to believe. It is sad that how much human dynamics dominate the outcome."

Finally, gaining senior management support is also critical to the approval of business cases based on the following ideas.

A1: "Buy in from senior management is always necessary."

C1: "I think the biggest thing is have a strong leadership at the top of house to drive the initiative to put forward. People tend engage a lot more, quickly if their leadership teams are involved into the outcome of the project."

D1: "The support from management is very important. The business leader will have to kind of decide how important each of stakeholder's opinions are and given situation and that probably the combination of human dynamics like whether they really value that person's opinion."

H1: "Sometimes there are challenges because people are busy. But then we, that's why we need sponsorship or the technology of business sponsorship support make sure they are engaged and they can help us with it. So that's the only efficiency and effect to make sure people on board and they can help us with it. So that's what I would say the only thing to improve the part of process." 
In conclusion, the findings from the interview analysis provides several insights in terms of how expert participants think of business cases for complex IT investments and how to make them more effective. They considered that using business cases was a very useful means for initiating the planning and decision-making needed for complex IT investments. Further, the interviews suggested that for complex IT investments in particular, the socialization of business cases plays a significant role in the effectiveness of the process of creating and evaluating business cases. In addition, the expert participants suggested various approaches to conducting cost and benefit analysis of both tangible and intangible things, and the evaluation of business cases. Also, they exposed the challenges they were facing, e.g., misunderstanding, change management, resistance from stakeholders. Ultimately, the interview data disclosed several valuable suggestions for creating and evaluating business cases for complex IT investments including: Ask more questions, Communicate, Focus on business strategy, Consider human dynamics, and Ensure senior management support. 


\section{CHAPTER 5: DATA ANALYSIS - Q METHODOLOGY}

\subsection{Introduction}

The results of the Q method analysis are reported below based on the recommendations from Thomas and Watson (2002) that the analysis and interpretation of the Q sorts should contain: 1) Factor loading arrays; 2) normalized factor scores; and 3) the statements on which arrays load. Thus, readers are able to examine the researcher's interpretation with this information. The following sections describe the detailed results of the one- and twofactor solutions. Solutions using three to five factors were also generated, but these solutions did not have as strong correlations (and their interpretation would be more complex without being more meaningful) compared to the two-factor solution, so only the one- and two-factor solutions are described here.

The one-factor solution below examines the relative importance of each of the 32 principles for the effective creation and evaluation of business cases for complex IT investments. The Q method analysis using PCQ software examined the correlations between each of the rankings to determine the consensus opinion.

The two-factor solution which follows examines the relative importance of two distinct clusters of opinions that was found in examining the correlations. In other words, the onefactor solution shows the first step of the analysis showing the consensus ranking of each principle; whereas the two-factor solution shows the second step of analysis by reporting on the differences between the two distinct groups of opinions that was found upon more detailed analysis. This thesis does not report results of the three- or higher-factor solutions, as their interpretation is not as meaningful and their statistical correlations were not as strong.

\subsection{Consensus Ranking on the Importance of Each Principle: The One Factor Solution}

As shown in Figure 15, 14 out of 19 sorts (74\%) were accounted for when the one-factor solution was generated using PCQ. This means that 14 of the 19 participants shared a general consensus opinion on the relative importance of the 32 statements. The remaining five sorts were not significantly correlated with the 14 sorts, meaning these five participants shared statistically different opinions on the relative importance of the statements. 


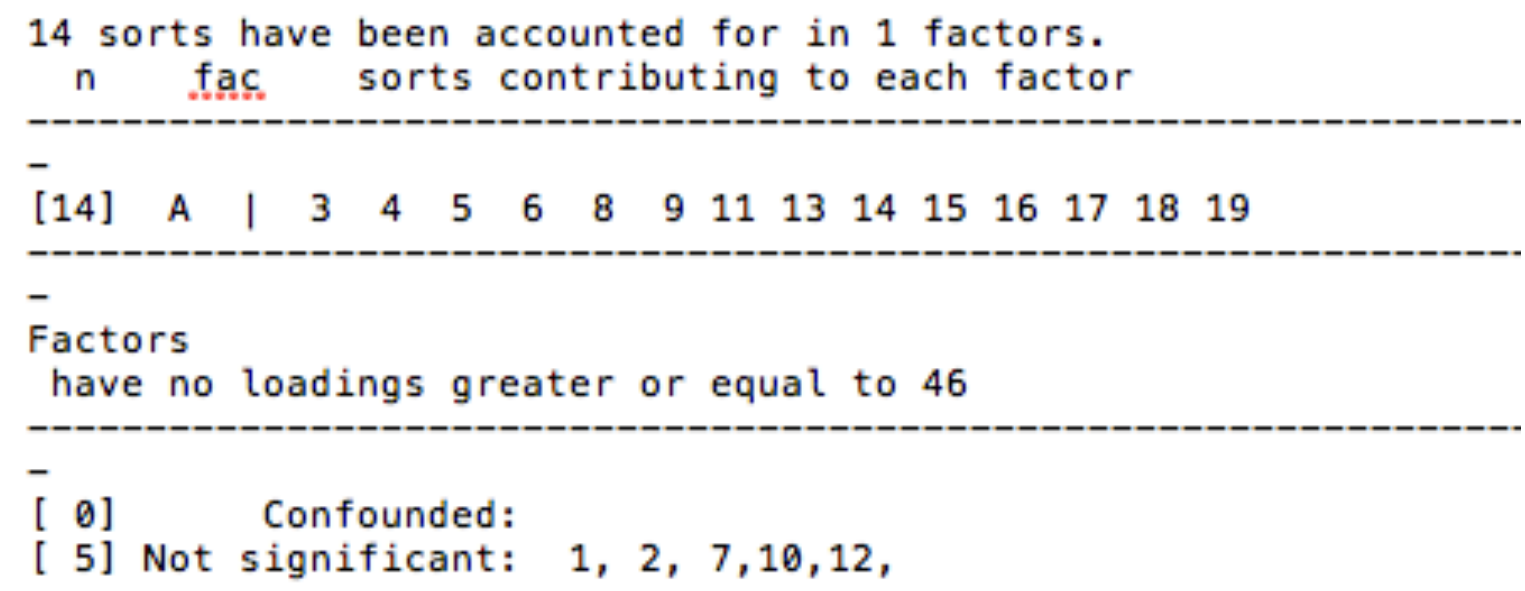

Figure 15: One-Factor Solution Summary

Although the analysis of prior studies and interviews reported in the previous chapter suggests all of the 32 statements are important for creating and evaluating business cases for complex IT investments, the results above can be used to identify the relative importance of each of the 32 statements. According to the ranking table (Figure 16) based on the varimax rotation, the consensus opinion was that statements relating to business alignment and management support were seen as most important. There were six statements that had the highest Z-values (greater than 1.0). In regards to the overall results for the respondents, "identify business purpose aligned with business strategy" was shown to be the most desirable to participants followed by "Gain senior management support at the beginning" and "Involve all relevant stakeholders and get the commitment" Next were the principles of analyzing requirements, costs, benefits and risks.

Similarly, there were 11 statements with normalized Z-values below -0.6, which were judged the least important. For instance, evaluating the information system quality by demo or testing, quantifying intangible information, analyzing the industry benchmark, collaborating with governance departments, discussing the business cases with innovative people, analyzing the revenue growth pattern with similar or previous projects, analyzing industry benchmarks, linking the total IT spend with organizational performance and scrutinizing the vendors. The three least important principles are "Create the standard documentation for the business cases" "Make presentations" "Obtain the outside view from third party consultants" by the point of view from the majority of the participants. However, the result does not mean that these statements are not important. Yet, comparing with the previous ones, these are not as important to practitioners. 


\begin{tabular}{|c|c|c|c|}
\hline No. & Statement & No. & Z-Values \\
\hline 3 & Identify business purpose aligned with business strategy & 3 & 2.160 \\
\hline 15 & Gain senior management support at the beginning & 15 & 1.809 \\
\hline 10 & Involve all relevant stakeholders and get the commitment & 10 & 1.798 \\
\hline 1 & Analyze costs and benefits & 1 & 1.413 \\
\hline 7 & Clarify requirements & 7 & 1.346 \\
\hline 4 & Assess risks & 4 & 1.153 \\
\hline 6 & Communicate with senior managers & 6 & 0.938 \\
\hline 16 & Ask questions & 16 & 0.803 \\
\hline 13 & Address the resistance from stakeholders & 13 & 0.667 \\
\hline 14 & Understand the preference of decision makers & 14 & 0.554 \\
\hline 2 & Socialize the projects with stakeholders & 2 & 0.475 \\
\hline 20 & Plan for change management & 20 & 0.124 \\
\hline 29 & Assign business executives to IT projects & 29 & 0.011 \\
\hline 5 & Make project plan in short term and long term & 5 & -0.136 \\
\hline 18 & Create an architecture design of the project & 18 & -0.158 \\
\hline 21 & Plan for process transformation & 21 & -0.170 \\
\hline 27 & offer different alternative solutions & 27 & -0.181 \\
\hline 26 & Examine the capabilities of current IT systems & 26 & -0.226 \\
\hline 12 & Hold a kick-off meeting before creating the business case & 12 & -0.373 \\
\hline 25 & $\begin{array}{l}\text { Review the effectiveness of the projects after } \\
\text { implementation and apply the new knowledge to new projects }\end{array}$ & 25 & -0.531 \\
\hline 22 & Understand market trends & 22 & -0.543 \\
\hline 28 & Evaluate the information system quality by demo or testing & 28 & -0.622 \\
\hline 8 & Quantify intangible information & 8 & -0.667 \\
\hline 9 & Collaborate with governance departments & 9 & -0.712 \\
\hline 24 & Discuss the business case with innovative people & 24 & -0.758 \\
\hline 19 & $\begin{array}{l}\text { Analyze the revenue growth pattern with similar or previous } \\
\text { projects }\end{array}$ & 19 & -0.803 \\
\hline 31 & Analyze industry benchmarks & 31 & -0.871 \\
\hline 32 & Link the total IT spend with organizational performance & 32 & -0.871 \\
\hline 17 & Scrutinize the vendors & 17 & -1.108 \\
\hline 11 & Create the standard documentation for the business cases & 11 & -1.176 \\
\hline 23 & Make presentations & 23 & -1.583 \\
\hline 30 & Obtain the outside view from third party consultants & 30 & -1.764 \\
\hline
\end{tabular}

Figure 16: Ranking of 32 Statements

\subsection{Ranking of Principles by Each of the Two Opinion Types: The Two-Factor Solution}

Next, a two-factor solution was generated to see if after loading the correlations on two factors, there were more meaningful and statistically significant results. As shown in the Figure 17,13 out of the 19 sorts $(68 \%)$ were correlated with one of the factors that were generated in this solution. Seven sorts loaded on Factor A and six sorts loaded on Factor B. In other words, if we look for two factors in the correlations between the sorts, we can see there were two different types of opinions (which we call the Factor (Opinion Type) A and Factor (Opinion Type) B. Two sorts were "confounded" (i.e., loaded on both of the factors) and four sorts were "not significant" (i.e., did not load significantly on either of the factors). 


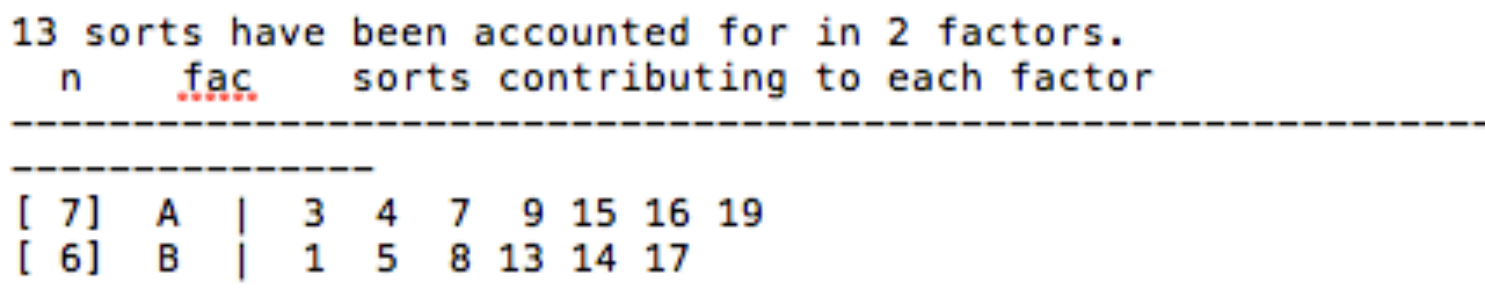

Factors

have no loadings greater or equal to 46

[ 2] Confounded: 11,18,

[ 4] Not significant: 2, 6,10,12,

\section{Figure 17: Two-Factor Solution}

The average rating of the importance of each statement was compared for each of the two Opinion Types (Factor A and Factor B). Recall that the sorting activity resulted in each participant rating each statement on a scale from -3 to +3 , where -3 was least important and +3 was most important. As shown in Figure 18, there were 11 statements for which the relative importance of the statement was agreed upon by both Opinion Type A and Opinion Type B agreed on. For example, both groups of opinions rated "Socialize the projects with stakeholders" as " 1 ", where 3 is most important, and -3 is least important. Note that Figure 18 shows the average rating of each statement from +3 to -3 for each Opinion Type (Factor) and hence consensus statements may be rated differently by up to 1 interval. For example, "Hold a kick-off meeting before creating the business case" was rated on average a "- 2 " by the participants with Opinion Type A and a "- 1 " by the participants with Opinion Type B, but this slight difference still indicates both Opinion Types essentially had a consensus opinion on the relative importance of that statement.

1. Socialize the projects with stakeholders

2. Make project plan in short term and long term

3. Collaborate with governance departments

4.Hold a kick-off meeting before creating the

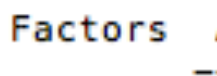

5. Ask questions

6.Plan for change management

7.Plan for process transformation

8. Discuss the business case with innovative people

9. Examine the capabilities of current IT systems

10.0ffer different alternative solutions

11. Assign business executives to IT projects

$\begin{array}{rr}\text { A } & \text { B } \\ -1 & -- \\ -2 & 1 \\ 0 & -2 \\ -2 & -1 \\ -1 & -1 \\ -1 & -1 \\ -1 & 0 \\ 0 & 1 \\ 0 & 1 \\ 1 & 0 \\ 1 & 0\end{array}$

\section{Figure 18: Consensus Statements}


In other words, the participants in both Opinion Types agreed on the relative importance of 11 of the 32 statements as listed in Figure 18. For example, they all considered that Statements $1,3,8,9,10$, and 11 above were neutral to slightly important ( 0 or 1 on a scale from +3 to -3 ) principles with respect to creating and evaluating business cases for complex IT investments. Similarly, they all agreed that Statement 2 below was fairly unimportant ( -2 on a scale of +3 to -3$)$ and that the remaining statements were neutral to slightly unimportant. . The lack of +3 and -3 rankings in the consensus statements indicate that consensus was not found for statements that some participants found either highly important or highly unimportant.

In contrast, there were eight statements (Figure 19) that strongly distinguished the two different types of opinions. These statements loaded significantly on only one of the two factors. For example, Opinion Type A on average rated "Analyze costs and benefits" fairly important ( 2 on a scale from +3 to -3 ), while the participants who held Opinion Type $B$ rated that statement of lowest importance ( -3 on a scale from +3 to -3$)$.

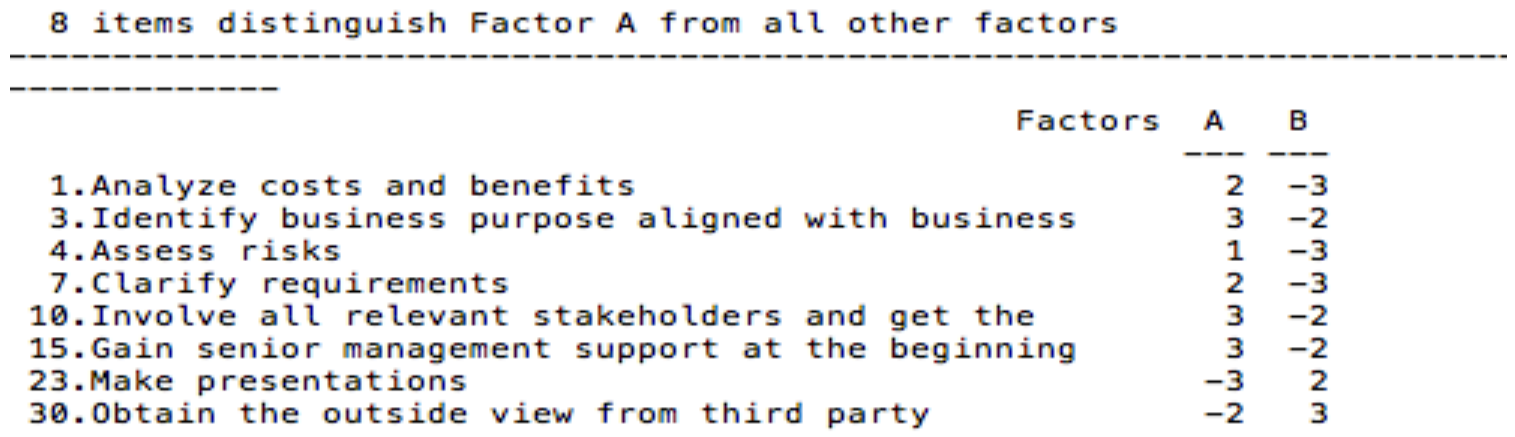

\section{Figure 19: Distinguishing Statements}

Figure 20 provides a more detailed view of the differences in the two types of opinions. Figure 20 lists each of the 32 statements in order starting with the statements that Opinion Type A (called Factor 1 in the table) found rated much more important than Opinion Type B and end with the statements that Opinion Type A rated much less important than Opinion Type B. The statements in the middle of Figure 20 were thus those with highest consensus. 
Descending Array of Differences Between Factors 1 and 2

\begin{tabular}{|c|c|c|c|c|c|}
\hline No. & Statement & No. & Factor 1 & Factor 2 & Difference \\
\hline 3 & $\begin{array}{l}\text { Identify business purpose aligned with business } \\
\text { strategy }\end{array}$ & 3 & 2.422 & -1.269 & 3.691 \\
\hline 10 & $\begin{array}{l}\text { Involve all relevant stakeholders and get the } \\
\text { commitment }\end{array}$ & 10 & 1.883 & -1.171 & 3.055 \\
\hline 7 & Clarify requirements & 7 & 1.362 & -1.613 & 2.975 \\
\hline 15 & Gain senior management support at the beginning & 15 & 1.665 & -1.206 & 2.871 \\
\hline 1 & Analyze costs and benefits & 1 & 1.362 & -1.438 & 2.800 \\
\hline 4 & Assess risks & 4 & 0.286 & -1.452 & 1.738 \\
\hline 6 & Communicate with senior managers & 6 & 0.639 & -0.414 & 1.053 \\
\hline 13 & Address the resistance from stakeholders & 13 & 0.488 & -0.330 & 0.817 \\
\hline 16 & Ask questions & 16 & -0.168 & -0.806 & 0.638 \\
\hline 14 & Understand the preference of decision makers & 14 & 0.185 & -0.442 & 0.627 \\
\hline 20 & Plan for change management & 20 & -0.168 & -0.666 & 0.498 \\
\hline 18 & Create an architecture design of the project & 18 & 0.504 & 0.049 & 0.455 \\
\hline 27 & offer different alternative solutions & 27 & 0.303 & 0.224 & 0.078 \\
\hline 29 & Assign business executives to IT projects & 29 & 0.269 & 0.281 & -0.011 \\
\hline 5 & Make project plan in short term and long term & 5 & -0.942 & -0.891 & -0.051 \\
\hline 2 & Socialize the projects with stakeholders & 2 & 0.454 & 0.638 & -0.184 \\
\hline 12 & $\begin{array}{l}\text { Hold a kick-off meeting before creating the } \\
\text { business case }\end{array}$ & 12 & -1.160 & -0.799 & -0.361 \\
\hline 26 & Examine the capabilities of current IT systems & 26 & -0.151 & 0.414 & -0.565 \\
\hline 24 & Discuss the business case with innovative people & 24 & -0.050 & 0.596 & -0.647 \\
\hline 21 & Plan for process transformation & 21 & -0.353 & 0.372 & -0.725 \\
\hline 19 & $\begin{array}{l}\text { Analyze the revenue growth pattern with similar } \\
\text { or previous projects }\end{array}$ & 19 & 0.067 & 0.940 & -0.872 \\
\hline 9 & Collaborate with governance departments & 9 & -0.118 & 0.792 & -0.910 \\
\hline 28 & $\begin{array}{l}\text { Evaluate the information system quality by demo } \\
\text { or testing }\end{array}$ & 28 & -0.572 & 0.393 & -0.964 \\
\hline 25 & $\begin{array}{l}\text { Review the effectiveness of the projects after } \\
\text { implementation and apply the new knowledge to new } \\
\text { projects }\end{array}$ & 25 & -1.295 & -0.224 & -1.070 \\
\hline 22 & Understand market trends & 22 & 0.168 & 1.262 & -1.094 \\
\hline 31 & Analyze industry benchmarks & 31 & -0.017 & 1.339 & -1.356 \\
\hline 17 & Scrutinize the vendors & 17 & -0.807 & 0.645 & -1.452 \\
\hline 32 & $\begin{array}{l}\text { Link the total IT spend with organizational } \\
\text { performance }\end{array}$ & 32 & -0.656 & 0.919 & -1.575 \\
\hline 8 & Quantify intangible information & 8 & -0.538 & 1.171 & -1.709 \\
\hline 11 & $\begin{array}{l}\text { Create the standard documentation for the } \\
\text { business cases }\end{array}$ & 11 & -2.018 & 0.133 & -2.151 \\
\hline 30 & $\begin{array}{l}\text { Obtain the outside view from third party } \\
\text { consultants }\end{array}$ & 30 & -1.244 & 1.325 & -2.570 \\
\hline 23 & Make presentations & 23 & -1.799 & 1.227 & -3.027 \\
\hline
\end{tabular}

\section{Figure 20: Difference between Opinion Type A and Opinion Type B}

Thus, we can see that from the top of the list, in contrast with the participants with Opinion Type B, the participants with Opinion Type A rated the following statements much more important (a difference greater than 2.0):

3. Identify business purpose aligned with business strategy;

10. Involve all relevant stakeholders and get the commitment;

7. Clarify requirements;

15. Gain senior management support at the beginning; and

1. Analyze costs and benefits.

Meanwhile, at the bottom of the descending array of differences table, the statements that Opinion Type A ranked much lower importance than Opinion Type B (a difference 
greater than -2.0) were:

11. Create the standard documentation for the business cases;

30. Obtain the outside view from third party consultants; and

23. Make presentations.

Furthermore, based on the ranking of Opinion Type A (Figure 21) and Opinion Type B (Figure 22), Opinion Type A places more importance on including the business point of view and getting buy in from senior management. They also tend to place more emphasis on cost, benefit, risk, and requirement analysis from practical facet. They concern less about presentations, the views from the third party, and the standardization of document for business cases. Opinion Type B seems to place more importance on presentations, standard documentation, and the viewpoint of consultants. Surprisingly, they place less emphasis on cost, benefit, risk and requirement analysis.

\begin{tabular}{|c|c|c|c|}
\hline No. & Statement & No. & Z-Values \\
\hline 3 & Identify business purpose aligned with business strategy & 3 & 2.422 \\
\hline 10 & Involve all relevant stakeholders and get the commitment & 10 & 1.883 \\
\hline 15 & Gain senior management support at the beginning & 15 & 1.665 \\
\hline 1 & Analyze costs and benefits & 1 & 1.362 \\
\hline 7 & Clarify requirements & 7 & 1.362 \\
\hline 6 & Communicate with senior managers & 6 & 0.639 \\
\hline 18 & Create an architecture design of the project & 18 & 0.504 \\
\hline 13 & Address the resistance from stakeholders & 13 & 0.488 \\
\hline 2 & Socialize the projects with stakeholders & 2 & 0.454 \\
\hline 27 & offer different alternative solutions & 27 & 0.303 \\
\hline 4 & Assess risks & 4 & 0.286 \\
\hline 29 & Assign business executives to IT projects & 29 & 0.269 \\
\hline 14 & Understand the preference of decision makers & 14 & 0.185 \\
\hline 22 & Understand market trends & 22 & 0.168 \\
\hline 19 & $\begin{array}{l}\text { Analyze the revenue growth pattern with similar or previous } \\
\text { projects }\end{array}$ & 19 & 0.067 \\
\hline 31 & Analyze industry benchmarks & 31 & -0.017 \\
\hline 24 & Discuss the business case with innovative people & 24 & -0.050 \\
\hline 9 & Collaborate with governance departments & 9 & -0.118 \\
\hline 26 & Examine the capabilities of current IT systems & 26 & -0.151 \\
\hline 16 & Ask questions & 16 & -0.168 \\
\hline 20 & Plan for change management & 20 & -0.168 \\
\hline 21 & Plan for process transformation & 21 & -0.353 \\
\hline 8 & Quantify intangible information & 8 & -0.538 \\
\hline 28 & Evaluate the information system quality by demo or testing & 28 & -0.572 \\
\hline 32 & Link the total IT spend with organizational performance & 32 & -0.656 \\
\hline 17 & Scrutinize the vendors & 17 & -0.807 \\
\hline 5 & Make project plan in short term and long term & 5 & -0.942 \\
\hline 12 & Hold a kick-off meeting before creating the business case & 12 & -1.160 \\
\hline 30 & Obtain the outside view from third party consultants & 30 & -1.244 \\
\hline 25 & $\begin{array}{l}\text { Review the effectiveness of the projects after } \\
\text { implementation and apply the new knowledge to new projects }\end{array}$ & 25 & -1.295 \\
\hline 23 & (1) & 23 & -1.799 \\
\hline 11 & Create the standard documentation for the business cases & 11 & -2.018 \\
\hline
\end{tabular}

Figure 21: Ranking of Opinion Type A 


\begin{tabular}{|c|c|c|c|}
\hline No. & Statement & No. & Z-Values \\
\hline 31 & Analyze industry benchmarks & 31 & 1.339 \\
\hline 30 & Obtain the outside view from third party consultants & 30 & 1.325 \\
\hline 22 & Understand market trends & 22 & 1.262 \\
\hline 23 & Make presentations & 23 & 1.227 \\
\hline 8 & Quantify intangible information & 8 & 1.171 \\
\hline 19 & $\begin{array}{l}\text { Analyze the revenue growth pattern with similar or previous } \\
\text { projects }\end{array}$ & 19 & 0.940 \\
\hline 32 & Link the total IT spend with organizational performance & 32 & 0.919 \\
\hline 9 & Collaborate with governance departments & 9 & 0.792 \\
\hline 17 & Scrutinize the vendors & 17 & 0.645 \\
\hline 2 & Socialize the projects with stakeholders & 2 & 0.638 \\
\hline 24 & Discuss the business case with innovative people & 24 & 0.596 \\
\hline 26 & Examine the capabilities of current IT systems & 26 & 0.414 \\
\hline 28 & Evaluate the information system quality by demo or testing & 28 & 0.393 \\
\hline 21 & Plan for process transformation & 21 & 0.372 \\
\hline 29 & Assign business executives to IT projects & 29 & 0.281 \\
\hline 27 & offer different alternative solutions & 27 & 0.224 \\
\hline 11 & Create the standard documentation for the business cases & 11 & 0.133 \\
\hline 18 & Create an architecture design of the project & 18 & 0.049 \\
\hline 25 & $\begin{array}{l}\text { Review the effectiveness of the projects after } \\
\text { implementation and apply the new knowledge to new projects }\end{array}$ & 25 & -0.224 \\
\hline 13 & Address the resistance from stakeholders & 13 & -0.330 \\
\hline 6 & Communicate with senior managers & 6 & -0.414 \\
\hline 14 & Understand the preference of decision makers & 14 & -0.442 \\
\hline 20 & Plan for change management & 20 & -0.666 \\
\hline 12 & Hold a kick-off meeting before creating the business case & 12 & -0.799 \\
\hline 16 & Ask questions & 16 & -0.806 \\
\hline 5 & Make project plan in short term and long term & 5 & -0.891 \\
\hline 10 & Involve all relevant stakeholders and get the commitment & 10 & -1.171 \\
\hline 15 & Gain senior management support at the beginning & 15 & -1.206 \\
\hline 3 & Identify business purpose aligned with business strategy & 3 & -1.269 \\
\hline 1 & Analyze costs and benefits & 1 & -1.438 \\
\hline 4 & Assess risks & 4 & -1.452 \\
\hline 7 & Clarify requirements & 7 & -1.613 \\
\hline
\end{tabular}

\section{Figure 22: Ranking of Opinion Type B}




\section{CHAPTER 6: DISCUSSION AND CONCLUSION}

\subsection{Introduction}

This chapter discusses the implications and conclusions of the findings from the analysis of literature, interviews, and Q methodology studies. In the first section, the major findings of the interviews are discussed in terms of participants in the process, socialization of business cases, cost and benefit analysis, evaluation of business cases, challenges in the process. Next the major findings of the Q method study are discussed. Finally, the researcher discusses the overall conclusions, limitations, and suggestions for further study.

\subsection{Discussion of Findings from Analysis of Interviews}

The analysis of interviews revealed several practices, challenges and suggestions in terms of creating and evaluating business cases for complex IT investments. These included: the importance of socializing a business case, the approaches of evaluating a business cases, and the challenges facing by expert practitioners.

The need for socialization of a business case was highlighted in several of the interviews. Socialization, in other words, communication is crucial during all stages of an IT project (Williams and Williams, 2007). By "socialization of a business case" it means that the communication during all stages of creating and evaluating business cases. For example, participants suggest that it is important to get everyone's commitment before presenting the business case in the decision-making meeting. Hence, it would address most of the resistance from stakeholders. The practitioners could also obtain the opinions from top management to ensure that the business case is on the right track. Similarly, Keen (2011) argues that good ROI is more about conversations than calculations. It influences the final acceptance and the trust of the information from the decision-maker.

The interview results illustrate that practitioners continue to use traditional financial calculations to do the budget review. However, according to the literature, the rational decision-making by traditional financial models such as NPV and IRR fails to capture most of strategic benefits (Lefley, 2008). These rationalist/positivist approaches should be complement with hermeneutic approaches as intuition, which is referred to act of faith or strategic insight (Lefley, 2008). Further, the interview results uncover the unique approaches the interviewees use for dealing with intangible cost and benefit. The majority of them suggested using a weighted measurement scale for intangibles.

Besides costs and benefits assessment, the results from interviews suggest the evaluation by risk mitigation strategy. Same as a 2010 CFO survey, it indicates that predictive analytics and risk management can be applied to address inappropriate investments 
(Williams, 2010). Further, the interview results outline the necessary of evaluating the gap, i.e., system quality. Similarly, Ram et al. (2013) accentuate the importance of perceived the system quality (PSQ) related with the implementation success of ERP projects (IMP). Managers should evaluate the functionalities and quality very carefully in the decision-making process of EPR investments. The findings also reveal the evaluation of the stability of vendors. As Ram et al. (2013) suggest, managers should not only rely on the proposal by vendors, but also find the evidence in their own network.

From analyzing the interviews, it appears that misunderstanding and miscommunication are major challenges in creating and evaluating business cases. Many executives do not understand IT well enough, while IT people do not seem to understand business problems (Ross and Weill, 2002). Moreover, change management is emphasized by expert participants in the interviews as well. Change management (e.g., technical aspects changes and business changes) is very important. Adopting a system is not just a technology change but also more business change (Ross and Weill, 2002). Many times the failures entailed from complex IT projects are not due to the complexity of the system but lack of the organizational and business process changes the system required (Ross and Weill, 2002).

Several of the interview participants suggested that the primary challenges centred on human dynamics, e.g., the participants in the process of creating and evaluating business cases should ask questions to each other and communicate more with each other. The individuals who take charge of business cases should consider human dynamics more than IT technology and focus on the business strategy. Additionally, top management support is essential as has been strongly suggested in the prior literature.

\subsection{Discussion of Findings from Analysis of Q-sorting Exercise}

The findings from Q-sorting uncover the ranking of importance of 32 principles in terms of making effective business cases. Looking at the ranking of all of the 19 participants collectively, the ten most important principles were:

1. Identify business purpose aligned with business strategy;

2. Gain senior management support at the beginning;

3. Involve all relevant stakeholders and get the commitment;

4. Analyze costs and benefits;

5. Clarify requirements;

6. Assess risks;

7. Communicate with senior managers;

8. Ask questions;

9. Address the resistance from stakeholders; and

10. Understand the preference of decision makers.

The most important is the alignment with business strategies. The findings are consistent with the literature. Duchessi et al. (2012) outline the importance of business strategies. 
Chan and Reich (2007) summarize many facets of alignment between business and IT. For example, the business plan should be linked with IT plan, the business strategy should be congruent with IT strategy, the business needs should fit with IS priorities. The authors argue that IT planning is created in support of business planning (Chan and Reich, 2007).

Further, the Q-sorting analysis also showed that there are at least two distinct differences of opinions on the relative importance of the principles. Opinion Type A felt that the ten most important principles were:

1. Identify business purpose aligned with business strategy;

2. Involve all relevant stakeholders and get the commitment;

3. Gain senior management support at the beginning;

4. Analyze costs and benefits;

5. Clarify requirements;

6. Communicate with senior managers;

7. Create an architecture design of the project;

8. Address the resistance from stakeholders;

9. Socialize the projects with stakeholders; and

10. Offer different alternative solutions.

On the other hand, Opinion Type B felt that the ten most important principles were:

1. Analyze industry benchmarks;

2. Obtain the outside view from third party consultants;

3. Understand market trends;

4. Make presentations;

5. Quantify intangible information;

6. Analyze the revenue growth pattern with similar or previous projects;

7. Link the total IT spend with organizational performance;

8. Collaborate with governance departments;

9. Scrutinize the vendors; and

10. Socialize the projects with stakeholders.

Opinion Type A ranked identifying business purpose aligned with business strategy top one. The same result with an annual CIO ranking (Duvall, 2009), IT and business alignment is the number one priority and concern. Similarly, another Society for Information Management survey (Luftman, 2008) ranked IT and business alignment as the top management concern by CIOs and other executives, whilst IT strategic planning ranked third and managing change ranked sixth. Strategies, processes, infrastructures and individuals are inseparable (Weiss and Thorogood, 2011). The CIO leaders must acknowledge how to align IT to support business strategy (Weiss and Thorogood, 2011).

Opinion type B emphasized outside view from the third party. Complex IT investments usually embrace both outside view and inside view. Although managers usually prefer inside view more than outside view from independent consultants, the inside view will distort the realistic estimations (Lovallo and Kahneman, 2003). Lovallo and Kahneman 
(2003) propose a five steps method to make a forecast using the outside view. However, misunderstanding of the internal process or strategy by external consultants would be a potential issue to the accuracy of business cases.

Surprisingly, none of the factor analysis shows the significant importance of the post implementation review process although one of the participants emphasized the importance of it. According to the feedback from respondents, it seems that the participants in this research treat each project as an independent and unique process. Thus, they do not concern about the learning from previous IT projects. However, Nelson (2007) suggests the post implementation review process at a macro level (i.e., a "metaretrospective") to uncover patterns of IT projects practices is very useful to practitioners. Ward et al. (2008) also indicates that reviewing projects after implementation and transferring the knowledge to new projects are important. Managers should revisit the past success or failures and reflect them before initiate new IT projects (Irani, 2010). Further, organization should focus their education and training on these areas. Ultimately, these will help project managers to avoid infamous failures.

\subsection{Implications for Theory and Practice}

This thesis draws on those earlier analyses, which broke the ground for a deeper understanding of the challenges or limitations in the process of creating and evaluating business cases for complex IT investments. It satisfied the requirements to explore the potential value of a better process to be used by practitioners and to better manage uncertainty and unexpected change. This thesis thus has important implications for academics and practices.

One of the contributions to academics is that this research lies in its specific, actionable, and more importantly, viable prescriptions, as well as the substantive recommendations on how to be flexible and adaptive when conducting an exploratory mixed methods research. Practitioners seeking explanations of the failure of IT investments variance in this study were motivated by the realization that, creating and evaluating a theoretically and empirically supported business case is salient for complex IT investments. For business case researchers, this study introduces a number of conceptual innovations and provides an organizational science research on constituting a theoretical and novel set of principles of creating and evaluating a business case. Some researchers have noted that a better business case appears to be struggling in the field of complex IT investments, given the lack of legitimacy of information system adoption, the lack of an agreed theoretical basis, and the lack of clarify of the aims of building a better business case in complex IT investments.

The results from this research contribute to a better understanding of behavioral decision theory in the context of creating and evaluating business cases for complex IT investments. Most of decision-making theories assume human decision-making to be a rational process that is based on the "hard" information, e.g., costs and benefits. 
Behavioral decision theory is one of the decision-making theories, which tries to incorporate some decision-making pattern such as underweighting or overweighting of probabilities, choice framing, and trade-offs based on these "hard" information (Carter, 1971; Cyert and March, 1963). It also reveals that the conflicting interests of the participants affect decision-making. Similarly, the results of this study show the conflicting interests among participants, e.g., business managers are focused on business strategy more than technology. However, in contrast with decision-making theory, the findings from the interviews and Q-sorting analyzed in this thesis highlight that expert participants considered "soft" elements, i.e., human dynamics (e.g., the resistance from stakeholders, the emotional component, the preferences of decision-makers, etc.) were important in terms of effective decision-making, rather than costs and benefits. They suggested that these irrational decision-making elements needed to be taken into account when creating and evaluating business cases for complex IT investments.

While criteria or principles for conducting IT investments have been widely discussed in literatures, the criteria or principles for building an effective business case are lacking. The contribution of this research to practices is in providing practitioners with principles that could be applied into the process of creating and evaluating business cases to enhance its effectiveness. For example, socializing the business cases, taking change management into account, and addressing the intangible costs and benefits can make the process of creating and evaluating business cases more effectively. Furthermore, the results of the Q-method analysis define what are the most important practices that influence the creating and evaluating of effective business cases for complex IT investments, i.e., aligning IT with business strategy, gaining the support from senior management, analyzing costs, benefits and risks. The findings from Q-method analysis also help practitioners to understand various perspectives on the relative importance of different principles for creating and evaluating business cases for complex IT investments. This identification of important principles can guide practice and lay the foundation for further research in an area that has seen little focus, but is of tremendous interest to IT decision-makers.

In addition, this research contributes to the IS research field in several ways. The contribution this research makes to theory lies in its combination of a variety of theories to explain the inherent phenomena in the process. Further, this thesis also makes a methodological contribution to the field of IS. It illustrates in descriptive detail what doing qualitative and quantitative research combined with interviews and Q methodology is like.

\subsection{Limitations and Future Work}

This research highlights the importance of creating and evaluating the business case with respect to the role it plays in IT investments to facilitate practitioners make right decisions. However, creating and evaluating business cases is a complex, difficult and crucial task and there are many potential extensions to the current research. Although the 
researcher employs a rigorous, multiphase approach to the development of a novel set of principles of creating and evaluating business cases for complex IT investments in line with many other researches, this research has several limitations that provide researchers for potential future study. First, this study is limited in its sampling strategy as one may expect bias in the self-reported performance of the interviewed senior executives, IT project managers, business managers, and scholars given their role and experiences related with IT projects to the company. Being aware of this limitation, the researcher maintains openness and skepticism, triangulating the views of the interviewees within each company whenever possible and seeking further evidence from their documents. Thus, the data collection can be extended to include a wider range of stakeholders, such as end users and accountants as well as considering different views for creating and evaluating business cases. Further, the future research could explore the role of decisionmaker preferences. Some of decision-makers are closed minded and some of them are open minded. Some of them desire for hard tangible numbers and others play more emphasize on intangibles. Moreover, as market environment and IT development change rapidly, a large-scale, longitudinal study would help to indicate the wider application of the research results, particularly if it included end-users or enterprises in an extensive range of industries. Other IT projects besides of complex IT projects would also help to complement the theory.

Second, in this study the researcher relies on the assumption, based on prior literatures and observations of the real world. The elements exist in a process are complex IT projects, decision-makers and other participants. The elements excluded from this process are external forces, such as market dynamics, demand context and society. Excluding these factors may result in a loss of contextual richness; however, by limiting the number of elements in the process, the research gains control and specificity and reduces complexity for the use of the process. In terms of future research directions, the future work can expand the process with including external forces and context-specific factors. Moreover, pilot-test of the theory would enhance the utility and reliability of the process.

Third, the online Q-sorting did not consider the person identity such as gender, age and personal characteristics. Mainly, the list of Q-sorting includes the important information that should be considered in the phase of creating and evaluating business cases for complex IT investments. The business cases comprise the planning of the whole project phase, i.e., initialization, execution, and ending. However, the findings from this research are based on the experience of participants without taking their personal identities and preference (e.g., gender and age) into account. The future research can further explore the correlation across these factors (e.g., the characteristics of practitioners) and how they influence the final decisions of complex IT investments.

Last but not least, although the researcher employs a rigorous, exploratory study to the development of a novel set of principles of creating a written business case for effective IT investments, the approach could be enhanced by action research that involves researchers and practitioners acting together to conduct business case creation (Adomavicius et al., 2008). Since the business case is confidential for every company, the researcher could not collect a sample of business cases during the research process. 
However, based on action research, researchers could work with individuals in complex IT projects or attend their decision-making meetings in the organizations to observe how they make decisions to invest complex IT projects and gain a high-level understanding of the process. Combining the action would improve the refinement and extension of the current work and advance the utility of the resulting principles for creating a written business case. Another direction for future research would be to use simulation to demonstrate the principles of creating and evaluating business cases in order to extend the research and manifest the results.

\subsection{Conclusion}

In light of the recession of the global economy, many IT departments have to cut costs while investing in complex IT projects to improve operational efficiency and revenue growth (Duchessi et al., 2012). While principles for evaluating IT investments in general have been widely discussed, principles for creating and evaluating effective business cases for complex IT investments in particular are lacking.

This study uses exploratory mixed methods by semi-structured interviews and online Qsorting based on the experiences of expert participants to suggest that complex IT investments (such as ERP) require a more nuanced approach to the creation and evaluation of business cases. Several practices that have not been previously emphasized in business case preparation were judged to be important for business cases for complex IT investments, such as: (i) the need for socialization of business cases, (ii) the need for address intangible costs and benefits, and (iii) the need for using change management techniques.

The findings from Q-sorting in terms of one-factor solution indicate that alignment with business strategy is the most important principle for creating and evaluating business cases. Regarding two-factor solution, the research depicts two distinct opinions on the most important principles of creating and evaluating business cases. Opinion Type A recommends on getting buy in from senior management. They also tend to place more emphasis on cost, benefit, risk, and requirement analysis from practical facet. In contrast, Opinion Type B seems to place more importance on presentations, standard documentation, and the viewpoint of consultants.

This study, through its rigorous analysis, helps practitioners to avoid the pitfalls commonly associated with IT project failures in the preliminary phase. The contributions of this research are twofold. In terms of theoretical contribution, the research identifies several theoretical principles related to the creation and evaluation of business cases specifically for complex IT investments. This identification of theoretical principles lays the foundation for further research in an area that has seen little focus, but is of tremendous interest to IT decision-makers. In terms of practical contribution, this study provides practitioners with principles that could be applied into the process of creating and evaluating business cases to enhance its effectiveness. Furthermore, the results of the 
Q-method analysis help practitioners to understand various perspectives on the relative importance of different principles for creating and evaluating business cases for complex IT investments. The researcher encourages other researchers to conduct similar studies and examine the principles and apply them into industries in the future. 


\section{REFERENCES}

Adomavicius, G., Bockstedt, J., Gupta, A., and Kauffman, R. (2008). Making sense of technology trends in the information technology landscape: A design science approach. MIS Quarterly, 32(4), 779-809.

Agosto, D. E. (2002). Bounded rationality and satisficing in young people's Web - based decision making. Journal of the American Society for Information Science and Technology, 53(1), 16-27.

Akkermans, H., \& Van Helden, K. (2002). Vicious and virtuous cycles in ERP implementation: A case study of interrelations between critical success factors. European Journal of Information Systems, 11(1), 35-46.

Ahadi, H. R. (2004). An examination of the role of organizational enablers in business process reengineering and the impact of information technology. Information Resources Management Journal (IRMJ), 17(4), 1-19.

Altshuller, G.S. (1988). Creativity as an exact science. New York: Gordon and Breach.

Altshuller, G. S. (1996). And suddenly the inventor appeared: TRIZ, the theory of inventive problem solving. Technical Innovation Center, Inc.

Andriole, S. J. (2009). Boards of directors and technology governance: The surprising state of the practice. Communications of the AIS, 24(22), 373-394.

Avnet. (1999). ERP not living up to promise. Global Supply Chain. 2(1), 7.

Bacon, C. J. (1992). The use of decision criteria in selecting information systems/technology investments. MIS Quarterly, 16, 335-335.

Banathy, B. H. (1996). Designing social systems in a changing world. New York: Plenum Publishers.

Bart, C., \& Turel, O. (2010). IT and the board of directors: An empirical investigation into the "governance questions" Canadian board members ask about IT. Journal of Information Systems, 24(2), 147-172.

Barney, J. B. (1991). Firm Resources and Sustained Competitive Advantage. Journal of Management, 17(1), 99-120.

Bazeley, P. (2007). Qualitative data analysis with NVivo. Sage Publications, London

Benaroch, M. (2002). Managing information technology investment risk: A real 

options perspective. Journal of Management Information Systems, 19(2), 43-84.

Bergin, M. (2011). NVivo 8 and consistency in data analysis: reflecting on the use of a qualitative data analysis program. Nurse Researcher, 18(3), 6.

Boeije, H. (2010). Analysis in qualitative research. London: Sage Publications, Inc.

Boyatzis, R. E. (1998). Transforming qualitative information: Thematic analysis and code development. SAGE Publications, Incorporated.

British Computer Society (2004). Challenge of complex IT projects. London: BCS.

Broadbent, M., Weill, P. and St.Clair, D. (1999). The implications of information technology for business process redesign. MIS Quarterly, 23(2), 159-182.

Brown, S. R. (1980). Political Subjectivity - Applications of Q Methodology in Political Science. Westford, MA: Yale University Press.

Brown, S. R. (1993). A primer on Q methodology. Operant Subjectivity, 16(3/4), 91-138.

Brugha, D. C. C. M. (2005). Understanding the situation of information systems development failure: A role for pragmatism. Action in Language, Organisations and Information Systems, 48.

Buckby, S., Best, P., \& Stewart, J. (2005). The role of boards in reviewing information technology governance (IT governance) as part of organizational control environment assessments. In B. Cusack (Ed.), Proceedings of 2005 IT Governance International Conference (1-14).

Buckhout, S. E., Frey, J. and Nemec, J. R. (1999). Making ERP succeed; turning fear into promise. Strategy and Business, 2nd quarter. Booz- Allen and Hamilton http://www.strategy-business.com.

Carter, E. E. (1971). The behavioural theory of the firm and top-level corporate decisions. Administrative Science Quarterly, (16), 413-428.

Cavallucci, D. and Lutz, P. (2000). Intuitive to Design Method (IDM) - A new approach on design methods integration. Proceedings of ICAD2000, 1st International Conference on Axiomatic Design, Cambridge, MA, USA.

Chandler, A. D. (1962). Strategy and structure. Cambridge, MA: MIT Press.

Chatterjee, D., Grewal, R., \& Sambamurthy, V. (2002). Shaping up for e-commerce: institutional enablers of the organizational assimilation of web technologies. MIS Quarterly, 65-89. 
Chernyshenko, O. S., Miner, A. G., Baumann, M. R., \& Sniezek, J. A. (2003). The impact of information distribution, ownership, and discussion on group member judgment: The differential cue weighting model. Organizational Behavior and Human Decision Processes, 91(1), 12-25.

Chircu, A. M., \& Kauffman, R. J. (2000, January). Limits to value in electronic commerce-related IT investments. In System Sciences, 2000. Proceedings of the 33rd Annual Hawaii International Conference on (10-pp). IEEE.

Chou, T. Y., Chou, S. C. T., \& Tzeng, G. H. (2006). Evaluating IT/IS investments: A fuzzy multi-criteria decision model approach. European Journal of Operational Research, 173(3), 1026-1046.

Chua, C. E., Lim, W. K., Soh, C., \& Sia, S. K. (2012). Enacting clan control in complex IT projects: a social capital perspective. MIS Quarterly, 36(2), 577-600.

Cintrón, J., Rabelo, L. C. and Housel, T. J. (2008). Estimating the knowledge valueddded of information technology investments. IIE Annual Conference. Proceedings: 1849-1854.

Clegg, C., Axtell, C., Damodaran, L., Farbey, B., Hull, R., Lloyd-Jones, R., Nicholls, J., Sell, R. and Tomlinson, C. (1997). Information Technology: A study of performance and the role of human and organizational factors. Ergonomics, 40(9), 851-871.

Clemons, E. K., \& Weber, B. W. (1990). Strategic information technology investments: guidelines for decision making. Journal of Management Information Systems, 7(2), 928.

Cobb, M. (1996). Unfinished Voyages, a Follow-up to the CHAOS Report. The Standish Group.

Cohen, M. D., March, J. G., \& Olsen, J. P. (1972). A garbage can model of organizational choice. Administrative Science Quarterly, 17(1), 1-25.

Cong, G., Zhang, J., Huazhong, T. C., \& Lai, K. K. (2008). A variable precision fuzzy rough group decision-making model for IT offshore outsourcing risk evaluation. Journal of Global Information Management (JGIM), 16(2), 18-34.

Computer Economics. (2010). 2010/2011 IT spending, staffing and technology trends. Irvine, CA: Computer Economics.

Creswell, J. W. (2012). Qualitative inquiry and research design: Choosing among five approaches. SAGE Publications, Incorporated.

Curlee, W., \& Gordon, R. L. (2010). Complexity theory and project management. Wiley. 
Cyert, R. M., \& March, J. G. (1963). A behavioural theory of the firm. Englewood Cliffs, New Jersey: Prentice-Hall, Inc.

Dacin, M. T., Goodstein, J., \& Scott, W. R. (2002). Institutional theory and institutional change: Introduction to the special research forum. The Academy of Management Journal, 45(1), 43-56.

Davenport, T. H. (1998). Putting the enterprise into the enterprise system. Harvard business review, 76(4).

Davis, C. H. (2004). Perceived Effects of ERP on Jobs and Work in a Contact Centre. In Proceedings of the International Conference on Work with Computer Systems, Kuala Lumpur.

Davis, J. H. (1973). Group decision and social interaction: A theory of social decision schemes. Psychological Review, 80(2), 97-125.

DellaVecchia, T., Scantlebury, S. and Stevenson, J. G. (2007). Three CIO advisory board responses to "Managing the Realizatioatio $\mathrm{n}$ of Business Benefit $\mathrm{s}$ from IT Investments". MIS Quarterly Executive, 6(1), 13-16.

DeLone, W. H., \& McLean, E. R. (1992). Information systems success: The quest for the dependent variable. Information systems research, 3(1), 60-95.

Delone, W. H., \& Mclean, E. R. (2004). Measuring e-commerce success: Applying the DeLone \& McLean information systems success model. International Journal of Electronic Commerce, 9(1), 31-47.

Dennis, K. E. (1988). Q-Methodology: New Perspectives on Estimating Reliability and Validity. In Measurement of Nursing Outcomes, edited by Ora L. Strickland and Carolyn F. Waltz. New York: Springer.

Dequech, D. (2001). Bounded rationality, institutions, and uncertainty. Journal of Economic Issues, 35(4), 911-929.

Devaraj, S., \& Kohli, R. (2000). Information technology payoff in the health-care industry: a longitudinal study. Journal of Management Information Systems, 41-67.

Dewan, S. and Ren, F. (2011). Information technology and firm boundaries: Impact on firm risk and return performance. Information Systems Research, 22(2), 369-388.

Dhaoui, A. \& Jouini, F. (2011). R\&D Investment, governance and management entrenchment in french companies listed in SBF250. Journal of Economic and Social Studies, 1(2), 5-33.

Doherty, N. F., Ashurst, C., and Peppard, J. (2011). Factors affecting the successful 
realisation of benefits from systems development projects: findings from three case studies. Journal of Information Technology, (27), 1-16.

Donnelly, J. P. \& Trochim, W. M. K. (2007). The research methods knowledge base. United States of America: Thomson Custom Publishing.

Douglas, D. (2003). Grounded theories of management: A methodological review. Management Research News, 26(5), 44-60.

Drucker, P. F. (2004). What makes an effective executive? Harvard Business Review, 82 (6), 58-63.

Duchessi, P., Nevo, S., \& Chengalur-Smith, I. (2012). Coping Strategies for Turbulent Times: A Survey of IT Executives. IT Professional, 14(2), 43-53.

Duval, M. (February 5, 2009). Poll Finds IT/Business Alignment Still Top Priority. ExecutiveBrief, Technology Resource for Business Leaders, CIOZONE, Retrieved from http://www.executivebrief.com/blogs/poll-finds-it-business-alignment-stilltop-priority/

Eason, K. (1988). Information technology and organizational change. London: Taylor \& Francis.

Edelhauser, E. (2011). IT\&C Impact on the Romanian Business and Organizations. The Enterprise Resource Planning and Business Intelligence Methods Influence on Manager's Decision: A Case Study. Informatica Economica Journal, 1(5), 16-28.

Eisenhardt, K. M. (1989). Building theories from cast study research. The Academy of Management Review, 14(4), 532-550.

Eisenhardt, K. M. (1989), “Agency theory: An assessment and review,” Academy of Management Review, 14(1), 57.

El Emam, K. \& Koru, A. G. (2008). A replicated survey of IT software project failures. IEEE Software, 25(5), 84-90.

Fama, E. F. (1980). Agency problems and the theory of the firm. The Journal of Political Economy, 288-307.

Ferrell, O. C., \& Gresham, L. G. (1985). A contingency framework for understanding ethical decision making in marketing. The Journal of Marketing, 87-96.

Fickenscher, K., \& Bakerman, M. (2011). Leadership and governance for IT projects. Physician Executive, 37(1), 72.

Fink, D. (1998). Guidelines for the successful adoption of information technology in 
small and medium enterprises. International journal of Information Management, $18(4), 243-253$.

Frenklach, G. and Savransky, S. D. (1998). New advantages of cross-fertilization of TRIZ and some quality methods. The 1998 International TRIZ Conference, Industry Hills, CA, USA.

Fudenberg, D. and Tirole, J. (1990). "Noncooperative Game Theory for Industrial Organization," In Handbook of Industrial Organizations, R. Schmalensee and R. D. Willig (Ed.), Vol.1, 259-327, New York, Oxford, Tokyo.

Gambles, I. (2009). Making the business case: Proposals that succeed for projects that work. England: Gower Publishing Limited.

Giddens, A. (1984). The constitution of society. Berkeley: University of California Press.

Glaser, B. G., \& Strauss, A. (1967). The discovery of grounded theory: Strategies for qualitative research. Hawthorne, NY: Aldine Publishing Company.

Goulding, C. (2002). Grounded theory: A practical guide for management, business and market researchers. Thousand Oaks, CA: Sage Publications.

Grabski, S. V., Leech, S. A., \& Schmidt, P. J. (2011). A review of ERP research: A future agenda for accounting information systems. Journal of Information Systems, 25(1), $37-78$.

Grover, V., Jeong, S. R., Kettinger, W. J., \& Teng, J. T. (1995). The implementation of business process reengineering. Journal of Management Information Systems, $12(1), 109-144$.

Gruenfeld, D. H., Mannix, E. A., Williams, K. Y., \& Neale, M. A. (1996). Group composition and decision-making: How member familiarity and information distribution affect process and performance. Organizational Behavior and Human Decision Processes.

Hambrick, D. C., \& Mason, P. A. (1984). Upper echelons: The organization as a reflection of its top managers. Academy of Management Review, 9(2), 193-206.

Hammond, J. S., Keeney, R. L. \& Raiffa, H. (1999). Smart choices: A practical guide to making better decisions. Boston, Massachusetts: Harvard Business School Press.

Hanson, W. (2007). Principles of Internet marketing and e-commerce. Mason, OH: Thomson/South-Western.

Harper, G. R., \& Utley, D. R. (2001). Organizational culture and successful information technology implementation. Engineering Management Journal, 13(2), 11-15. 
Harvard Business School. (2011). Developing a business case: expert solutions to everyday challenges. Boston, Massachusetts: Harvard Business School Publishing.

Harwood, T. G., \& Garry, T. (2003). An overview of content analysis. The Marketing Review, 3(4), 479-498.

Haslett, T. and Shankar. S. (2009). Applying multi-methodological systems theory to project management. Proceedings from International Society for The Systems Sciences $53^{\text {rd }}$ Annual Conference. Brisbane.

Heath, C., \& Gonzalez, R. (1995). Interaction with others increases decision confidence but not decision quality: Evidence against information collection views of interactive decision-making. Organizational Behavior and Human Decision Processes, 61(3), 305-326.

Hersey, P. and Blanchard, K. H. (1977). Management of organizational behaviour $\left(3^{\text {rd }}\right.$ eds). Utilizing Human Resources. New Jersey/Prentice Hall.

Hersey, P. (1985). The situational leader. New York, NY: Warner Books.

Hitt, L. M., Wu, D. J., \& Zhou, X. (2002). Investment in enterprise resource planning: Business impact and productivity measures. Journal of Management Information Systems, 19(1), 71-98.

Hochstrasser, B. and Griffiths, C. (1991). Controlling IT investment, London: Chapman Hall.

Hogbin, G. \& Thomas, D. V. (1994). Investing in information technology: Managing the decision-making process. England: McGRAW-HILL, Book Company Europe.

Hollingshead, A. B. (1996). The rank-order effect in group decision making. Organizational Behavior and Human Decision Processes, 68(3), 181-193.

Hoving, R. (2007). Information technology leadership challenges - Past, present, and future. Information Systems Management, 24(2), 147-153.

Hua, Z., Yang, J., Coulibaly, S. and Zhang, B. (2006). Integration TRIZ with problemsolving tools: A literature review from 1995 to 2006. International Journal of Business Innovation and Research, 1(2), 111-128.

Huang, L. K. (2012). The impact of IT management sophistication on perceived IT importance in strategic alignment, 52(3), 50-64.

Huber, G., and Van de Ven, A. (1995). Longitudinal field research methods. Thousand Oaks, CA: Sage Publications. 
Irani, Z. (2010). Investment evaluation within project management: an information systems perspective. Journal of the Operational Research Society, 61(6), 917-928.

IT Governance Institute. (2003). Board briefing on IT governance (2nd ed). Retrieved January, 2007, from

http://wikimp.mp.go.gov.br/twiki/pub/EstruturaOrganica/AreaMeio/Superintendencias/S

INFO/Estrategia/BibliotecaVirtual/MaterialExtra/26904_Board_Briefing_final.pdf

IT Governance Institute. (2006). Enterprise value: Governance of IT investments, the business case. USA: IT Governance Institute.

Jack, M. K., \& Bonnie, D. (2003). The emotional enigma of intangibles; There are equal measures of art and science to factoring the intangible benefits of IT investment decisions into a business case. CIO, 78 .

Jensen, M. C., \& Meckling, W. H. (1976). Theory of the firm: Managerial behaviour, agency costs and ownership structure. Journal of Financial Economics, 3(4), 305360 .

Jewer, J., \& McKay, K. N. (2012). Antecedents and Consequences of Board IT Governance: Institutional and Strategic Choice Perspectives. Journal of the Association for Information Systems, 13(7), 1.

Johnson, B., \& Christensen, L. (2007). Educational research: Quantitative, qualitative, and mixed approaches. USA: Sage Publications, Incorporated.

Jurison, J. (1996) Toward more effective management of information technology benefits. Journal of Strategic Information Systems, 5, 263-74.

Kahneman D., Slovic P. and Tversky A. (1982). Judgement under uncertainty: Heuristics and biases. Cambridge: Cambridge University Press.

Kanaracus, C. (2011), “10 biggest ERP software failures of 2011”, available at: www. computerworld.com/s/article/9222864/10_biggest_ERP_software_failures_of_2011? taxonomyId $1 / 4144 \&$ pageNumber $1 / 41$. Computerworld (accessed 12 August 2012).

Kaplan, R.S. and Norton, D.P. (1996), The Balanced Scorecard: Translating strategy into action. Harvard Business School Press, Boston, MA.

Karanja, E., \& Zaveri, J. (2012). IT leaders: who are they and where do they come from? Journal of Information Systems Education, 23(2), 143.

Kearns, G. S. (2004). A multi-objective, multi-criteria approach for evaluating IT investments: Results from two case studies. Information Resources Management Journal (IRMJ), 17(1), 37-62. 
Keen, J. M. (2011). Making technology investments profitable: ROI road map from business case to value realization (2nd ed.). New Jersey: John Wiley \& Sons, Inc.

Klaus, T., Wingreen, S., \& Blanton, J. E. (2007, April). Examining user resistance and management strategies in enterprise system implementations. In Proceedings of the 2007 ACM SIGMIS CPR conference on Computer personnel research: The global information technology workforce (55-62). ACM.

Klein, G., Moon, B. and Hoffman, R.F. (2006). Making sense of sensemaking I: Alternative perspectives. IEEE Intelligent Systems, 21(4), 70-73.

Kohli, R., \& Devaraj, S. (2003). Measuring information technology payoff: A metaanalysis of structural variables in firm-level empirical research. Information Systems Research, 14(2), 127-145.

Kohli, R., Devaraj, S. and Ow, T. T. (2012). Does information technology investment influence a firm's market value? A case of non-publicly traded healthcare firms. MIS Quarterly, 36(4), 1145-1163.

Kohli, R., \& Grover, V. (2008). Business value of IT: an essay on expanding research directions to keep up with the times. Journal of the Association for Information Systems, 9(1), 23-39.

Krell, K., Matook, S., \& Rohde, F. (2011). Development of an IS change reason-IS change type combinations matrix. European Journal of Information Systems, 20(6), 629-642.

Kreps, D., Wilson, R., Milgrom, P. and Robertsm, J. (1982). Rational Cooperation in the Finitely Repeated Prisoner's Dilemma. Journal of Economic Theory, 27, 245-252.

Krivokapic-Skoko, B., \& O'Neill, G. (2011). Beyond the qualitative-quantitative distinction: Some innovative methods for business and management research. International Journal of Multiple Research Approaches, 5(3), 290-300.

Latour, B. (2005). Reassembling the social: An introduction to Actor-Network-Theory. Oxford: Oxford UP.

Langley, A., and Truax, J. (1994). A process study of new technology adoption in smaller manufacturing firms. Journal of Management Studies, 31(5), 619-652.

Langley, A. (1999). Strategies of theorizing from process data. Academy of Management Review, 24(4), 691-710.

LaPlante, A. (1995). Scope grope. Computerword, 29(12), 81-4. 
Leaptrott, J. (2005). An institutional theory view of the family business. Family Business Review, 18(3), 215-228.

Leckson-Leckey, G. T., Osei, K. A., \& Harvey, S. K. (2011). Investments in information technology (IT) and bank business performance in Ghana. International Journal of Economics and Finance, 3(2), 133.

Lee, A. H. I., Chen, H. H., \& Kang, H. Y. (2008). Operations management of new project development: innovation, efficient, effective aspects. Journal of the Operational Research Society, 60(6), 797-809.

Leedy, P. D., \& Ormrod, J. E (2005). Practical Research: Planning and Design (8th ed). Upper Saddle River: Merrill Prentice Hall.

Lefley, F. (2008). Research in applying the financial appraisal profile model to an information communication technology project within a professional association. International Journal of Managing Projects in Business, 1(2), 233-259.

Leiblein, M. J. (2003). The choice of organizational governance form and performance: Predictions from transaction cost, resource-based, and real options theories. Journal of Management, 29(6), 937-961.

Levine, R. (2004). Risk management systems: Understanding the need. Information Systems Management, 31-37.

Levinson, M. (2009). Recession causes rising IT project failure rates. CIO Magazine, 18 June.

Lincoln, Y.S., and Guba, E.G. (1985). Naturalistic Inquiry. Beverly Hills, CA: Sage.

Locke, K. (2001). Grounded theory in management research. Thousand Oaks, CA: Sage Publications.

Long, M., \& Walkling, R. (1984). Agency theory, managerial welfare, and takeover bid resistance. Rand Journal of Economics, 15(1), 54-68.

Lovallo, D., \& Kahneman, D. (2003). Delusions of success. Harvard Business Review, 81(7), 56-63.

Lu, Y., \& Ramamurthy, K. (2010). Proactive or reactive IT leaders\&quest; A test of two competing hypotheses of IT innovation and environment alignment. European Journal of Information Systems, 19(5), 601-618.

Luftman, J. (2003). Assessing IT/Business Alignment. Information Strategy, 20(4), 915. 
Markus, L., and Robey, D. (1988). Information technology and organizational change: Causal structure in theory and research. Management Science, 34(5), 583-598.

March, J. G., Olsen, J. P., \& Christensen, S. (1979). Ambiguity and Choice in Organizations. Sweden: Scandinavian University Press.

Marshall, M. N. (1996). Sampling for qualitative research. Family Practice, 13(8), 522 525.

Maxwell, J. A. (1998). Designing a qualitative study in Rog, D. J., \& Bickman, L. (Eds.). (1998). The Sage handbook of applied social research methods, 69-100, California: Sage Publications, Incorporated.

May, T. (2011). Social research: Issues, methods and research (4th ed.). New York: Open University Press.

Mazur, G. (2000). QFD 2000: integrating supporting methodologies into quality function deployment. Proceedings of the 12th Symposium on Quality Function Deployment, Novi, MI, USA: QFD Institute.

McKeown, B., \& Thomas, D. (Eds.). (1988). Q methodology (Vol. 66). Sage.

McKinnie, R. M. (2007). The application of complexity theory to the field of project management. (Doctoral dissertation). Retrieved from ProQuest Dissertations and Theses. (Accession Order No. AAT 3283983)

Miles, M. B. (1979). Qualitative data as an attractive nuisance: The problem of analysis. Administrative Science Quarterly, 24(4), 590-601.

Miles, M. B., \& Huberman, A. M. (1994). Qualitative data analysis: An expanded sourcebook (2nd ed.). California: Sage Publications, Incorporated.

Miles, R. and Snow, C. (1978). Organizational Strategy, Structure and Process. New York: McGraw-Hill.

Mohamed, N. (2012). A conceptual framework for information technology governance effectiveness in private organizations. Information Management \& Computer Security, 20(2), 88-106.

Mohsen, Z. A., Ali, M., \& Jalal, A. (2011). The significance of knowledge management systems at financial decision making process. International Journal of Business and Management, 6(8), 130.

Myers, M. D., \& Newman, M. (2007). The qualitative interview in IS research: Examining the craft. Information And Organization, 17(1), 2-26. 
Nagm, F., \& Cecez-Kecmanovic, D. (2008). Pre-Investment Information Systems Assessment: An Actor Network Theory Account. In 16th EUROPEAN CONFERENCE ON INFORMATON SYSTEMS, W. Golden, T. Acton, K. Conboy, $H$. van der Heijden, VK Tuunainen, eds (422-433).

Nash, J. F. (1953). Two-Person cooperative games. Econometrica, 21, 128-140.

Nelson, R. R. (2007). IT project management: infamous failures, classic mistakes, and best practices. MIS Quarterly Executive, 6(2), 67-78.

Neuendorf, K. A. (2002). The content analysis guidebook. SAGE Publications, Incorporated.

Neuman, L.W. (2011). Social research methods: Qualitative and quantitative approaches. (7th ed.). Boston: Allyn and Bacon, Pearson Education, Inc.

Nfuka, E. N., \& Rusu, L. (2011). The effect of critical success factors on IT governance performance. Industrial Management \& Data Systems, 111(9), 1418-1448.

Nolan, R., \& McFarlan, F. W. (2005). Information technology and the board of directors. Harvard Business Review, 83(10), 96-106.

Orlikowski, W. J. (1993). CASE tools as organizational change: Investigating incremental and radical changes in systems development. MIS quarterly, 17(3), 309340 .

Orlikowski, W. J. \& Robey, D. (1991). Information technology and the structuring of organizations. Information Systems Research, 2(2), 398-427.

Orlikowski, W. J., \& Yates, J. (1994). Genre repertoire: The structuring of communicative practices in organizations. Administrative Science Quarterly, 541574.

Pan, S. L., \& Tan, B. (2011). Demystifying case research: A structured-pragmaticsituational (SPS) approach to conducting case studies. Information and Organization, 21(3), 161-176.

Panorama Consulting Group (2010), 2010 ERP Report, available at: http://panoramaconsuling.com/resource-center/2010-erp-report/.

Peloza, J. (2009). The challenge of measuring financial impacts from investments in corporate social performance. Journal of Management, 35(6), 1518-1541.

Penrose, E. T. (1959). The Theory of the Growth of the Firm, New York: Blackwell. 
Peppard, J., Ward, J., \& Daniel, E. (2007). Managing the realization of business benefits from IT investments. MIS Quarterly Executive, 6(1), 1-11.

Pevzner, L. and Katsman, Y. (2001). Theory and practical use of TRIZ tools during FMEA. Proceedings of TRIZCON2001, 3rd Annual Altshuller Institute for TRIZ Studies International Conference, Woodland Hills, CA, USA.

Platteau, J. P. (1994). Behind the market stage where real societies exist - part I: The role of public and private order institutions. The Journal of Development Studies, 30(3), 533-577.

Porter, M. E. (1985). Competitive advantage: Creating and sustaining superior performance. New York, London: Free Press; Collier Macmillan.

Previte, J., Pini, B., \& Mc-Kenzie, F. H. (2007). Q methodology and rural research. Sociologia Ruralis, 47, 135-147.

Project Management Institute. (2004). A guide to the project management body of knowledge (PMBOK" Guide), Project Management Institute, Upper Darby, PA.

Quinn, J. B. (1980). Strategies for Change: Logical Incrementalism. Homewood, Ill: Richard D. Irwin.

Ram, J., Corkindale, D., \& Wu, M. L. (2013). Examining the role of system quality in ERP projects. Industrial Management \& Data Systems, 113(3), 350-366.

Ramirez, R., Melville, N., and Lawler, E. (2010). Information technology infrastructure, organizational process design, and business value: An empirical analysis. Decision Support Systems, 49(4), 417-429.

Ravichandran, T., and Lertwongsatien, C. (2005). Effect of information systems resources and capabilities on firm performance: A resource-based perspective. Journal of Management Information Systems, 21(4), 237-276.

Real options theory. (n.d.). In Wikipedia. Retrieved 15 November 2011, from http://istheory.byu.edu/wiki/Real_options_theory

Remenyi, D. (1999). IT Investment: Making a business case. Woburn: ButterworthHeinemann.

Robson, C. (2002). Real world research: a resource for social scientists and practitionerresearchers (Vol. 2). Oxford: Blackwell.

Ross, J. W., \& Beath, C. M. (2002). Beyond the business case: New approaches to IT investment. MIT Sloan Management Review, 43(2), 51-59. 
Ross, J. W., \& Weill, P. (2002). Six IT decisions your IT people shouldn't make. Harvard Business Review, 80(11), 84-95.

Rottgers. F. \& Ritter, J. (2011). The definitive guide to getting your budget approved! Measure intangibles to calculate your ROI business case. Unite States: Solution Matrix.

Saaty TL (1980). The Analytic Hierarchy Process. McGraw-Hill: New York.

Saaty TL (1996). Decision making with dependence and feedback: The analytic network process. RWS Publications: Pittsburgh.

Sarkis, J., \& Sundarraj, R. P. (2003). Evaluating componentized enterprise information technologies: a multiattribute modeling approach. Information Systems Frontiers, 5(3), 303-319.

Schmidt, M. J. (2002). The business case guide (2nd ed.). Boston, MA: Solution Matrix Ltd.

Schniederjans, M. J., \& Hamaker, J. L. (2003). A new strategic information technology investment model. Management Decision, 41(1), 8-17.

Schryen, G. (2013). Revisiting IS business value research: what we already know, what we still need to know, and how we can get there. European Journal of Information Systems, 22, 139-169.

Schultze, U. (2000). A confessional account of an ethnography about knowledge work. MIS quarterly, 3-41.

Schwab, S. F. and Kallman, E. A. (1991). The software selection process can't always go by the book. Journal of Systems Management, 42(5), 9-17.

Shleifer, A. and Vishny, R.W. (1989). Management entrenchment: The case of manager-specific investments. Journal of Financial Economics, 25, 123-140.

Shpilberg, D., Berez, S., Puryear, R. and Shah, S. (2007). Avoiding the Alignment Trap in Information Technology, MIT Sloan Management Review, 49(1), 51-58.

Simon, H. A. (1977). The new science of management decision. Englewood cliffs, New Jersey: Prentice-Hall, Inc.

Simon, H. A. (1991). Bounded rationality and organizational learning. Organization science, 2(1), 125-134.

Singh, H., \& Singh, A. (2002). Principles of complexity and chaos theory in project execution: A new approach to management. Cost engineering, 44(12), 23-33. 
Smart, A. (2010). Exploring the business case for e-procurement. International Journal of Physical Distribution \& Logistics Management, 40(3), 181-201.

Sniezek, J. A. (1992). Groups under uncertainty: An examination of confidence in group decision making. Organizational Behavior and Human Decision Processes, 52(1), 124-155.

Snowden, D. J. (2005). Multi-ontology sense making: a new simplicity in decision making. Informatics in Primary Care, 13(1), 45-54.

Soh, C., \& Markus, M. L. (1995, December). How IT creates business value: a process theory synthesis. In Proceedings of the International Conference on Information Systems (29-42). Society for Information Management.

Spence, M. (1976). Competitive and Optimal Responses To Signals. Journal of Economic Theory, 7, 298-315.

Stephenson, W. (1935). Technique of factor analysis. Nature.

Stephenson, W. (1953). The study of human behaviour. Chicago, IL: University of Chicago Press.

Stewart, R., \& Mohamed, S. (2002). IT/IS projects selection using multi-criteria utility theory. Logistics Information Management, 15(4), 254-270.

Strauss, A., \& Corbin, J. (1998). Basics of qualitative research: Techniques and procedures for developing grounded theory (2nd ed.). Thousand Oaks, CA: SAGE Publications, Inc.

Sumner, M. (2000). Risk factors in enterprise-wide/ERP projects. Journal of Information Technology, 15(4), 317-327.

Tarter, C. J., \& Hoy, W. K. (1998). Toward a contingency theory of decision making. Journal of Educational Administration, 36(3), 212-228.

Taylor, M. C. (2001). The moment of complexity: Emerging network culture. Chicago: University of Chicago Press.

Teng, J. T., \& Calhoun, K. J. (1996). Organizational computing as a facilitator of operational and managerial decision making: An exploratory study of managers' perceptions. Decision Sciences, 27(4), 673-710.

Terninko, J. (2000). Using QFD's customer context table to identify system failures. Proceedings of TRIZCON2000, 2nd Annual Altshuller Institute for TRIZ Studies International Conference, Nashua, NH, USA. 
Tesch, D., Kloppenborg, T. J., \& Frolick, M. N. (2007). IT project risk factors: The project management professionals perspective. Journal of Computer Information Systems, 47(4), 61.

The Standish Group (1999). CHAOS: the recipe for success. Research report, available at www.standishgroup.com/chaos_resources/index.php.

Thomas, D. M., and Watson, R. T. (2002). Q-Sorting and MIS Research: A Primer. Communications of the Association for Information Systems, 8, 141-156.

Thomas, G., \& Fernandez, W. (2008). Success in IT projects: A matter of definition? International Journal of Project Management, 26(7), 733-742.

Thompson, R. L. (1967). Organizations in action, New York: McGraw-Hill.

Thong, J. Y., \& Yap, C. S. (1995). CEO characteristics, organizational characteristics and information technology adoption in small businesses. Omega, 23(4), 429-442.

Tiwana, A., Wang, J., Keil, M., \& Ahluwalia, P. (2007). The bounded rationality bias in managerial valuation of real options: Theory and evidence from it projects. Decision Sciences, 38(1), 157-181.

Tolbert, P. S., \& Zucker, L. G. (1999). The institutionalization of institutional theory. Studying Organization. Theory \& Method. London, Thousand Oaks, New Delhi, 169-184.

Topicos, U., \& Escolha, D. S. E. O. S. (2011). A theoretical analysis of key points when choosing open source ERP systems. Journal of Information Systems and Technology Management, 8(2), 441-458.

Tractinsky, N., \& Jarvenpaa, S. L. (1995). Information systems design decisions in a global versus domestic context. MIS Quarterly, 507-534.

Trites, G. (2004). Director responsibility for IT governance. International Journal of Accounting Information Systems, 5, 89-99.

Trochim, W. M. K., \& Donnelly, J. P. (2007). The Research methods knowledge base (3nd ed.). Mason, $\mathrm{OH}$ : Thomson Custom.

Tsai, W. H., Chen, S. P., Hwang, E. T., \& Hsu, J. L. (2010). A study of the impact of business process on the ERP system effectiveness. International Journal of Business and Management, 5(9), 26.

Turban, E., \& Aronson, J. E. (2001). Decision support systems and intelligent systems (6th ed.). New Jersey: Prentice-Hall, Inc. 
Urquhart, C. 2007. "The Evolving Nature of Grounded Theory Method: The Case of the Information Systems Discipline," in The SAGE Handbook of Grounded Theory, $A$. Bryant and K. Charmaz (eds.) Los Angeles, CA: Sage Publications, 339-359.

Uwizeyemungu, S., \& Raymond, L. (2011). Information technology adoption and assimilation: Towards a research framework for service sector SMEs. Journal of Service Science and Management, 4(2), 141-157.

Van de Ven, A. H. (1992). Suggestions for studying strategy process: A research note. Strategic management journal, 13(5), 169-188.

Walls, J. G., Widmeyer, G. R., and El Sawy, O. A. (1992). Building an information system design theory for vigilant EIS. Information Systems Research, 3(1), 36-59.

Walsham, G. (1995). Interpretive case studies in IS research: Nature and method. European Journal of Information Systems, 4(2), 74-81.

Walsham, G. (2006). Doing interpretive research. European Journal of Information Systems, 15(3), 320-330.

Walsham, G., \& Waema, T. (1994). Information systems strategy and implementation: A case study of a building society. ACM Transactions on Information Systems (TOIS), 12(2), 150-173.

Ward, J., Daniel, E., and Peppard, J. (2008). Building better business cases for IT Investments. MIS Quarterly Executive, 7(1), 1-15.

Webler, T., Danielson, S., \& Tuler, S. (2009, February). Using $Q$ method to reveal social perspectives in environmental research. Retrieved February 10, 2010, from www.seri-us.org: http://www.seri-us.org/sites/default/files/Qprimer.pdf

Weick, K. E., Sutcliffe, K. M., \& Obstfeld, D. (2005). Organizing and the process of sensemaking. Organization Science, 16(4), 409-421.

Weick, K. E. (2007). The generative properties of richness. Academy of Management Journal, 50(1), 14-19.

Weill, P., and Olson, M. H. (1989). Managing investment in information technology: Mini case examples and implication. MIS Quarterly, 13(1), 3-17.

Weiss, J. W., \& Thorogood, A. (2011). Information Technology (IT)/Business alignment as a strategic weapon: A Diagnostic Tool. EMJ-Engineering Management Journal, 23(2), 30-41.

Whittaker, B. (1999). What went wrong? Unsuccessful technology projects. KPMG 
Consulting Canada Report, 34.

Williams, C. A. (2010). 2010 CFO survey: Increasing ROI with streamlined communications and a reduced financial footprint. Journal of Government Financial Management, 46-50.

Williams, M. D., \& Williams, J. (2007). A change management approach to evaluating ICT investment initiatives. Journal of Enterprise Information Management, 20(1), $32-50$.

Woodward, J. (1958). Management and technology. London: Her Majesty's Stationary Office.

Xue, Y., Liang, H., \& Boulton, W. R. (2008). Information technology governance in information technology investment decision processes: The impact of investment characteristics, external environment, and internal context. MIS Quarterly, 32(1), 67-96.

Yayla, A. A., and Hu, Q. (2011). The impact of information security events on the stock value of firms: The effect of contingency factors. Journal of Information Technology, 26(1), 60-77.

Yin, R. K. (1981). The case study crisis: Some answers. Administrative Science Quarterly, 26(1), 58-65.

Yin, R. K. (2009). Case study research: Design and methods (4th ed.). Thousand Oaks, CA: Sage Publications.

Yin, R. K. (2011). Qualitative research from start to finish. New York: The Guilford Press.

Zeidner, L. and Wood, R. (2000). The Collaborative Innovation (CI) process. Proceedings of the 12th Symposium on Quality Function Deployment, Novi, MI, USA: QFD Institute. 


\section{APPENDICES}

\section{Appendix A - Interview Protocol}

\section{INTRODUCTION}

This interview will cover the participant's experiences with developing and evaluating business cases for complex IT investments. The term "business case" refers to a document created by an organization that outlines the expected benefits, costs, risks, and feasibility of a possible investment. The term "IT investments" refers to a potential project, acquisition, or development of information technology and related goods and services. The term "complex IT investments" refers to IT investments like enterprise systems (ERP, SCM, CRM, etc.) where the expected costs and benefits are more difficult to predict as compared to simple software acquisitions.

The purpose of this interview is to discover unique challenges in creating business cases for complex IT investments and to uncover prospective solutions to these challenges.

The interview covers areas related to the role of the business case, the process of creating business cases, Complex IT investment decision-making using business cases and other challenges in evaluating the business case for a complex IT investment.

\section{PART A - PARTICIPANT BACKGROUND AND EXPERIENCE}

1. Briefly describe your role and experience with business cases for complex IT investments in your current job and previous jobs.

Typical Probing Questions (Probes):

- What types of complex IT investments have you been involved in?

- Have you been involved in the creation of business cases for complex IT investments? If so, describe your role/year completed/budget.

- Have you been involved in the design of business cases for complex IT investments? If so, describe your role/year completed/budget. 


\section{PART B - BUSINESS CASES}

2. What do you think about the role or value of preparing a business case for a complex IT investment?

Probes:

- Why?

- Do you see any differences in the role or value of a business case for complex IT investments, such as ERP versus a business case for a simpler IT project? If yes, what are they?

- Do you see any differences in the role or value of a business case for complex IT investments versus non-IT related business cases? If yes, what are they?

3. What things do you find make a business case for a complex IT investment more effective?

Probes:

- Why do you think so?

- What things make them less effective?

- What attributes of the document are needed to be effective as well as what elements of the creation and evaluation process are needed to be more effective?

- Could you please briefly give me some examples of well-designed and effective business cases and the ones that are not according to your experience?

4. What kind of information do you include in a business case for a complex IT investment?

Probes:

- What are the challenges to include these data?

- How do you address them so far?

- What kind of information do you think are not suitable for a complex IT investment?

5. How do you estimate the cost, benefit and risk of a business case?

Probes: 
- What kind of tool do you use?

- Are there any intangible benefits, risks and indirect cost in an IT project?

- If yes

What are they?

$>$ Why do you think so?

- If no

$>$ No question

- Do you involve them in a business case?

O If yes

How do you do that?

$>$ Do you use some tools for estimating?

- If no

What are the reasons to insure a valid business case?

\section{PART C - THE PROCESS OF CREATING AND EVALUATING A BUSINESS CASE}

6. What are the steps in the process of creating and evaluating a business case for a complex IT investment?

Probes:

- Is there any difference in the steps between ERP implementations and other IT projects?

$$
\begin{aligned}
\circ \text { If yes } & \\
> & \text { What are they? } \\
& >\text { Why do you think so? } \\
\circ \text { If no } & \\
> & \text { No question }
\end{aligned}
$$

- What decision criteria or tool do you use to create or evaluate a buisness case?

- How to evaluate the intangible risks, benefits and indirect cost?

Is there any hidden value in IT projects? What is it?

7. What other departments or participants are involved in this process besides your department and you?

Probes:

- Besides of these, who do you think need to be involved in this process? 
- Why do you think so?

8. How do you collect information for creating and evaluating a business case for a complex IT investment?

Probes:

- How do you communicate with other participants in the process?

- What is the template or tool you used for creating business cases?

- How do you feel about the utility of it? (convinient or not)

- Why you think so?

- Is there any practices you want the other participants to make a change for creating an effective business case?

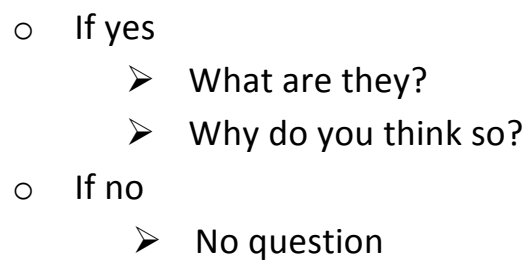

9. What kind of practice such as communication between participants, do you think influence the process of creating a business case?

Probes:

- Why do you think they are important?

- Are there any other practices in the process of creating business cases that are not suitable for complex IT projects?

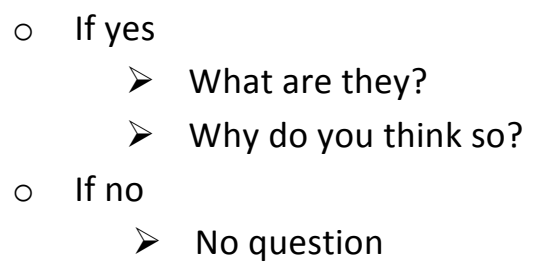

10. Have you ever experienced rejections of your business cases for a complex IT investment?

Probes: 
- Why do you think this happened?

- Do you agree with the decision?

- Is there anything you would have done differently with the business case if you could do it again?

\section{PART D - COMPLEX IT INVESTMENT DECISION-MAKING}

11. Based on your experience, can your recall any instance where you observed about complex IT investment decision-making?

Probes:

- How do you think about the role of management support?

- How do you think about the importance of shareholders interest?

12. Are there any other practices or issues that we haven't talked about and that you think are important in creating or evaluating a business case?

13. Is there anything you want to ask about?

o If yes

Answer the questions

- If no

$>$ End the interview 


\section{Appendix B - Summary of Theories}

\begin{tabular}{|c|c|c|c|}
\hline Category & Theory & Description & Reference \\
\hline \multirow[t]{2}{*}{ Process } & $\begin{array}{l}\text { Theory of Inventive } \\
\text { Problem Solving } \\
\text { (TRIZ) }\end{array}$ & $\begin{array}{l}\text { It is a useful problem-solving, } \\
\text { analysis and forecasting tool } \\
\text { that can solve the problem of } \\
\text { "how to do" in solutions } \\
\text { generation in the innovative } \\
\text { design problem-solving process. } \\
\text { It was developed by Altshuller } \\
\text { and his colleagues, beginning in } \\
\text { 1946. It is intended for } \\
\text { application in problem } \\
\text { formulation, system analysis, } \\
\text { failure analysis, and patterns of } \\
\text { system evolution. }\end{array}$ & $\begin{array}{l}\text { Altshuller, 1988; } \\
\text { Altshuller and Altov, } \\
\text { 1996; Hua, Yang, } \\
\text { Coulibaly and Zhang, } \\
2006 .\end{array}$ \\
\hline & $\begin{array}{l}\text { Failure Mode and } \\
\text { Effects Analysis } \\
\text { (FMEA) }\end{array}$ & $\begin{array}{l}\text { It is a structured technique to } \\
\text { analyze a design, a product or a } \\
\text { process to identify shortcomings } \\
\text { and opportunities for } \\
\text { improvement. It was developed } \\
\text { by reliability engineers in the } \\
\text { 1950s to study problems that } \\
\text { might arise from malfunctions } \\
\text { of military systems. This tool } \\
\text { answers the question "What } \\
\text { might be wrong with a system?" } \\
\text { and provides a documented } \\
\text { method for selecting a design } \\
\text { with a high probability of } \\
\text { successful operation and safety. } \\
\text { It involves reviewing as many } \\
\text { components, assemblies, and } \\
\text { subsystems as possible to } \\
\text { identify failure modes, and their } \\
\text { causes and effects. }\end{array}$ & $\begin{array}{l}\text { Frenklach and } \\
\text { Savransky, 1998; } \\
\text { Cavallucci and Lutz, } \\
\text { 2000; Mazur, 2000; } \\
\text { Terninko, 2000; } \\
\text { Zeidner and Wood, } \\
\text { 2000; Pevzner and } \\
\text { Katsman, 2001. }\end{array}$ \\
\hline
\end{tabular}




\begin{tabular}{|c|c|c|c|}
\hline Category & Theory & Description & Reference \\
\hline \multirow[t]{2}{*}{$\begin{array}{l}\text { Decision- } \\
\text { making }\end{array}$} & $\begin{array}{l}\text { Garbage Can } \\
\text { theory }\end{array}$ & $\begin{array}{l}\text { To understand processes within } \\
\text { organizations, individuals can take a } \\
\text { choice opportunity as a garbage can } \\
\text { into where problems and solutions } \\
\text { are dumped by participants as they } \\
\text { are generated. It was developed by } \\
\text { Cohen, March, and Olsen in 1972. An } \\
\text { organization "is a collection of choices } \\
\text { looking for problems, issues and } \\
\text { feelings looking for decision situations } \\
\text { in which they might be aired, } \\
\text { solutions looking for issues to which } \\
\text { they might be the answer, and } \\
\text { decision makers looking for work". } \\
\text { The model explains why solutions are } \\
\text { proposed to problems that don't } \\
\text { exist, why decisions are made that } \\
\text { don't solve problems, why problems } \\
\text { persist despite solutions, and why so } \\
\text { few problems are solved. When } \\
\text { circumstances are complex and } \\
\text { uncertain, problems, solutions, } \\
\text { participants, and choice opportunities } \\
\text { may be independent events that may } \\
\text { or may not connect. }\end{array}$ & $\begin{array}{l}\text { Cohen, } \\
\text { March and } \\
\text { Olsen, } \\
\text { 1972; } \\
\text { March, } \\
\text { Olsen and } \\
\text { Christensen } \\
\text {, } 1979 .\end{array}$ \\
\hline & $\begin{array}{l}\text { Behavioral } \\
\text { decision theory }\end{array}$ & $\begin{array}{l}\text { It is a theory of human decision- } \\
\text { making in an organization that is } \\
\text { based on Bayesian decision-making } \\
\text { and tries to incorporate decision- } \\
\text { making patterns of individuals such as } \\
\text { underweighting or overweighting of } \\
\text { probabilities, decision or choice } \\
\text { framing, and trade-offs. It is related to } \\
\text { interactions of agents with at least } \\
\text { partially conflicting interests whose } \\
\text { decisions affect each other. }\end{array}$ & $\begin{array}{l}\text { Carter, } \\
\text { 1971; Cyert } \\
\text { and March, } \\
1963 .\end{array}$ \\
\hline
\end{tabular}




\begin{tabular}{|c|c|c|c|}
\hline Category & Theory & Description & Reference \\
\hline \multirow[t]{2}{*}{ Decision-making } & $\begin{array}{l}\text { Prospect } \\
\text { theory }\end{array}$ & $\begin{array}{l}\text { It indicates that people make } \\
\text { decisions based on the potential value } \\
\text { of losses and gains rather than the } \\
\text { final outcome in order to manage risk } \\
\text { and uncertainty. It was developed by } \\
\text { Kahneman and Tversky in 1979. It } \\
\text { describes the decision processes in } \\
\text { two stages, editing and evaluation. It } \\
\text { demonstrates that people's attitudes } \\
\text { toward risks concerning gains may be } \\
\text { quite different from their attitudes } \\
\text { toward risks concerning losses. }\end{array}$ & $\begin{array}{l}\text { Kahneman, } \\
\text { Slovic and } \\
\text { Tversky, 1982; } \\
\text { Thomas and } \\
\text { Fernandez, } \\
2008 .\end{array}$ \\
\hline & $\begin{array}{l}\text { Contingency } \\
\text { theory }\end{array}$ & $\begin{array}{l}\text { It claims that there is no best way to } \\
\text { organize a corporation, to lead a } \\
\text { company, or to make decisions. } \\
\text { Instead, the optimal course of action } \\
\text { is contingent (dependent) upon the } \\
\text { internal and external situation. The } \\
\text { point is to design an organizational } \\
\text { structure that can handle } \\
\text { uncertainties in the context } \\
\text { effectively and efficiently. It } \\
\text { demonstrates that companies } \\
\text { operating in less stable environments } \\
\text { operated more effectively, if the } \\
\text { organizational structure was less } \\
\text { formalized, more decentralized and } \\
\text { more reliant on mutual adjustment } \\
\text { between various departments in the } \\
\text { company. On the other hand, } \\
\text { companies operating in more stable } \\
\text { and certain environments functioned } \\
\text { more effectively if the organization } \\
\text { was more formalized, centralized in } \\
\text { the decision-making and less reliant } \\
\text { on mutual adjustment between } \\
\text { departments. }\end{array}$ & $\begin{array}{l}\text { Woodward, } \\
\text { 1958; Ferrell } \\
\text { and Gresham, } \\
\text { 1985; Tarter and } \\
\text { Hoy, } 1998 .\end{array}$ \\
\hline
\end{tabular}




\begin{tabular}{|c|c|c|c|}
\hline Category & Theory & Description & Reference \\
\hline \multirow[t]{2}{*}{$\begin{array}{l}\text { Decision- } \\
\text { making }\end{array}$} & Sensemaking theory & $\begin{array}{l}\text { A set of processes that is } \\
\text { initiated when an individual or } \\
\text { organization recognizes the } \\
\text { inadequacy of their current } \\
\text { understanding of events. } \\
\text { Concepts such as creativity, } \\
\text { comprehension, curiosity, } \\
\text { mental modeling, explanation } \\
\text { and situational awareness can } \\
\text { help understand connections } \\
\text { among individuals, contexts } \\
\text { and events in order to } \\
\text { anticipate their trajectories } \\
\text { and act effectively. }\end{array}$ & $\begin{array}{l}\text { Klein, Moon } \\
\text { and Hoffman, } \\
\text { 2006; } \\
\text { Snowden, } \\
\text { 2005; Weick, } \\
\text { Sutcliffe and } \\
\text { Obstfeld, } \\
2005 .\end{array}$ \\
\hline & Institutional theory & $\begin{array}{l}\text { It suggests that organizational } \\
\text { governance and decision- } \\
\text { making are significantly } \\
\text { influenced by the need for } \\
\text { institutional legitimacy. It } \\
\text { considers the processes by } \\
\text { which structures, including } \\
\text { schemes, rules, norms, and } \\
\text { routines, become established } \\
\text { as authoritative guidelines for } \\
\text { social behavior. Different } \\
\text { components of institutional } \\
\text { theory explain how these } \\
\text { elements are created, } \\
\text { diffused, adopted, and } \\
\text { adapted over space and time; } \\
\text { and how they fall into decline } \\
\text { and disuse. }\end{array}$ & $\begin{array}{l}\text { Xue, Liang and } \\
\text { Boulton, 2008; } \\
\text { Tolbert and } \\
\text { Zucker, } 1999 .\end{array}$ \\
\hline
\end{tabular}




\begin{tabular}{|c|c|c|c|}
\hline Category & Theory & Description & Reference \\
\hline \multirow[t]{2}{*}{ Relationship } & $\begin{array}{l}\text { Structuration } \\
\text { theory }\end{array}$ & $\begin{array}{l}\text { It provides the relationship } \\
\text { between agency and structure } \\
\text { in terms of the activities and } \\
\text { context. Human agency and } \\
\text { social structure are not two } \\
\text { separate concepts or } \\
\text { constructs, but are two ways } \\
\text { of considering social action. } \\
\text { There is a duality of structures } \\
\text { so that on one side it is } \\
\text { composed of situated actors } \\
\text { who undertake social action } \\
\text { and interaction, and their } \\
\text { knowledgeable activities in } \\
\text { various situations. Meanwhile, } \\
\text { it is also the rules, resources, } \\
\text { and social relationships that } \\
\text { are produced and reproduced } \\
\text { in social interaction. Structure } \\
\text { is what gives form and shape } \\
\text { to social life and agency does } \\
\text { not refer to individual's } \\
\text { intentions in doing things but } \\
\text { rather to the flow or pattern of } \\
\text { individual's action. }\end{array}$ & $\begin{array}{l}\text { Giddens, 1984; } \\
\text { Brugha, 2005; } \\
\text { Orlikowski and } \\
\text { Robey, } 1991 .\end{array}$ \\
\hline & $\begin{array}{l}\text { Actor network } \\
\text { theory }\end{array}$ & $\begin{array}{l}\text { It is a method of thoroughly } \\
\text { exploring the relational ties } \\
\text { within a network. The actors } \\
\text { that can be human or non- } \\
\text { human in a network form an } \\
\text { apparently coherent whole } \\
\text { while contain conflicts as well. } \\
\text { It is a constructivist approach } \\
\text { in that it avoids essentialist } \\
\text { explanations of events or } \\
\text { innovations (e.g., explaining a } \\
\text { successful theory by saying it is } \\
\text { "true" and the others are } \\
\text { "false"). }\end{array}$ & $\begin{array}{l}\text { Latour, 2005; } \\
\text { Nagm and } \\
\text { Cecez- } \\
\text { Kecmanovic, } \\
2008 .\end{array}$ \\
\hline
\end{tabular}




\begin{tabular}{|c|c|c|c|}
\hline Category & Theory & Description & Reference \\
\hline Relationship & Agency theory & $\begin{array}{l}\text { It explains the relationship between } \\
\text { principals and agents in business. A } \\
\text { principal is pervasively considered as } \\
\text { shareholders and an agent represents } \\
\text { the principal in transactions with a third } \\
\text { party such as managers or company } \\
\text { executives. It is concerned with resolving } \\
\text { two problems that can occur in agency } \\
\text { relationships. The first is the agency } \\
\text { problem that arises when (a) the desires } \\
\text { or goals of the principal and agent } \\
\text { conflict and (b) it is difficult or expensive } \\
\text { for the principle to verify what the agent } \\
\text { is actually doing. The problem here is } \\
\text { that the principal cannot verify that the } \\
\text { agent has behaved appropriately. The } \\
\text { second is the problem of risk sharing that } \\
\text { arises when the principal and agent have } \\
\text { different attitudes towards risk. The } \\
\text { problem here is that the principle and } \\
\text { the agent may prefer different actions } \\
\text { because of the different risk preferences. }\end{array}$ & $\begin{array}{l}\text { Eisenhardt, } \\
\text { 1989; Fama, } \\
\text { 1980; } \\
\text { Jensen and } \\
\text { Meckling, } \\
\text { 1976; Long } \\
\text { and } \\
\text { Walkling, } \\
\text { 1984. }\end{array}$ \\
\hline
\end{tabular}




\begin{tabular}{|c|c|c|c|}
\hline Category & Theory & Description & Reference \\
\hline \multirow[t]{2}{*}{$\begin{array}{l}\text { Investment } \\
\text { governance }\end{array}$} & $\begin{array}{l}\text { Entrenchment } \\
\text { theory }\end{array}$ & $\begin{array}{l}\text { It can be used to interpret the } \\
\text { behavior of corporate managers in } \\
\text { terms of investing in businesses and } \\
\text { making contracts. Managers can } \\
\text { make investments that are more } \\
\text { valuable under themselves than } \\
\text { under alternative managers. Those } \\
\text { investments might not maximize } \\
\text { shareholder value. So shareholders } \\
\text { have a moral hazard in contracting } \\
\text { with managers. Managerial } \\
\text { entrenchment occurs when } \\
\text { managers gain so much power that } \\
\text { they are able to use the firm to } \\
\text { further their own interests rather } \\
\text { than the interests of shareholders. }\end{array}$ & $\begin{array}{l}\text { Shleifer and } \\
\text { Vishny, 1989; } \\
\text { Dhaoui and } \\
\text { Jouini, } 2011 .\end{array}$ \\
\hline & $\begin{array}{l}\text { Real options } \\
\text { theory }\end{array}$ & $\begin{array}{l}\text { A real option is the right, but not the } \\
\text { obligation, to undertake some } \\
\text { business decision, typically the } \\
\text { option to make a capital investment. } \\
\text { Real options capture the value of } \\
\text { managerial flexibility to adapt } \\
\text { decisions in response to unexpected } \\
\text { market developments. The real } \\
\text { options method applies financial } \\
\text { options theory to quantify the value } \\
\text { of management flexibility in a world } \\
\text { of uncertainty. If used as a } \\
\text { conceptual tool, it allows } \\
\text { management to characterize and } \\
\text { communicate the strategic value of } \\
\text { an investment project. It can } \\
\text { supplement concepts such as Net } \\
\text { Present Value (NPV) to incorporate } \\
\text { uncertainty about future cash flows. } \\
\text { This theory includes five types of } \\
\text { real options: Waiting-to-Invest } \\
\text { option, Growth option, Flexibility } \\
\text { option, Exit option and Learning } \\
\text { option. }\end{array}$ & $\begin{array}{l}\text { Benaroch, 2002; } \\
\text { Leiblein, } 2003 .\end{array}$ \\
\hline
\end{tabular}




\begin{tabular}{|c|c|c|c|}
\hline Category & Theory & Description & Reference \\
\hline \multirow[t]{2}{*}{$\begin{array}{c}\text { Systems } \\
\text { and project } \\
\text { manageme } \\
\text { nt }\end{array}$} & $\begin{array}{l}\text { Complexity } \\
\text { theory }\end{array}$ & $\begin{array}{l}\text { It is used to understanding how } \\
\text { organizations or firms adapt to their } \\
\text { environments and how they cope } \\
\text { with conditions of uncertainty. The } \\
\text { theory treats organizations and firms } \\
\text { as collections of strategies and } \\
\text { structures. The structure is complex; } \\
\text { in that they are dynamic networks of } \\
\text { interactions, and their relationships } \\
\text { are not aggregations of the } \\
\text { individual static entities. They are } \\
\text { adaptive; in that the individual and } \\
\text { collective behavior mutate and self- } \\
\text { organize corresponding to the } \\
\text { change-initiating micro-event or } \\
\text { collection of events. It explains how } \\
\text { complex adaptive systems function, } \\
\text { and thus suggests the project } \\
\text { manager needs tools and techniques } \\
\text { that can model both linear and } \\
\text { nonlinear behavior. }\end{array}$ & $\begin{array}{l}\text { Taylor, 2001; } \\
\text { Curlee and Gordon, } \\
\text { 2010; McKinnie, } \\
2007 .\end{array}$ \\
\hline & Systems theory & $\begin{array}{l}\text { It is a transdisciplinary study of the } \\
\text { abstract organization of phenomena, } \\
\text { independent of their substance, } \\
\text { type, or spatial or temporal scale of } \\
\text { existence. It investigates both the } \\
\text { principles common to all complex } \\
\text { entities, and the (usually } \\
\text { mathematical) models, which can be } \\
\text { used to describe them. It has a well- } \\
\text { established history in explaining } \\
\text { organizational behavior. Both } \\
\text { projects and organizations are } \\
\text { complex adaptive systems. The } \\
\text { foundation of systems theory is } \\
\text { discussed and systems are classified } \\
\text { as hard and soft, a perspective that } \\
\text { points to the issue of flexibility as } \\
\text { found in social science. }\end{array}$ & $\begin{array}{l}\text { Banathy, 1996; } \\
\text { Haslett and } \\
\text { Sankaran, } 2008 .\end{array}$ \\
\hline
\end{tabular}




\begin{tabular}{|c|c|c|c|}
\hline Category & Theory & Description & Reference \\
\hline $\begin{array}{c}\text { Systems and } \\
\text { project } \\
\text { management }\end{array}$ & Chaos theory & $\begin{array}{l}\text { It refers to an apparent lack } \\
\text { of order in a system that } \\
\text { nevertheless obeys } \\
\text { particular laws or rules, is } \\
\text { the study of nonlinear } \\
\text { dynamics, in which } \\
\text { seemingly random events } \\
\text { are actually predictable } \\
\text { from simple deterministic } \\
\text { equations. } \\
\text { It describes that no matter } \\
\text { how complex they may be - } \\
\text { rely upon an underlying } \\
\text { order, and that are very } \\
\text { simple or small systems and } \\
\text { events can cause very } \\
\text { complex behaviors or } \\
\text { events. }\end{array}$ & $\begin{array}{l}\text { Taylor, 2001; Singh and } \\
\text { Singh, } 2002 .\end{array}$ \\
\hline
\end{tabular}

